UNIVERSIDADE DE SÃO PAULO

INSTITUTO DE PSICOLOGIA

ANNA CAROLINA MULLER QUEIROZ

Ambientes Virtuais Imersivos e Aprendizagem

São Paulo

2020 
ANNA CAROLINA MULLER QUEIROZ

Ambientes Virtuais Imersivos e Aprendizagem

Tese de Doutorado apresentada ao Instituto de Psicologia da Universidade de São Paulo como requisito para obtenção do título de Doutor em Ciências na Linha de Pesquisa de Desenvolvimento Humano e Aprendizagem.

Área de concentração:

Psicologia Escolar e do Desenvolvimento Humano (PSA)

Orientadora: Prof ${ }^{a}$. Maria Isabel da Silva Leme

São Paulo

2020 
AUTORIZO A REPRODUÇÃO E DIVULGAÇÃO TOTAL OU PARCIAL DESTE TRABALHO, POR QUALQUER MEIO CONVENCIONAL OU ELETRÔNICO, PARA FINS DE ESTUDO E PESQUISA, DESDE QUE CITADA A FONTE.

\author{
Catalogação na publicação \\ Biblioteca Dante Moreira Leite \\ Instituto de Psicologia da Universidade de São Paulo \\ Dados fornecidos pelo(a) autor(a)
}

\title{
Queiroz, Anna Carolina Muller
}

Ambientes Virtuais Imersivos e Aprendizagem / Anna Carolina Muller Queiroz; orientadora Maria Isabel da Silva Leme. -- São Paulo, 2020.

$183 \mathrm{f}$.

Tese (Doutorado - Programa de Pós-Graduação em Psicologia Escolar e do Desenvolvimento Humano) -- Instituto de Psicologia, Universidade de São Paulo, 2020.

1. Ambientes Virtuais Imersivos. 2. Realidade Virtual. 3. Aprendizagem. 4. Psicologia da Aprendizagem. 5. Auto eficácia. I. Leme, Maria Isabel da Silva, orient. II. Título. 
Nome: Queiroz, Anna Carolina Muller

Título: Ambientes Virtuais Imersivos e Aprendizagem

Tese apresentada ao Instituto de Psicologia da Universidade de São Paulo para obtenção do título de Doutor em Ciências na Linha de Pesquisa de Desenvolvimento Humano e Aprendizagem.

Aprovado em:

Banca Examinadora

Prof. Dr.:

Instituição:

Assinatura:

Prof. Dr.:

Instituição:

Assinatura:

Prof. Dr.:

Instituição:

Assinatura:

Prof. Dr.:

Instituição:

Assinatura:

Prof. Dr.:

Instituição:

Assinatura:

Prof ${ }^{\text {a. }}$ Dra.: Maria Isabel da Silva Leme Instituição: Universidade de São Paulo

Assinatura: 


\section{AGRADECIMENTOS}

À Profa. Dra. Maria Isabel da Silva Leme, por todo apoio, inspiração e parceria há mais de dez anos. Ao longo dessa jornada, tive a honra de tê-la como minha orientadora no mestrado e no doutorado. Sua enorme experiência, amizade e suporte foram fundamentais para minha paixão por educação e aprendizagem, bem como para a conclusão dessas importantes etapas.

Ao Prof Dr. Jeremy Bailenson, pela acolhida e todo suporte durante esses dois anos no Virtual Human Interaction Lab (VHIL) na Universidade de Stanford. Foi um período de grandes aprendizados, que levarei comigo por toda vida. Agradeço imensamente todo suporte e oportunidades que você me deu e que permitiram que esse trabalho extrapolasse as fronteiras do Brasil.

À Profa Dra. Fraulein Vidigal de Paula, por tantos ensinamentos e incentivos ao longo dessa jornada. Suas contribuições foram muito importantes não apenas para meu desenvolvimento acadêmico, mas também para o meu desenvolvimento humano.

Ao Prof Dr. Romero Tori, pela acolhida no Interlab e importante parcerias ao longo desses anos. Muito obrigada por me apresentar ao mundo da Realidade Virtual e da Educação a (sem!) Distância. Seu apoio foi fundamental para os passos dados ao longo deste doutorado.

Ao Lemann Center da Universidade de Stanford, em especial à Cristina Antunes, Prof Martin Carnoy e Prof David Plank, pelas importantes reflexões sobre o uso das tecnologias na educação, pelo incentivo e apoio durante esses anos.

Ao Google VR Lab pelo gentil acesso aos equipamentos que permitiram a realização desta pesquisa.

Aos colegas do VHIL, pelas contribuições ao longo dessa jornada. 
À Dra. Catherine Oh, pela imensa amizade e carinho durante essa caminhada.

Aos amigos, que compartilharam comigo as dificuldades e alegrias, e estiveram sempre presentes para ajudar.

Aos meus pais, que embora já não estivessem comigo nessa etapa, sempre me incentivaram e fizeram enormes esforços para minha educação.

À minha irmã, Anna Beatriz, e minhas sobrinhas, Anna Laura e Anna Luísa, pelo carinho e incentivo de sempre.

À minha família, em especial meu marido Alexandre e minhas filhas Anna Elise e Anna Elena (chegando em breve!), que viveram comigo cada dia dessa jornada. Embarcaram junto nessa aventura, enfrentando desafios e abrindo mão de suas necessidades em muitos momentos. Mudamos de país, enfrentamos doenças, dificuldades financeiras e uma pandemia sem precedentes num ambiente de grandes incertezas. Mas vocês se mantiveram firmes ao meu lado e me deram todo o apoio para que eu pudesse realizar esse grande sonho. A todos sacrifícios que vocês fizeram para me apoiar, a todo amor que vocês me deram e dão, eu sou imensamente grata e assim serei eternamente. Essa conquista não será só minha, ela será nossa. 


\section{RESUMO}

Queiroz, A. C. M (2020). Ambientes Virtuais Imersivos e Aprendizagem. Tese apresentada para obtenção do título de Doutor em Ciências, Instituto de Psicologia, Universidade de São Paulo, São Paulo.

Os avanços tecnológicos e as mudanças sociais vivenciadas nas últimas décadas têm impactado significativamente a educação no Brasil e no mundo. Os ambientes virtuais imersivos (AVI) vêm despertando interesse de pesquisadores e da população em geral. Estes ambientes são capazes de simular computacionalmente estímulos visuais, auditivos e sensoriais de situações reais e imergir os sentidos do usuário no conteúdo digital. O interesse da aplicação de AVI para a aprendizagem é de longa data, mas somente nos últimos anos estes estudos se intensificaram, por conta da maior acessibilidade aos recursos tecnológicos e de desenvolvimento gráfico necessários. Entretanto, os estudos sobre o impacto dos AVIs na aprendizagem sob a ótica da Psicologia da Aprendizagem são escassos. Principalmente no que diz respeito à aprendizagem conceitual, não há evidências suficientes na literatura para se tirar conclusões sólidas do impacto dos AVIs. Diante disso, dois estudos foram conduzidos para comparar os efeitos de vídeos educacionais em $\mathrm{AVI}$ com uso de óculos de realidade virtual e vídeos tradicionais na aprendizagem conceitual e em aspectos afetivos da aprendizagem. No Estudo 1, 53 alunas da 8a série de uma escola exclusivamente feminina aprenderam sobre o impacto das ações praticadas pelos seres humanos no oceano por meio de vídeos em AVI (usando óculos de realidade virtual), ou vídeos tradicionais (usando um computador). No Estudo 2, 139 alunas da 6a à 8a série da mesma escola usaram o mesmo material instrucional e equipamento do estudo 1 e as variáveis de estudo foram avaliadas 4 vezes (antes da intervenção, logo após cada uma das duas sessões de intervenção e 8 semanas após a intervenção). No Estudo 1, não houve diferença significativa na aprendizagem conceitual entre as condições, mas as participantes que assistiram vídeos em AVI relataram maior percepção de auto eficácia e expressaram sentimentos de presença mais intensos do que as participantes que usaram um computador. Os resultados do estudo 2 mostraram que as participantes na condição AVI obtiveram uma pontuação mais alta do que as participantes na condição computador na avaliação qualitativa de aprendizado conceitual, e também se verificou resultado semelhante para auto eficácia do primeiro estudo. Análises posteriores revelaram que o sentimento de presença e auto eficácia mediaram a relação entre condição e os resultados nos aspectos cognitivos e afetivos da aprendizagem. Os resultados e suas implicações são discutidos à luz da Psicologia Cognitiva e estudos futuros são propostos.

Palavras-chave: Ambientes Virtuais Imersivos. Realidade Virtual. Aprendizagem. Psicologia da Aprendizagem. Auto eficácia. 


\begin{abstract}
Queiroz, A. C. M (2018). Immersive Virtual Environments and Learning. Projeto de pesquisa apresentado para Exame Geral de Qualificação, Instituto de Psicologia, Universidade de São Paulo, São Paulo.
\end{abstract}

Technological advances and social development experienced in the last decades have significantly impacted education in Brazil and in the world. Immersive virtual environments (IVE) have been attracting interest from researchers and the general population. These environments are able to simulate computationally visual, auditory and sensory stimuli of real situations and to immerse the user's senses in the digital content. The interest of applying IVE for learning is a long-standing one, but only in recent years have these studies intensified, due to the greater accessibility to the necessary technological resources and graphic development. However, studies on the impact of IVE on learning, from the perspective of Learning Psychology, are scarce. Particularly with regard to conceptual learning, there is not enough evidence in the literature to draw solid conclusions about the impact of IVEs in learning. Therefore, two studies were conducted to compare the effects of educational videos in IVE (using virtual reality headsets) and 2D videos (using a computer monitor) on conceptual learning and on affective aspects of learning. In Study 1, fifty-three 8th grade students from an all-female school learned about the impact of human activities in the ocean through immersive videos, or 2D videos. In Study 2, 139 students from the 6th to the 8th grade of the same school used the same instructional material and equipment from Study 1, and the variables were measured 4 times (before the intervention, just after each of the two intervention sessions and 8 weeks after intervention). In Study 1, there was no significant difference for conceptual learning between conditions, but participants who watched videos in IVE reported a greater perception of selfefficacy and expressed higher feelings of presence than participants who used a computer. The results of study 2 showed that participants in the IVE condition scored higher than participants in the computer condition in the qualitative assessment of conceptual learning. Also, Study 2 showed similar results for self-efficacy from Study 1. Analyzes revealed that the feeling of presence and self-efficacy mediated the relationship between condition and results in cognitive and affective aspects of learning. The results and their implications are discussed in the light of the theory of Cognitive Psychology and future studies are proposed.

Keywords: Immersive Virtual Environments. Virtual Reality. Learning. Psychology of Learning. Self-efficacy. 


\section{LISTA DE FIGURAS}

Figura 1. Continuum Real-Virtual adaptado de (Milgram \& Kishino, 1994) ............................ 14

Figura 2. Dispositivos de realidade virtual imersiva: ..................................................... 19

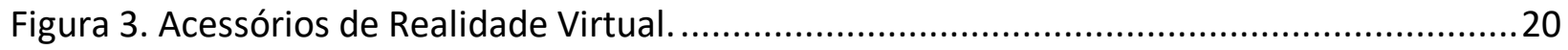

Figura 4. Distribuição geográfica dos grupos de pesquisa...............................................57

Figura 5. Ano de Formação dos Grupos de Pesquisa ......................................................... 59

Figura 6. Formação Acadêmica dos Pesquisadores e Estudantes...........................................60

Figura 7. Domínio do Conhecimento das Linhas de Pesquisa em RV aplicada à Educação .........61

Figura 8. Finalidade das Pesquisas das Linhas em RV aplicada à Educação .............................62

Figura 9. Modalidade das Pesquisas das Linhas em RV aplicada à Educação...........................63

Figura 10. Distribuição das Linhas de Pesquisa em RV aplicada à Educação de acordo com o nível

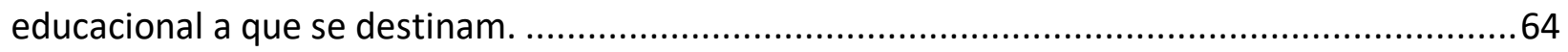

Figura 11. Fluxograma da revisão sistemática de literatura ............................................67

Figura 12. Quantidade de publicações por ano ........................................................... 70

Figura 13. Quantidade de publicações por país de afiliação ............................................70

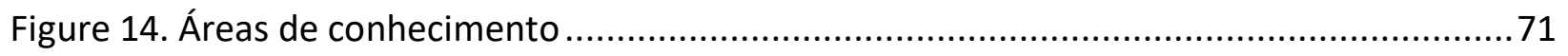

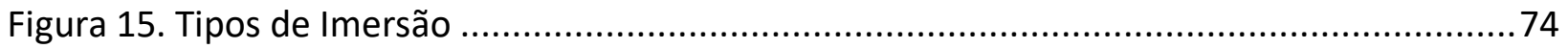

Figura 16. Técnicas, processos e formas de avaliação..................................................... 74

Figura 17. Imagens do vídeo The Crystal Reef.. ........................................................... 83

Figura 18. Imagens do vídeo Coral Compass................................................................... 84

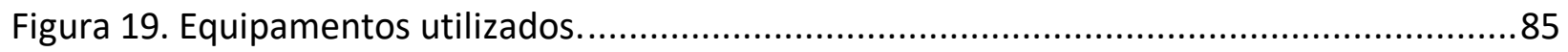


Figura 20. Porcentagem de respostas sobre as causas da acidificação do oceano.

Figura 21. Porcentagem de respostas por condição e tempo para a questão: "Você acha que o aumento de dióxido de carbono na atmosfera foi causado por:" 


\section{LISTA DE TABELAS}

Tabela 1. Trabalhos revisados 42

Tabela 2. Quantidade de publicações de acordo com a área de pesquisa.................................50

Tabela 3. Quantidade de artigos de acordo com o objetivo e nível educacional.......................52

Tabela 4 Médias e desvio-padrão no pré-teste e no pós-teste no estudo 1 ...........................92

Tabela 5 Resultados dos modelos lineares de curva de crescimento no estudo 1 ....................93

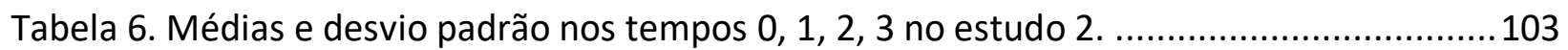

Tabela 7. Resultados dos modelos de curva de crescimento linear. ....................................104

Tabela 8. Médias e desvio padrão para os itens sobre atitudes em relação às disciplinas escolares 


\section{LISTA DE ABREVIATURAS E SIGLAS}

2D

ACME

AVI

CIAED

CNPq

$\mathrm{CO}_{2}$

DGP

DP

EaD

ERIC

HMD

IA

IC

LL

M

MIT

RA

RBIE

RM

RV

SBC

SBGames

SBIE

$\mathrm{SE}$

SVR

UL

USP
Duas dimensões

Average Causal Mediation Effects (Média dos Efeitos de Mediação Causal)

Ambiente Virtual Imersivo

Congresso Internacional ABED de Educação a Distância

Conselho Nacional de Pesquisa

Dióxido de Carbono

Diretório de Grupos de Pesquisa

Desvio Padrão

Ensino a Distância

Education Resources Information Center

Head-mounted Display (Dispositivo Montado na Cabeça)

Inteligência Artificial

Intervalo de Confiança

Lower Level (Margem Inferior)

Média

Massachussetts Institute of Technology

Realidade Aumentada

Revista Brasileira de Informática na Educação

Realidade Mista

Realidade Virtual

Sociedade Brasileira de Computação

Simpósio Brasileiro de Games

Simpósio Brasileiro de Informática na Educação

Erro Padrão

Symposium on Virtual and Augmented Reality

Upper Level (Margem Superior)

Universidade de São Paulo 


\section{LISTA DE SÍMBOLOS}

$\begin{array}{ll}\omega & \text { Ômega } \\ d & \text { Efeito } \\ F & \text { Teste } \mathrm{F} \\ \mathrm{N} & \text { Amostra } \\ p & \text { Probabilidade } \\ \text { St } B & \text { Estimativa padrão } \\ \mathrm{t} & \text { Teste T de Student } \\ X^{2} & \text { Teste Qui-Quadrado de Pearson } \\ \text { B } & \text { Estimativa }\end{array}$




\section{SUMÁRIO}

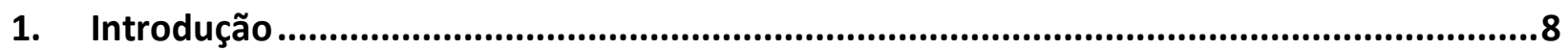

1.1. Avanços tecnológicos e mudanças no processo de ensino-aprendizagem..................8

1.2. Ambientes Virtuais: Evolução e Conceitos ...............................................................13

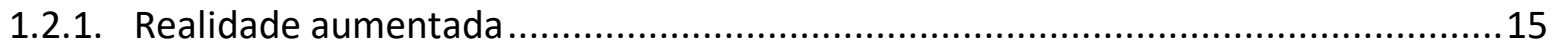

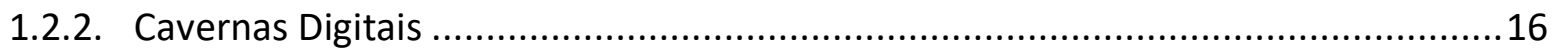

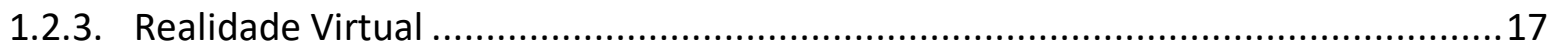

1.3. Aspectos Afetivos e Cognitivos da Aprendizagem em Ambientes Virtuais

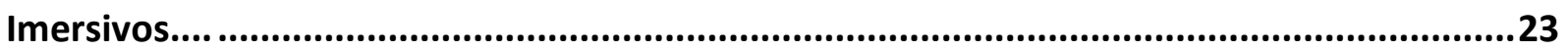

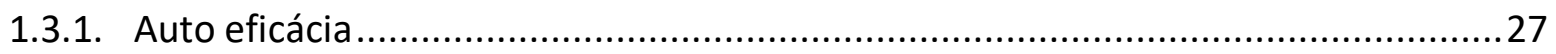

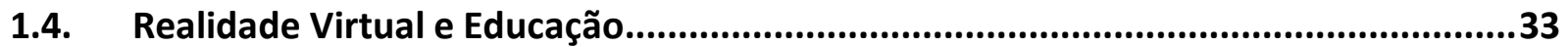

1.4.1. Revisão sistemática de pesquisas que usam Realidade Virtual na educação básica 36

1.4.2. Pesquisas e artigos científicos em Realidade Virtual no Brasil ..............................50

1.4.3. Grupos de pesquisa sobre Realidade Virtual na Educação no Brasil ......................56

1.5. Avaliação da aprendizagem em Ambientes Virtuais Imersivos................................65

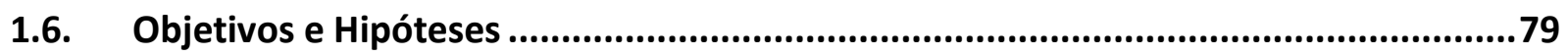

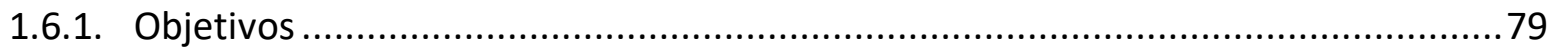

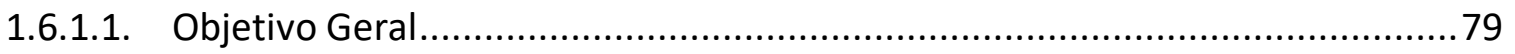

1.6.1.2. Objetivos específicos................................................................. 79

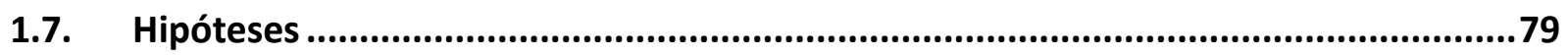


2. Estudos Empíricos

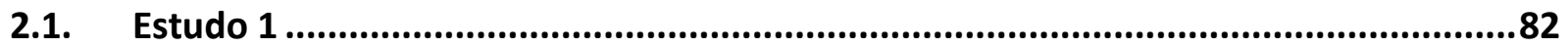

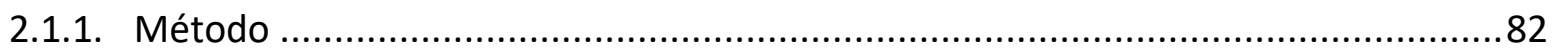

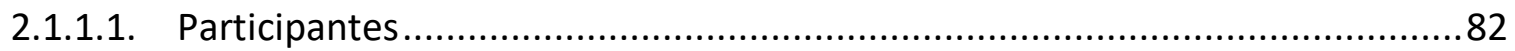

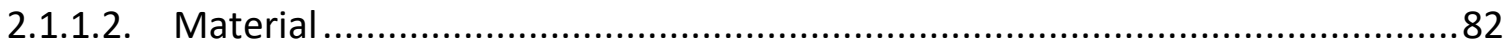

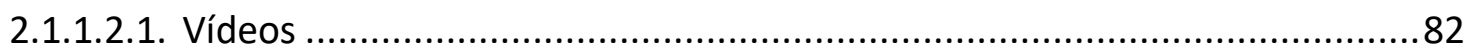

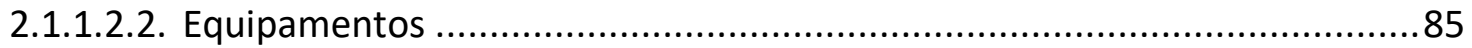

2.1.1.2.3. Instrumentos de avaliação...................................................... 85

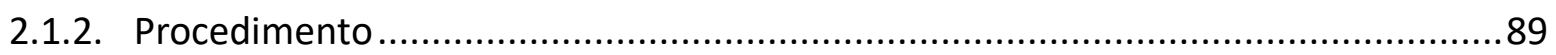

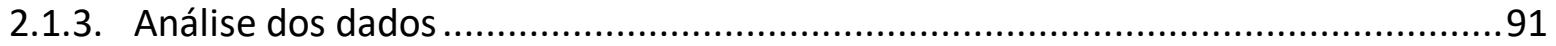

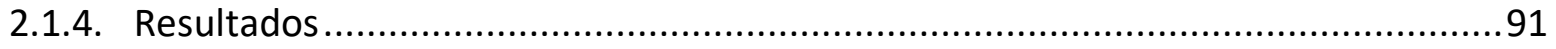

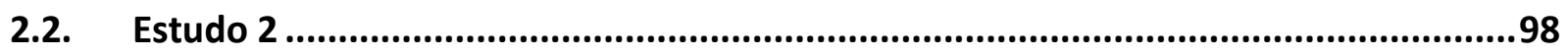

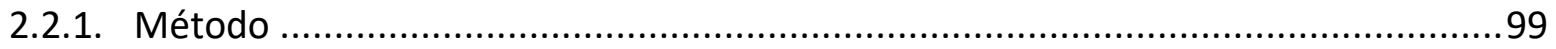

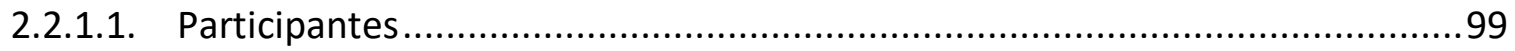

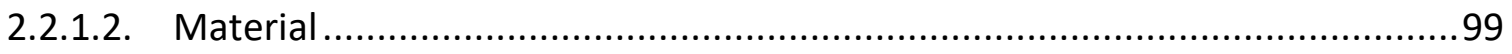

2.2.1.2.1. Instrumentos de avaliação............................................................... 99

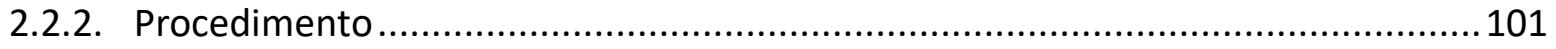

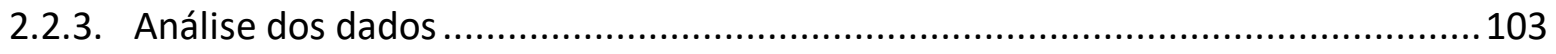

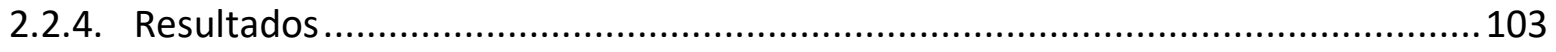

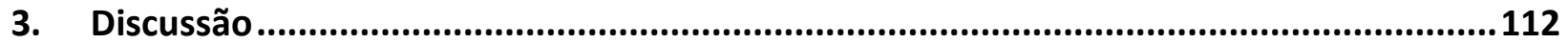

4. Limitações e estudos futuros .....................................................................................119 
5. Conclusão

6. Referências Bibliográficas.......................................................................................122

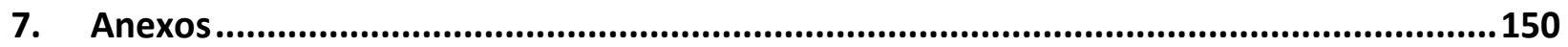

7.1. Anexo 1 - Questionário Estudo 1 (português) .....................................................150

7.2. Anexo 2 - Questionário Estudo 1 (inglês) ........................................................157

7.3. Anexo 3 - Questionário Estudo 2 (português) ..................................................162

7.4. Anexo 4 - Questionário Estudo 2 (inglês) .............................................................172

7.5. Anexo 5 - Questões e análise multinível das atitudes em relação às disciplinas

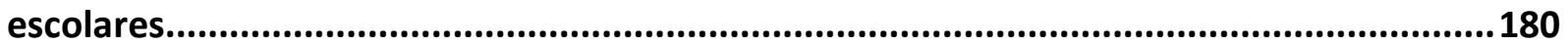

7.6. Anexo 6. Lista de produção acadêmica durante o programa de doutorado ............182 


\section{Introdução}

1.1. Avanços tecnológicos e mudanças no processo de ensino-aprendizagem

O engajamento dos alunos (IBGE, 2011; Soares \& Candian, 2007), a efetividade do ensino (Boruchovitch, 1994; IBGE, 2011; Ribeiro, 1991), os formatos de avaliação da educação (Bonamino \& Sousa, 2012), de avaliação da aprendizagem (Darsie, 1996) e principalmente, os novos hábitos de aquisição de conhecimento (Hsin et al., 2014; Lévy \& Bononno, 1998; Thompson, 2013; Werthein, 2000), têm oferecido desafios e oportunidades para a área de Educação e Aprendizagem no Brasil e no mundo (Arruda, 2013). A disponibilidade de recursos tecnológicos de entretenimento impactou a educação básica de tal forma que a mesma começou a rever suas estratégias de ensino (Belloni, 2001; Dede et al., 2017; National Research Council, 2013; Rangel, 2005), o que aumenta a importância dos estudos científicos sobre os novos métodos de ensino e de avaliação de aprendizagem.

A aula tradicional, com exposição verbal e algumas vezes também textual, é o formato de ensino mais comum em instituições de ensino formal (Lemos \& Perl, 2015). Esse modelo, preconiza que a presença física dos professores e de um grupo de alunos reunidos numa sala de aula favorece a explicitação do conhecimento (Bordenave \& Pereira, 2000). Muito frequentemente, o professor apresenta o conteúdo a ser apreendido, estimula o questionamento e gradativamente apresenta novos elementos necessários para o entendimento do assunto (Ausubel, 1982; Tedesco, 2004). Variações nas estratégias de ensino - na maneira como o professor apresenta o conteúdo, como envolve a participação do aluno no processo de aprendizagem, como estimula o questionamento e como utiliza recursos didáticos, por exemplo - são amplamente estudadas principalmente na área da Pedagogia (Libâneo, 2001) e da 
Psicologia da Aprendizagem (Boruchovitch, 1999; Perrenoud et al., 2002) com intuito de favorecer a aprendizagem (Santos, 2005).

A grande e crescente oferta de cursos de formação a distância (Associação Brasileira de Educação a Distância, 2015) tem demandado a utilização cada vez mais diversificada de recursos didáticos, principalmente de recursos audiovisuais que possam ser reproduzidos a qualquer hora e em qualquer lugar (Coll, 2008; Coll \& Monereo, 2010; Fino \& Sousa, 2018). Os chamados ambientes virtuais de aprendizagem estão substituindo as salas de aula tradicionais parcial ou até mesmo totalmente em alguns cursos de educação formal, que podem ser totalmente cursados a distância (Associação Brasileira de Educação a Distância, 2015). Inicialmente, estes ambientes ofereciam principalmente recursos textuais estáticos, canais de comunicação escrita com os professores e outros alunos, e alguns vídeos (temáticos ou vídeo-aulas) (Fischer, 2017; Gerbase, 2006; Moore \& Kearsley, 2007).

Com o avanço das tecnologias, o formato de apresentação de conteúdos tem variado imensamente bem como a maneira pela qual as pessoas acessam a informação (Hsin et al., 2014; Lévy \& Bononno, 1998; Thompson, 2013). Desde a ausência de um professor, apresentações estáticas de projeções visuais até apresentações muito dinâmicas, com uso intensivo de cores, movimento e sons têm sido utilizadas para o ensino tanto formal quanto informal (S. P. Anderson et al., 2016; Gerbase, 2006).

A realidade infantil hoje é composta por crianças que passam grande parte do tempo que estão fora da escola diante de recursos de entretenimento (celulares, televisão, tablets, computadores, videogames) (Strasburger et al., 2013). Estes recursos muitas vezes despertam 
mais a sua atenção do que o ambiente tradicional de sala de aula (Gouvêa, 2006), uma vez que utilizam recursos gráficos e sonoros desenvolvidos com intuito de entreter e chamar a atenção. Muitas escolas já estão inserindo em suas práticas pedagógicas o uso de computadores portáteis e tablets para pesquisa, leitura e execução de tarefas, sendo que em algumas este artefato já faz parte do material escolar (Barbosa et al., 2015; Moran et al., 2005; Real et al., 2013). A exibição de vídeos com conteúdo educativo tem tomado cada vez mais espaço dentro da sala de aula, pois proporcionam uma grande quantidade de informação, com riqueza de detalhes, num formato que prende a atenção dos alunos (Moran et al., 2005). Uma das estratégias destas escolas é aliar o entretenimento com a educação, numa tentativa de guiar as escolhas de diversão dos alunos em seu tempo livre, para que se habituem a utilizar as ferramentas tecnológicas também para o aprendizado de conteúdos curriculares (Arruda, 2013).

O excesso de informação disponível online faz com que veículos de comunicação não acadêmicos, que precisam de audiência para manterem-se ativos, como as redes sociais, utilizem com intensidade os recursos midiáticos, apostando em vídeos curtos (muitos com menos de 1 minuto) muito bem editados com cores e sons atraentes para chamar mais a atenção do público. Até mesmo revistas têm lançado suas versões digitais com conteúdos audiovisuais (Rolfsen-Belda \& de-Souza-Lima, 2016). Por exemplo, se há alguns anos para se aprender sobre o ciclo das águas na disciplina de ciências era necessário comprar um livro específico e dispender alguns minutos lendo sobre os estados da água na natureza, hoje é possível entrar em contato com esse conhecimento de qualquer lugar por meio de um telefone celular conectado à internet. Basta 
acessar um vídeo ${ }^{1}$ online gratuito com duração de poucos minutos, rico em detalhes visuais e sonoros e que pode ser reproduzido quantas vezes e onde o aluno quiser.

Com tanta informação facilmente acessível aos alunos, a aquisição de conhecimento informal tem sido cada vez maior, o que torna a sala de aula um importante espaço de integração do conhecimento formal e informal, do aprendizado implícito e explícito (Paula \& Leme, 2010). Os processos de aprendizagem implícita, de acordo com Paula e Leme, "são aqueles baseados na associação, extração de regularidades do ambiente e que permitem aumentar a previsibilidade a respeito do mesmo. Dentre esses processos, destacam-se a reação de orientação, a habituação e as aprendizagens baseadas na contiguidade, generalização e discriminação de estímulos" (Paula \& Leme, 2010, p.16). Portanto, a intensa exposição ao conhecimento fora da sala de aula pode contribuir para que o aluno chegue ali com um repertório maior de conhecimentos implícitos e explícitos, menos formalizados, do que o fazia há alguns anos.

A prática de acessar o conhecimento de qualquer lugar e com frequência é tão comum entre os indivíduos que nomenclaturas e definições sobre este comportamento foram criadas e são muito utilizadas no campo e pesquisa de educação à distância. M-learning, ou mobile learning refere-se à aprendizagem com mobilidade apoiada no uso de tecnologias, na qual os aprendizes podem estar distantes um dos outros e dos espaços formais de educação (Prezi, 2016; Saccol et al., 2011; Yahya et al., 2010). Outro termo recente é o de U-learning ("aprendizagem ubíqua"), que diz respeito à aprendizagem apoiada no uso de tecnologias móveis associadas a diversos dispositivos computacionais que integram os indivíduos ao seu entorno e ao contexto de aprendizagem, criando redes entre pessoas, objetos, situações e eventos (Saccol et al., 2011;

\footnotetext{
${ }^{1}$ https://www.youtube.com/watch?v=js0Sv8iPT08 disponível em 20/09/2016
} 
Yahya et al., 2010). O ambiente de realidade virtual e a realidade aumentada (descritos na próxima sessão) são considerados recursos de U-learning, os quais criam oportunidades de aprendizado ao integrar o aprendiz com diferentes contextos, pessoas ou situações, reais ou virtuais (Brill \& Park, 2008; Crompton et al., 2016).

Aprender em processos de mobilidade e ubiquidade implica abrir-se às potencialidades que essas tecnologias oferecem. Envolve aguçar o senso de observação do entorno para perceber tais possibilidades, ser autônomo e autor do seu processo de aprender. Abrange ainda explorar, experimentar, relacionar, deixar-se provocar pelo meio, agindo e interagindo com ele, realizando aproximações e distanciamentos necessários para a significação. (Saccol et al., 2011, p. 6)

Aos professores ressalta-se cada vez mais o papel de mediador do conhecimento, e não mais o de único detentor do conhecimento que o expõe aos alunos. O professor se apresenta como uma figura que seleciona, refina e traz conhecimento por meios variados de comunicação. A ele cabe o papel de incentivar a busca constante pelo aprendizado, o questionamento crítico, o estímulo ao pensamento criativo e à solução de problemas, entre outros elementos importantíssimos na formação dos indivíduos, os quais o acesso à tecnologia não proporciona.

No que se refere à avaliação da educação e da aprendizagem, há um grande interesse e preocupação em adequá-las às intensas mudanças educacionais, tecnológicas e sociais de aquisição e aplicação do conhecimento (M. Silva, 2006; Wiliam \& Thompson, 2017). O contexto atual demanda habilidades diferentes das exigidas há algumas décadas (Dede, 2010; National Research Council, 2013; Voogt et al., 2013). Estudiosos do campo da avaliação da aprendizagem têm questionado os métodos avaliativos baseados em testes e exames classificatórios; e sugerem 
que a avaliação contemple habilidades cognitivas de ordem superior e que tenham um impacto positivo sobre a educação e a aprendizagem (Gipps, 1998; Van Merriënboer \& Kirschner, 2017). Memorizar e reproduzir conceitos, embora fundamentais para a aprendizagem, deixaram de ser o item principal das avaliações (Gipps, 1998; Van Merriënboer \& Kirschner, 2017). O mais importante é saber o que fazer com estes conceitos, como aplicá-los e introduzi-los em situações diversas para atingir os objetivos desejados (Gipps, 1994; Santos, 2005; Santos, 2014).

A avaliação pautada na solução de problemas oferece interessante arcabouço teórico e aplicabilidade prática para avaliar a efetividade da aprendizagem de conteúdos apresentados por meio de recursos de realidade virtual (ricos em estímulos visuais, sonoros e perceptivos), uma vez que "a atenção, a memória e a percepção trabalham juntos para processar a informação do ambiente e se combinam na solução de problemas" (Boruchovitch, 2006, p.145).

\subsection{Ambientes Virtuais: Evolução e Conceitos}

O conceito e a utilização de ambientes virtuais tornaram-se mais conhecidos a partir de 1990, embora as primeiras tentativas de criação de um ambiente de realidade virtual foram feitos desde 1945 (Kalawsky, 1993). Um marco importante para a evolução da realidade virtual foi a defesa da tese de doutorado de Ivan Sutherland, na qual a computação gráfica interativa foi utilizada pela primeira vez e conceitos importantes para o desenvolvimento desta área foram introduzidos - como a interação em tempo real e dispositivos especiais, na época, uma caneta óptica que interagia com os gráficos computacionais (Sutherland, 1965). Desde então, com o aumento da capacidade computacional e desenvolvimento da tecnologia, a interface gráfica está 
cada vez mais próxima do ambiente real e acessórios para interação com o conteúdo computacional tem sido aprimorados (Tori, Kirner \& Siscoutto, 2006).

Os ambientes virtuais, tipicamente referidos como realidade virtual (RV), realidade aumentada (RA) ou realidade mista (RM), apresentam as seguintes características fundamentais: "combinam objetos reais e virtuais em um ambiente real; executados interativamente, e em tempo real; e registram (alinha) objetos reais e virtuais entre si" (Azuma et al. 2001, p34). Diante da possibilidade de variações no grau desses estímulos e combinações, Milgram e Kishino (1994) propõem um contínuo para representar todo um gradiente de possibilidades na fusão do real e virtual, como mostrado na figura a seguir.

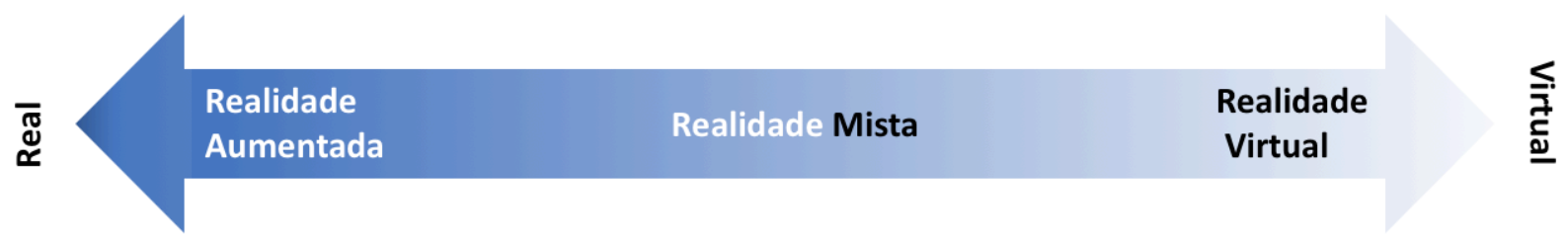

Figura 1. Continuum Real-Virtual adaptado de (Milgram \& Kishino, 1994)

Conceitos importantes ligados aos ambientes virtuais são "imersão" e "presença" (Cummings \& Bailenson, 2016; Sanchez-Vives \& Slater, 2005; Steuer, 1992). Esses conceitos são frequentemente usados indistintamente na literatura (Cummings \& Bailenson, 2016; McMahan, 2003; Steuer, 1992), entretanto a distinção entre deles é fundamental e será feita a seguir.

Jerald (2015) considera a imersão como "o grau objetivo ao qual um sistema de RV projeta estímulos aos receptores sensoriais dos usuários de forma extensa, correspondente, circundante, vívida, interativa e informante de enredo" (Jerald 2015, p.73). Slater e Wilbur (1997) definem imersão como "até que ponto o computador é capaz de fornecer uma ilusão abrangente, envolvente e vívida da realidade aos sentidos de um participante humano" (Slater \& Wilbur, 
1997; p. 3). Ou seja, é a capacidade do sistema de imergir os sentidos do usuário no ambiente virtual, sejam esses sentidos visuais, sonoros ou sensoriais.

Os estímulos artificiais oferecidos por estes sistemas imersivos são interpretados como reais, eliciando comportamentos e respostas fisiológicas como se os estímulos estivessem presentes (Sanchez-Vives \& Slater, 2005; Slater \& Usoh, 1993). O sentimento do usuário é como se estivesse envolvido e interagindo com este ambiente, ou seja, de provocar sentimentos de estar presente, chamado de "presença” pelos pesquisadores da área de Realidade Virtual. Para Jerald (2015), presença é definida como "uma sensação de 'estar lá', dentro de um espaço, mesmo quando fisicamente localizada em um local diferente. Como a presença é um estado psicológico interno [...] é difícil descrever em palavras - é algo que só pode ser compreendido quando experimentado" (Jerald, 2015, p.74).

Alinhada com esta definição, está a definição de Sanchez-Vivez \& Slater de que presença é uma experiência subjetiva e "refere-se ao fenômeno de se comportar e sentir como se estivéssemos no mundo virtual criado por monitores de computador" (Sanchez-Vives \& Slater, 2005 , p. 332). Finalmente, o aumento da imersão tem mostrado aumentar os sentimentos de presença (Sanchez-Vives \& Slater, 2005), ou seja, o sentimento de estar de fato vivenciando aquele ambiente digital como se fosse real.

\subsubsection{Realidade aumentada}

Um tipo de ambiente virtual muito utilizado é a chamada Realidade Aumentada, na qual imagens reais são mescladas com efeitos artificiais em tempo real (Azuma et al., 2001; Tori et al., 
2006). Por exemplo, ao focar a câmera de um aparelho celular para um lago qualquer, a tela do aparelho celular mescla à imagem do lago uma imagem em movimento de um peixe saltando e espirrando água, concomitantemente à emissão do som de água sendo espirrada. Neste caso, é necessário um equipamento capaz de gravar e reproduzir imagens em tempo real com capacidade computacional para mesclar imagens e sons previamente desenvolvidos à imagem que está sendo gerada no momento (Barfield, 2015). As ferramentas de realidade aumentada têm chamado a atenção para sua aplicação na educação, pois permitem inserir sons e imagens gráficas explicativas ao ambiente real. Isso facilita a concretização de conceitos abstratos e permite um entendimento mais rápido e consolidado por parte dos alunos (Saccol et al., 2011). Nesse âmbito, podemos citar o projeto EcoMOBILE da Universidade de Harvard ${ }^{1}$ que permite aos alunos interagirem com o ecossistema de um lago de maneira virtual por meio de um aplicativo instalado em seus aparelhos celulares. No Brasil, o Núcleo de Realidade Virtual da Universidade de São Paulo (USP) desenvolve sistemas de Realidade Virtual Imersiva e de Realidade Mista, levando em conta o baixo custo e o alto desempenho².

\subsubsection{Cavernas Digitais}

As Cavernas Digitais (do termo em inglês Cavern Automatic Virtual Environment) e os óculos de realidade virtual, que permitem a exibição estereoscópica montada na cabeça, são dois ambientes virtuais imersivos bastante utilizados na Educação (Biocca \& Delaney, 1995; Blascovich

\footnotetext{
${ }^{1}$ Disponível em http://ecolearn.gse.harvard.edu/ecoMOBILE/overview.php, acessado em 16/09/2016

${ }^{2}$ Disponível em http://www.Isi.usp.br/citi/, acessado em 22/09/2016
} 
et al., 2002b). Um exemplo é a Caverna Digital ${ }^{1}$ do Núcleo de Realidade Virtual do Laboratório de Sistemas Integráveis, vinculado à Escola Politécnica da USP. Numa sala estão 5 telas de 3×3m que projetam imagens num campo de visão de 360 graus.

Por permitir a integração de imagem, som e interatividade com o conteúdo, a Caverna Digital é muito utilizada para educação formal e informal e em pesquisa em diversas áreas, como Engenharia, Medicina, Biologia, Química, Artes, Pedagogia (uso de jogos interativos) e Arquitetura. Em diversos museus, aquários e exposições é possível encontrar este tipo de ambiente, em que os visitantes podem (ou não) interagir com o conteúdo digital projetado nas paredes, chão e teto. As cavernas digitais oferecem um ambiente de simulação que tem sido utilizado no treinamento de habilidades motoras (por exemplo, o treino do uso de bisturi na Medicina) e de habilidades cognitivas (em jogos interativos, por exemplo).

\subsubsection{Realidade Virtual}

Outro tipo de ambiente virtual que está em franca expansão é a chamada realidade virtual$^{2}$. Há variadas definições de realidade virtual na literatura (Steuer, 1992), sendo que algumas delas conflitam entre si em relação aos equipamentos utilizados bem como aspectos objetivos e subjetivos do ambiente virtual (Earnshaw, 2014). Por essa razão, será apresentado o conceito sobre o qual se pauta este trabalho.

\footnotetext{
${ }^{1}$ Disponível em http://www.lsi.usp.br/interativos/nrv/caverna.html, acessado em 18/09/2016

2 Dados estatísticos disponíveis em https://www.statista.com/statistics/550461/virtual-reality-market-sizeworldwide/ acessado em 10/06/2020
} 
O conceito estabelecido por Jerald (2015) afirma que "realidade virtual é [...] um ambiente digital gerado por computador que pode ser experimentado e interagido como se esse ambiente fosse real" (Jerald 2015, p.49). Assim, do lado do usuário, RV é diferente de outras formas derivadas de alterar um ambiente real, a RV substitui o ambiente real por um ambiente virtual (Azuma et al., 2001; Biocca \& Delaney, 1995; Milgram \& Kishino, 1994).

Mais especificamente, a realidade virtual imersiva é composta por um sistema que depende de dispositivos usados na cabeça, semelhantes a óculos ou capacetes (head-mounted displays; HMD), como pode ser visto na Figura 2. Estes óculos bloqueiam os estímulos visuais ao redor do usuário, substituindo-o por uma projeção digital visual (diretamente nos olhos do usuário) e criando um ambiente virtual. Estes sistemas de realidade virtual imersiva rastreiam o movimento da cabeça do usuário e atualizam o ambiente virtual de acordo com esse movimento, fornecendo uma visão em 360 graus do conteúdo digital. 


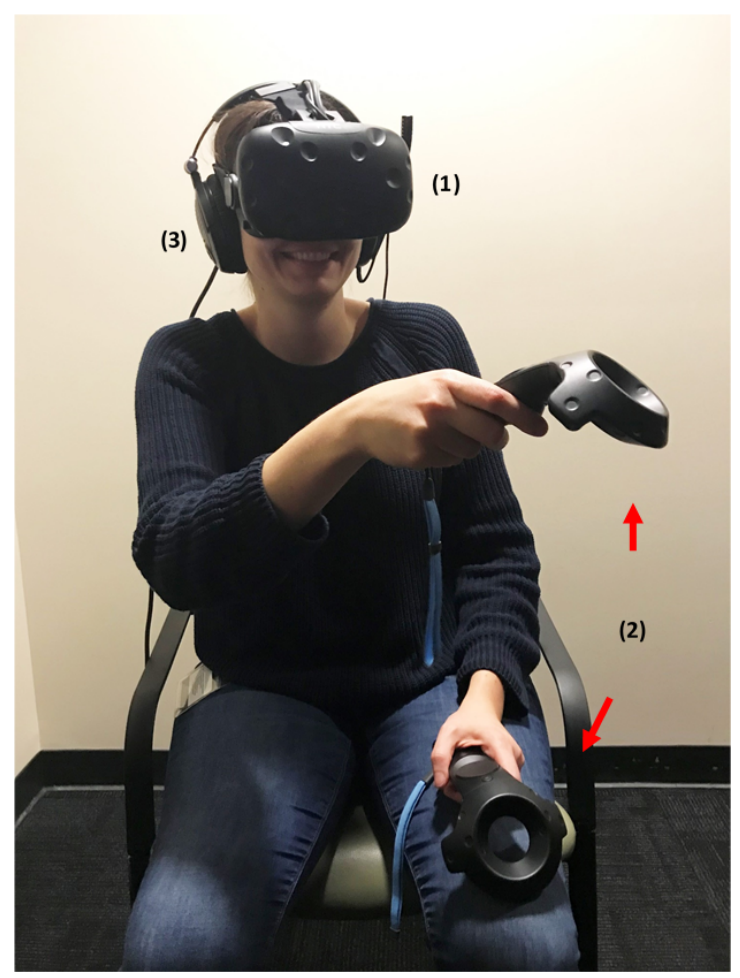

Figura 2. Dispositivos de realidade virtual imersiva: (1) Óculos de RV (HTC Vive); (2) Controles remotos (HTC Vive) \& (3) Fones de ouvido.

Neste ambiente virtual, a pessoa é rodeada por estímulos artificiais e há possibilidade do uso de acessórios que emitem estímulos visuais, sonoros, táteis e olfativos (Bailenson et al., 2008). O uso de controles remotos permite a interação do usuário com o conteúdo digital, selecionando e movendo objetos virtuais, por exemplo. Com a utilização de caixas de som localizadas em diferentes pontos do ambiente físico, é possível também a criação do som espacializado, ou seja, diferentes fontes de som de forma a reproduzir com mais fidelidade 0 ambiente real. Além disso, é possível fornecer estímulos hápticos, como vibrações.

Estes estímulos podem ser fornecidos via controles remotos ou por outros dispositivos, como luvas e equipamentos hápticos, que vibram de acordo com o movimento do usuário (por exemplo, ao "tocar" um objeto virtual) ou com alguma programação específica (após algum tempo, por exemplo). Finalmente, existem dispositivos capazes de emitir odores. Estes 
dispositivos podem estar acoplados ao HMD, emitindo odores diretamente na face do usuário, ou serem usados separadamente, como o caso de colares que emitem odores. Exemplos destes equipamentos podem ser visualizados na figura abaixo.

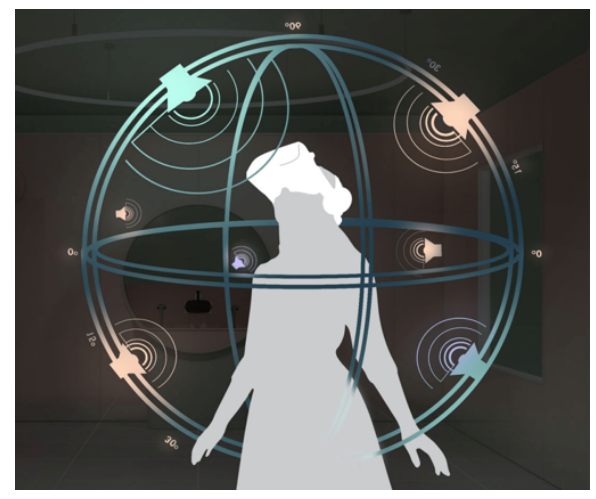

(a)

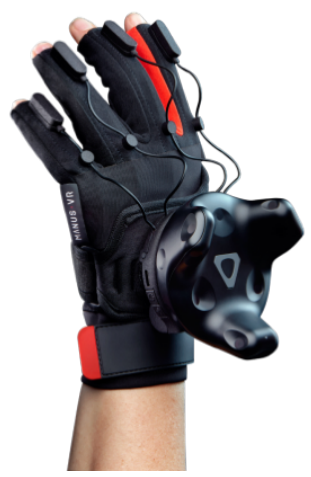

(b)

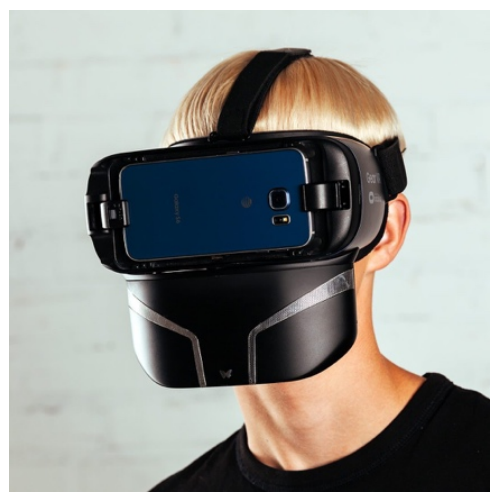

(c)

Figura 3. Acessórios de Realidade Virtual. (a) Esquema de áudio espacializadoi (b) Luva háptica (ManusVR²); (c) Máscara que emite odores (Feelreal ${ }^{3}$ )

Além dos equipamentos utilizados, os sistemas de RV imersiva podem variar dependendo da configuração e do conteúdo digital usado. Neste último item, as duas principais categorias utilizadas são baseadas em gráficos gerados por computador ou em vídeos imersivos, também chamados vídeos 360-graus imersivos (Li et al., 2017). A principal diferença entre esses ambientes é que o conteúdo baseado em gráficos computacionais permite um maior grau de interatividade e de criação de conteúdo gerado pelo usuário do que os vídeos imersivos.

\footnotetext{
${ }^{1}$ http://vr.amp.amsterdam/what-is-spatial-audio/

2 https://www.manus-vr.com/

${ }^{3}$ https://feelreal.com/
} 
Em ambientes virtuais criados por computação gráfica, os usuários podem escolher avatares, selecionar objetos, mover-se no ambiente virtual e atualizar esse ambiente de acordo com diferentes tipos de movimento do corpo. Por outro lado, os vídeos imersivos são criados usando imagens reais capturadas com uma câmera 360 graus, que são mapeadas para o interior de uma esfera digital. Esta esfera digital envolve o usuário sem problemas e traz maior realismo fotográfico para o ambiente do que o conteúdo em computação gráfica. Normalmente, os vídeos imersivos são atualizados apenas em função dos movimentos da cabeça dos usuários, em oposição ao rastreamento de movimento do corpo possível em ambientes baseados em computação gráfica, onde as pessoas andam fisicamente. Ambas as categorias são imersivas, mas variam em termos de realismo e interatividade.

Os ambientes virtuais baseados em computação gráfica permitem que o usuário explore e interaja com o conteúdo digital, causando modificações neste ambiente, testando hipóteses e traçando diferentes cursos ao longo da experiência. Isso favorece o aprendizado por experimentação, e por outro lado, exige maior processamento cognitivo para manusear os controles e aprender como interagir com o ambiente. Os vídeos imersivos em 360 graus não permitem tanta interatividade, em sua maioria, a interação é restrita aos movimentos de cabeça, que permitem a visualização do conteúdo em 360 graus. Também é limitada a escolha do fluxo da experiência, sendo normalmente o fluxo semelhante a um filme, em que não é possível interromper ou mudar o curso da experiência. Por outro lado, os vídeos imersivos em 360 graus não exigem o manuseio simultâneo de controles nem a interação constante, o que permite ao usuário focar sua atenção na narrativa e visuais da experiência virtual. 
A oferta no mercado a preços mais acessíveis de filmadoras 360 graus e de adaptadores de realidade virtual - que podem usar aparelhos celulares inseridos e permitem a interação do usuário com o conteúdo visualizado - popularizou tanto o uso doméstico de ambientes de realidade virtual (com a utilização destes adaptadores de realidade virtual e fones de ouvido) quanto o desenvolvimento de vídeos e aplicativos para a criação de ambientes de realidade virtual (Burke et al., 2018; Paul Armstrong, 2017; Rosedale, 2017). Esta popularização é também observada na oferta de conteúdo em 360 gratuito. Por exemplo, é possível acessar gratuitamente milhares de vídeos 360 on-line na plataforma Youtube ${ }^{\circledast}$. Nesta plataforma, são encontrados desde vídeos amadores até vídeos profissionais e educativos.

Entretanto, vale ressaltar a diferença entre a experiência com o ambiente virtual usando óculos de realidade virtual com telefone celular inserido (meio pelo qual a maior parte dos usuários acessa conteúdos gratuitos em 360 graus) e óculos de realidade virtual integrado a um computador (equipamento mais caro, normalmente utilizado para reproduzir experiências que precisam de controles remotos ou outros equipamentos para interação com o conteúdo). O ambiente virtual criado com uso de telefone celular acoplado a um adaptador de RV não permite que a imagem acompanhe movimentos outros do que os da cabeça (uma vez que se usam os sensores existentes no celular).

Os óculos de realidade virtual integrados a computadores, como os das marcas Oculus e HTC Vive ${ }^{\circledast}$, são mais caros e exigem maior poder computacional, mas por outro lado permitem que o usuário tenha seus movimentos de caminhar, abaixar ou mesmo os movimentos dos braços acompanhados pelas imagens, já que usam sensores externos ao óculos para rastrear os movimentos do corpo, o que torna o ambiente de realidade virtual mais imersivo (Rosedale, 
2017). Estes óculos de RV ligados a computadores permitem também a integração de outros equipamentos que aumentam a imersão e interação, como luvas hápticas, colares olfativos, dentre outros.

\subsection{Aspectos Afetivos e Cognitivos da Aprendizagem em Ambientes Virtuais Imersivos}

De acordo com a Psicologia Cognitiva, a aprendizagem pode ser categorizada como conceitual ou procedimental. A aprendizagem conceitual é a que conecta os elementos básicos que já foram organizados e explicados (Anderson et al., 2001; Krathwohl, 2002). Ela envolve conhecimento de classificação, categorização, de teorias, modelos, estruturas, princípios e generalizações. Esse tipo de aprendizagem está relacionado à explicação do que é conhecido e que foi aprendido.

A aprendizagem procedimental refere-se ao uso de critérios e métodos na resolução de problemas. Abrange o conhecimento de técnicas, habilidades e métodos específicos, bem como a percepção de como e quando usar um determinado procedimento (Anderson et al., 2001; Krathwohl, 2002). Em relação ao impacto dos ambientes virtuais imersivos na aprendizagem conceitual e procedimental, Queiroz e colegas (2018) e Jensen e Konradsen (2018) realizaram abrangentes revisões de literatura e relataram escassez de estudos direcionados à aprendizagem conceitual utilizando ambientes imersivos. Estes estudos indicam que não há evidências suficientes para favorecer o uso de ambientes virtuais imersivos quando comparado a outras mídias no que diz respeito à aprendizagem conceitual. 
Ainda de acordo com a Psicologia Cognitiva, Bloom (1956) propôs uma taxonomia hierárquica enfatizando os objetivos cognitivos da aprendizagem. Mayer, Paul, Raths e Wittrock (2001) revisaram esta taxonomia desenvolvida por Bloom e propuseram seis níveis de processos cognitivos envolvidos nos objetivos de aprendizagem. Estes níveis são, em ordem crescente: memorização, compreensão, aplicação, análise, avaliação e criação de conhecimentos.

Esses níveis são descritos a seguir:

- Memorização refere-se à recuperação de informações a que se foi exposto, como por exemplo, memorizar a data de descobrimento do Brasil.

- Compreensão refere-se à capacidade de traduzir o que foi aprendido nas próprias palavras do aprendiz, como por exemplo, compreender o momento histórico em que o Brasil foi descoberto;

- Aplicação está relacionada à capacidade de utilizar o conhecimento memorizado e compreendido em novas situações que não foram ensinadas diretamente, como por exemplo, aplicar o conhecimento sobre o momento histórico da descoberta do Brasil para o entendimento da descoberta de outros países na América Latina;

- Analisar refere-se à capacidade de decompor uma informação e discutir seus elementos. Por exemplo, conseguir distinguir e analisar os elementos que compuseram o momento histórico da descoberta do Brasil;

- Avaliação refere-se à capacidade de fazer julgamentos sobre algo, usando alguns critérios, como por exemplo, julgar as consequências do fato do Brasil ter sido colonizado pelos portugueses; e, 
- Criação é considerada o nível cognitivo mais alto e refere-se ao pensamento indutivo e à capacidade de criar com base no que o aluno já sabe. Ampliando o exemplo sobre a descoberta e colonização do Brasil pelos portugueses, o nível de criação seria a capacidade de criar teorias ou histórias fictícias baseadas em fatos reais a partir desse fato.

Essa taxonomia é particularmente útil no planejamento e avaliação de atividades de aprendizagem, ajudando a avaliar níveis de processos cognitivos mais baixos e / ou mais altos. Essa teoria se mostra de particular interesse nas pesquisas com ambientes imersivos, uma vez que eles permitem a reprodução de contextos diferenciados, bem como a execução de tarefas diversas, que envolvem tanto a aprendizagem conceitual como procedimental.

De acordo com a revisão de literatura de Jensen e Konradsen (2018), especificamente sobre os impactos do AVI na aprendizagem, não foi encontrado nenhum estudo investigando o impacto da imersão nos níveis mais altos propostos pela taxonomia de Bloom, como aplicação e criação, indicando a necessidade desse tipo de investigação e a originalidade do presente estudo.

Quando se trata de estudos comparando o uso de realidade virtual com outras mídias para a aprendizagem conceitual, os resultados variam significativamente. Por um lado, alguns estudos relataram resultados significativos positivos na aprendizagem do uso de AVIs em comparação com outras mídias (Alhalabi, 2016; Webster, 2016).

Por outro lado, alguns estudos mostraram resultados significativos negativos na aprendizagem com o uso de AVIs (Dede et al., 1997; Parong \& Mayer, 2018). Uma das razões indicadas pelos estudiosos para o impacto negativo dos AVIs no aprendizado conceitual quando 
comparado a outras mídias é que o AVI pode ser muito rico em estímulos e atividades, o que pode causar sobrecarga cognitiva e exceder as capacidades do aluno para processar as informações conceituais (Mayer, 2017; Moreno \& Mayer, 2002; Parong \& Mayer, 2018).

Do ponto de vista da teoria da carga cognitiva (Cognitive Load Theory), Mayer e Clark (2009) sugerem que o ambiente multimídia rico em estímulos resulta em um paradoxo no qual a apresentação simultânea de múltiplos estímulos requer maior esforço cognitivo para processar informações visuais, auditivas e textuais. Essa sobrecarga cognitiva dificultaria o processamento das informações pelos alunos e prejudicaria o aprendizado em ambientes muito estimulantes, como por exemplo, ambientes virtuais imersivos que apresentam estímulos concorrentes simultâneos e alto nível de interatividade.

Ainda de acordo com esta teoria e considerando os processos cognitivos, três demandas cognitivas estão envolvidas na aprendizagem: carga cognitiva exógena (processamento de informações não relevantes para os objetivos de aprendizagem); carga cognitiva intrínseca (processamento de informações relevantes para os objetivos de aprendizado) e carga cognitiva pertinente (esforço do aluno para construir esquemas sobre as informações que estão sendo processadas) (Sweller, 2005). Portanto, para ser efetivo, o recurso multimídia deve projetar ambientes que busquem reduzir a carga cognitiva exógena para evitar sobrecarga cognitiva desnecessária, o que poderia impactar o processamento de informações (Mayer, 2017; Sweller, 2005).

Os princípios de design determinam como elementos multimodais, como figuras, texto e sons, podem ser apresentados para ajudar os alunos a gerenciar a carga cognitiva (Nelson \& 
Erlandson, 2008) e são muito úteis nas pesquisas sobre o desenvolvimento de ambientes virtuais imersivos. Pesquisas que investigam ambientes multimídia baseados em monitores bidimensionais e tridimensionais sugerem alguns princípios de design para melhorar o aprendizado e a atenção.

Entre estes princípios, podemos citar o princípio de contiguidade, no qual palavras e imagens com significado correspondentes devem ser apresentados próximos um do outro no tempo e no espaço e o conceito de segmentação, que sugere que a mensagem deve ser apresentada em segmentos e não continuamente para que o aprendiz tenha tempo suficiente para processar o conteúdo apresentado e relacioná-lo a conhecimentos já adquiridos anteriormente.

Embora esses princípios de design tenham sido amplamente estudados usando monitores baseados em multimídia (Mayer, 2005, 2019; Nelson \& Erlandson, 2008), poucos estudos investigaram como experiências em AVI impactam a aprendizagem, a percepção dos estímulos e processamento cognitivo. Portanto, evidencia-se a necessidade de mais pesquisas sobre uso de AVIs na aprendizagem, principalmente ao considerar seu uso em escala.

\subsubsection{Auto eficácia}

A auto eficácia, um conceito cunhado por Bandura (1977) à luz da Teoria da Aprendizagem Social, é definido como "o julgamento das pessoas sobre suas capacidades para organizar e executar cursos de ação necessários para atingir tipos de performances designados" 
(Bandura, 1986, p. 371). Em outras palavras, auto eficácia refere-se às crenças das pessoas de que elas podem ter sucesso em uma tarefa, tópico ou ambiente específico. Importante nesse conceito é a ideia de que "as expectativas de domínio pessoal afetam tanto a iniciação quanto a persistência do comportamento de enfrentamento" (Bandura, 1977, p. 193), que destaca a importância da percepção de auto eficácia para entender os comportamentos, realizações e resultados em diversas áreas da vida das pessoas.

De acordo com Bandura (1977), percepção de auto eficácia determina quanto esforço as pessoas colocarão em uma atividade específica e quanto tempo eles persistirão na busca de êxito dessa atividade. Usher e Pajares (2008) sugeriram que, quando as pessoas se consideram capazes de aprender e dominar alguma atividade, enfrentam desafios mais positivamente e serão mais persistentes em dominar essa atividade do que as pessoas que se consideram incapazes de tentar ou dominar a atividade.

Essa é uma habilidade importante, considerando as demandas da nossa sociedade atual. Aprender novas profissões e aprender como enfrentar e lidar com novas mudanças econômicas, sociais ou culturais são cruciais para ter sucesso em nosso ambiente em constante mudança (Bandura, 1995; Dede, 2010).

Devido à importância da percepção de auto eficácia nas escolhas diárias, ela tem sido amplamente pesquisada e aplicada em contextos educacionais (Harris et al., 2011; Schunk, 1991, 1995; Schunk \& Dibenedetto, 2016; Schunk \& DiBenedetto, 2020), e tem sido considerada um elemento que é capaz de predizer o desempenho acadêmico e escolhas de carreira dos indivíduos (Maddux, 2016; Zimmerman, 1995; Zimmerman et al., 1992, 2017). 
A percepção de auto eficácia afeta as escolhas de carreira dos indivíduos, influenciando o tipo de ambientes e atividades com as quais eles se envolvem, pois as pessoas tendem a evitar ambientes para os quais acreditam não possuir as habilidades necessárias para se inserirem. Dessa forma, a percepção de auto eficácia opera influenciando a seleção dos ambientes e redes sociais com os quais as pessoas escolhem se engajar ao longo da vida (Bandura, 1995; Zimmerman et al., 2017).

De acordo com Bandura e colegas (1999), as quatro principais fontes de percepção de auto-eficácia são: 1) experiências objetivas (perceber os resultados de sua própria ação), 2) experiências vicárias (observação dos resultados da ação de outras pessoas), 3) persuasões verbais (opinião dos outros sobre o desempenho) e 4) estados fisiológicos (por exemplo, emoções e sentimentos).

O autor afirma que as experiências objetivas são as que produzem efeito maior e mais generalizado na percepção de auto eficácia, pois fornecem evidências genuínas e imediatas de que é possível ter sucesso na tarefa em questão (Bandura et al., 1999). Depois de receber essas evidências e interpretar os resultados, os aprendizes tendem a desenvolver crenças sobre seu próprio desempenho. Verifica-se na literatura (Bandura, 1995, 1997; Schunk, 1995, Zimmerman, 1995), que essas crenças tem impacto na percepção de auto eficácia dos alunos.

A segunda fonte mais poderosa na percepção de auto eficácia dos aprendizes são as experiências indiretas, através das quais os alunos interpretam suas próprias capacidades observando os outros e fazendo comparações (Bandura et al., 1999; Schunk, 1987; Schunk \& Dibenedetto, 2016). Bandura (1995) argumenta que, embora as experiências objetivas mostrem 
maior impacto na percepção de auto eficácia, os aprendizes que não têm certeza de suas capacidades ou têm pouca experiência de domínio são mais sensíveis à influência de experiências vicárias.

Na literatura, muitos estudos destacam o papel dos professores, pais e colegas de escola na percepção de auto eficácia dos alunos (Schunk, 1995; Schunk \& Dibenedetto, 2016; Usher \& Pajares, 2008). No entanto, devido ao aumento da adoção de artefatos tecnológicos por parte dos estudantes, dentro e fora das escolas, principalmente nas últimas duas décadas, pesquisas recentes começaram a se concentrar na relação bidirecional entre tecnologia e a percepção de auto eficácia (Xiaoxia Huang \& Mayer, 2019; Kuo et al., 2014; Meyer et al., 2019; Sun \& Rueda, 2012).

Mais especificamente, dado o potencial dos AVIs para explorar as dimensões afetivas da aprendizagem dos alunos, mais atenção tem sido dada para entender como os AVIs afetam a percepção de auto eficácia. Esse interesse é válido considerando que o aumento na percepção de auto eficácia tem sido associado a efeitos positivos a longo prazo na aprendizagem, no ambiente acadêmico e no desempenho profissional (Bandura, 1986a; Pekrun, 2006; Plass \& Kaplan, 2016; Zimmerman, 2000).

Para esses domínios afetivos de aprendizagem, os impactos dos AVIs demonstraram ser encorajadores. Embora o número de pesquisas ainda seja insuficiente para tirar conclusões sobre os impactos dos AVIs na aprendizagem conceitual, os resultados de estudos que investigam os impactos de AVIs na percepção de auto eficácia parecem ser mais consistentes e correlacionam 
positivamente o uso destes ambientes imersivos com o aumento na percepção de auto-eficácia (Makransky et al., 2019; Meyer et al., 2019).

Além disso, existem algumas sugestões de que os AVIs podem favorecer o aprendizado devido ao seu impacto positivo em aspectos afetivos da aprendizagem, como motivação, senso de controle da aprendizagem e presença, dentre outros fatores (Johnson-Glenberg, 2018). Uma hipótese sobre este impacto positivo dos AVIs na aprendizagem é de que o senso de controle da aprendizagem dado pela imersão e interação permitidos nos AVIs possam impactar positivamente na percepção de auto eficácia, que, como já demonstrado na literatura, tem impacto positivo sobre a aprendizagem.

Considerando o nível de imersão, que é um dos grandes diferenciais entre a realidade virtual e outras mídias, estudos anteriores mostraram uma relação positiva entre o aumento do nível de imersão e a percepção de auto eficácia. Por exemplo, Meyer, Omdahl e Makranski (2019) compararam o efeito de um pré-treinamento na aprendizagem sobre as células do corpo humano usando óculos de RV ou um vídeo tradicional. O estudo utilizou um desenho experimental de medidas repetidas $2 \times 2$ e os participantes foram aleatoriamente distribuídos entre a condição AVI ou vídeo, com ou sem uma sessão de pré-treinamento.

Os resultados deste estudo mostraram que a sessão de pré-treinamento aumentou significativamente a aprendizagem e a transferência do conhecimento para participantes na condição AVI, mas não na condição vídeo. Os resultados também mostraram que os participantes nas condições AVI com e sem pré-treinamento relataram maior percepção de auto eficácia do que os participantes nas condições de vídeo (com ou sem pré-treinamento). Além disso, 
verificou-se que a sessão de pré-treinamento aumentou significativamente a percepção de auto eficácia dos alunos na condição AVI, mas não na condição vídeo.

Em um outro estudo, Makransky, Borre-Gude e Mayer (Makransky et al., 2019) compararam os efeitos motivacionais e cognitivos de uma simulação imersiva com uso de óculos de RV, uma simulação com uso de computador e um manual de segurança convencional impresso para o treinamento de segurança de laboratório. Embora os resultados não tenham indicado diferença significativa no teste de aprendizagem imediata entre as três condições, eles mostraram uma diferença significativa na transferência do conhecimento para a solução de problemas do mundo físico, motivação, satisfação e a percepção de auto eficácia entre a condição com óculos de RV e a condição texto, sendo que os participantes na condição com óculos de RV apresentaram pontuação superior nessas medidas.

Como a percepção de auto eficácia afeta o desempenho acadêmico e influencia as escolhas profissionais, Multon, Brown e Lent (Multon et al., 1991) já argumentavam que é crucial encontrar novas maneiras de apoiar e desenvolver a percepção de auto eficácia em ambientes educacionais, profissionais e pessoais. Assim, entender como os métodos de ensino e as ferramentas em sala de aula afetam a percepção de auto eficácia desempenha um papel importante na melhoria das chances de sucesso dos alunos. Considerando os AVIs em particular, dada sua recente e crescente adoção em ambientes de aprendizagem formais e informais, é necessário entender seu papel na promoção a percepção de auto eficácia. Além disso, é importante observar que a maioria dos estudos que avaliam a relação entre mídia imersiva e a 
percepção de auto eficácia utilizou apenas ambientes virtuais baseados em computação gráfica e a relação entre vídeos imersivos em 360 graus e a percepção de auto eficácia ainda não é clara.

\subsection{Realidade Virtual e Educação}

Se os vídeos tradicionais, transmitidos em duas dimensões (2D) numa tela e sem possibilidade de interação com o conteúdo já atraem substancialmente a atenção de jovens, os vídeos e jogos em ambiente de realidade virtual têm atraído ainda mais atenção, não apenas de jovens, mas também de adultos e idosos.

Vídeos em 360 graus tem sido amplamente procurados, conforme dados de busca pelas palavras-chaves "vídeo 360 graus" no maior site de buscas online Google 1 . Um exemplo de vídeo 360 graus $^{2}$ é ilustrado a seguir: as imagens na tela permitem que o espectador "nade" próximo a um tubarão enquanto ouve os sons do fundo do mar e a narração em inglês com dados sobre a espécie de tubarão é visualizada. Este vídeo já teve mais de 7 milhões de visualizações em apenas 8 meses. Tanto neste, como nos vídeos em 360 graus em geral, as imagens acompanham os movimentos da cabeça do espectador que o assiste utilizando óculos de realidade virtual, como se a câmera que filma estivesse na cabeça do espectador.

Como mencionado anteriormente, ao utilizar os óculos (que impedem estímulos visuais externos aos do vídeo) e fones de ouvidos que oferecem estímulos sonoros (e também impedem sons externos), o usuário fica imerso na experiência, de maneira muito mais intensa do que apenas assistindo a um vídeo numa tela tradicional (Bailenson et al., 2008).

\footnotetext{
${ }^{1}$ Disponível em https://www.google.com/trends/explore?geo=BR\&q=video\%20360\%20graus acessado em $16 / 09 / 2016$

${ }^{2}$ Disponível em https://www.youtube.com/watch?v=HNOT feL27Y acessado em 16/09/2016
} 
De maneira semelhante ao vídeo relatado acima, por meio do programa Expeditions ${ }^{1}$, desenvolvido pela empresa de tecnologia Google, o aluno "visita" o fundo do mar, qualquer lugar do mundo, ou até mesmo do universo, através de um ambiente de realidade virtual, com o uso de óculos de realidade virtual. Este programa começou a ser utilizado no Brasil em 2016 pela Escola Internacional Ítalo-Brasileira, em São Paulo, em aulas de ciências para os alunos. Os relatos de pais e professores é de que o interesse dos alunos por conteúdos de ciências e geografia aumentou muito (Oshima, 2016). Os professores relatam que os alunos pedem aos pais para assistirem conteúdos semelhantes em realidade virtual em casa. Estes relatos vão de encontro com a afirmação de Bailenson e colaboradores (2008) de que ambientes de realidade virtual despertam a atenção, curiosidade e envolvem mais os alunos.

Nos Estados Unidos, as universidades Stanford, Harvard, Massachussets Institute of Technology (MIT) e Carnegie Mellon se uniram e criaram o projeto Immersive Education ${ }^{2}$, para o desenvolvimento de programas voltados para a Educação que utilizam recursos de realidade virtual. Os resultados das pesquisas deste projeto foram publicados no Journal of Immersive Education $^{3}$, que se encontra em seu primeiro volume e apresenta apenas 3 artigos no prelo, o que revela a escassez de estudos sobre os impactos do uso de ambientes virtuais imersivos na educação básica, afirmação esta confirmada pela revisão de literatura feita por Freina e Ott (2015) e pela pesquisadora (Queiroz et al., 2018).

O uso de ambientes virtuais imersivos tem se mostrado bastante promissor na Educação Especial e na Avaliação Cognitiva, principalmente por sua capacidade de desenvolver tarefas

\footnotetext{
${ }^{1}$ Disponível em https://www.google.com.br/edu/expeditions/ acessado em 17/09/2016

${ }^{2}$ Disponível em http://immersiveeducation.org/ acessado em 17/09/2016

${ }^{3}$ Disponível em http://jied.org/1/1/index.html acessado em 17/09/2016
} 
específicas que permitem avaliar como determinados estímulos afetam o desempenho cognitivo, como também registrar e armazenar dados de desempenho motor e cognitivo dos alunos (Cidrim \& Madeiro, 2017; Collins et al., 2015; Passig \& Eden, 2003; Rosa et al., 2016; Shoaib et al., 2017).

Schloss, Jacobson e Handron (2012) utilizaram uma caverna digital móvel capaz de projetar imagens num campo de visão de 360 graus para criar uma representação virtual do funcionamento ecológico de uma floresta temperada. Os alunos de educação básica podem interagir com essa floresta virtual e explorar seu desenvolvimento num intervalo de 100 anos. Professores e alunos assistem às imagens de dentro da caverna e podem navegar pelos estágios de crescimento da floresta ou usar ferramentas virtuais de mensuração, por exemplo, por meio de controles semelhantes aos de videogames. Alunos do oitavo ano trabalharam em pares e conseguiram obter medidas de crescimento e do funcionamento do ecossistema da floresta. 0 envolvimento dos alunos oscilou entre turmas bastante engajadas e outras mais dispersas. De acordo com os autores, resultados preliminares indicam que este ambiente de realidade virtual é efetivo para o ensino de ciências ambientais em sala de aula e em ambientes informais, como em museus e em atividades de escoteiros.

O uso celulares inseridos em adaptadores de realidade virtual e fone de ouvido permite a criação de um ambiente de realidade virtual em casa com um investimento relativamente baixo (Burke et al., 2018; Paul Armstrong, 2017; Rosedale, 2017). Somado a isso, este ambiente chama muito a atenção e engaja os usuários (Bailenson et al., 2008) o que torna a sua utilização para fins de entretenimento, cultura e educação cada vez maior entre jovens, adultos e até mesmo crianças (Armstrong, 2017). 
De um lado, o uso deste recurso, por permitir a intensa e voluntária exposição a conteúdos e consequente aquisição de conhecimentos implícitos, "pode facilitar a aprendizagem frequentemente muito formalizada dos conhecimentos explícitos" (Paula \& Leme, 2010, p.20). Por outro, é possível que o excesso de informações e estímulos simultâneos dispersem a atenção do usuário do conteúdo que realmente é importante, como abordado na subseção anterior.

Por fim, como escolas já estão considerando inserir aulas em ambiente de realidade virtual em suas práticas pedagógicas e os impactos do uso dessa tecnologia na educação básica e na aprendizagem em geral são pouco conhecidos, destaca-se a relevância de estudos de avaliação do impacto dos ambientes virtuais imersivos na aprendizagem. Desta forma, serão apresentadas a seguir revisões sistemáticas de literatura realizadas e publicadas pela pesquisadora sobre o uso da realidade virtual na educação e na avaliação da aprendizagem (Queiroz et al., 2017, 2018, 2019).

1.4.1. Revisão sistemática de pesquisas que usam Realidade Virtual na educação básica Um levantamento sobre revisões de literatura que sintetizam estudos sobre o uso de ambientes virtuais imersivos na educação identificou: um estudo sobre ambientes virtuais educacionais (Mikropoulos \& Natsis, 2011), um sobre uso de realidade virtual imersiva em educação geral (Freina \& Ott, 2015), uma meta-análise dos resultados na aprendizagem de instrução baseada em RV na educação básica e ensino superior (Merchant et al., 2014), e uma revisão de estudos empíricos sobre o uso de mundos virtuais imersivos tridimensionais na educação básica e ensino superior (Hew \& Cheung, 2010). Nenhum deles focou especificamente 
estudos que investigam ambientes virtuais imersivos com uso de óculos de realidade virtual na educação básica.

Mikropoulos e Natsis (2011) analisaram 53 trabalhos e identificaram o contexto educacional em que esses estudos foram realizados, as características da RV e as teorias de aprendizagem seguidas pelos autores dos trabalhos. A maioria dos estudos revisados investigou a aplicação de ambientes virtuais para o ensino de ciências naturais e matemática, e alguns investigaram ciências sociais. O construtivismo foi o modelo teórico mais utilizado nos estudos revisados. Os resultados relatados nestes estudos indicaram impactos positivos na aprendizagem e sugerem a necessidade de mais pesquisas sobre as aplicações e retenção do conhecimento adquirido por meio do uso de ambientes virtuais imersivos.

Em outra revisão de literatura, Freina e Ott (2015) investigaram as vantagens e potencialidades do uso da Realidade Virtual Imersiva na educação usando o óculos de RV. A maioria dos estudos revisados investigaram a aplicação no ensino superior, na formação de adultos e no ensino de assuntos científicos. Apenas um estudo investigou a aplicação da RV na educação básica. As autoras indicam a necessidade de pesquisas futuras que investiguem a presença constante de um professor para mediar o uso da RV e de estudos sobre a transferência de aprendizagem com o uso de RV em comparação com as abordagens tradicionais.

Merchant, Goetz, Cifuentes, Keeney-Kennicutt e Davis (2014) realizaram uma metaanálise da literatura para examinar o impacto de princípios de design instrucional na instrução baseada RV na educação básica e no ensino superior. A pesquisa incluiu estudos usando instrução baseada em RV (imersiva e não-imersiva) na forma de jogos, simulação ou mundos virtuais. De acordo com seus resultados, jogos, simulações e mundos virtuais impactam positivamente a 
aprendizagem, sendo que os jogos (não imersivos) mostram ganhos mais significativos do que as simulações e os mundos virtuais. Além disso, o impacto na aprendizagem é maior quando os alunos jogam individualmente, e é menor quando há aumento das sessões com uso de ambientes virtuais imersivos. Os autores sugerem a necessidade de estudos futuros para testar mais variáveis do ambiente de RV e os efeitos dos recursos de design na aprendizagem.

Hew e Cheung (2010) revisaram artigos empíricos sobre o uso de mundos virtuais imersivos tridimensionais na educação para entender: (1) como os mundos virtuais estavam sendo utilizados por alunos e professores, (2) os métodos de pesquisa utilizados e (3) os tópicos de pesquisa. Os autores consideraram soluções como Second Life ${ }^{\circledR}$ e Active Worlds ${ }^{\circledR}$ como Mundos Virtuais 3D Imersivos. Eles identificaram que essa tecnologia estava sendo usada para espaços de comunicação, simulação de espaços físicos (representação espacial); e como espaços experienciais (representação da atuação sobre um mundo virtual). Ainda, os autores identificaram que apenas $12 \%$ dos estudos estavam relacionados ao ensino fundamental, enquanto $19 \%$ e $69 \%$ se referiam ao ensino médio e ensino superior, respectivamente.

Com intuito de identificar o impacto na aprendizagem de AVI com uso de óculos de RV na educação básica, bem como os tópicos abordados e recomendações de pesquisas futuras, foi feita uma revisão sistemática de literatura baseada nas seguintes perguntas de pesquisa: 1. Quais são os resultados de aprendizagem obtidos com o uso do AVI na educação básica? 2. Quais tópicos das disciplinas, habilidades e capacidades dos alunos foram investigados nos estudos? 3. O que os pesquisadores dos estudos selecionados sugerem para estudos futuros?

Buscou-se nas bases de dados Google Scholar, ERIC (Education Resources Information Center), SAGE, IEEE Explore, Scopus, ACM Digital Library, e Web of Science os estudos que 
investigaram o uso de óculos de RV na educação básica. Por se tratar de bases de dados internacionais, utilizaram-se termos de busca em inglês. Os principais termos utilizados, derivados das questões de pesquisa para este estudo, foram: (1) immersive virtual environment, (2) $K-12$, and (3) head-mounted display. O termo "head-mounted display" (monitor montado na cabeça, em tradução livre) foi incluído, pois esta revisão considerou apenas ambientes virtuais imersivos que utilizem os óculos de RV. Dois levantamentos adicionais foram realizados contemplando a literatura brasileira e são descritos nas subseções a seguir.

Sinônimos relevantes foram identificados para compor os termos de pesquisa. $O$ operador booleano "OR" foi usado para concatenar os sinônimos, enquanto "AND" foi usado para concatenar termos principais. Dessa forma, foram considerados os seguintes termos de busca: immersive videos, immersive digital environment, immersive environment, immersive system, immersive simulation, immersive virtual system, immersive projection, 360-degree video, K-12, primary school, kindergarten, grade school, high school, and head-mounted display. 0 termo “360-degree video" (vídeo em 360 graus) também foi incluído para contemplar os estudos que usaram um smartphone inserido em adaptadores de RV.

Devido à limitação de caracteres no campo de pesquisa, não foi possível construir apenas uma chave de busca. Assim, a principal chave de busca utilizada foi: (1) (("immersive video" OR "immersive digital environment" OR "immersive system" OR "immersive simulation" OR "immersive virtual reality" OR "immersive projection" OR "360 degrees video") AND ("K-12") AND ("head mounted display")). Variações dessa chave de busca foram usadas (uma por vez) para incluir sinônimos dos níveis educacionais. Além dessa busca sistemática, para complementar esta revisão, os autores buscaram as referências citadas nos artigos incluídos. 
O total de trabalhos encontrados por base de dados foi: Google Scholar (538), ERIC (151), SAGE (23), IEEE Xplore (11), Scopus (9), Biblioteca Digital ACM (8), e Web of Science (7), o que totalizou em 747 trabalhos.

Estes trabalhos foram selecionados com base nos critérios descritos a seguir. Critérios de Inclusão: (1) trabalhos empíricos revisados por pares, escritos em inglês (artigos de periódicos e anais de conferências); (2) estudos que investigaram diretamente as questões de pesquisa; e (3) trabalhos que descreveram a metodologia de pesquisa e os resultados de aprendizagem do uso de AVI com óculos de RV na educação básica. Critérios de Exclusão, de acordo com a metodologia proposta por Shoaib et al. (2017) : (1) publicações não revisadas por pares (por exemplo: livros, capítulos de livros, teses, dissertações e publicações não científicas; (2) trabalhos que não descreveram a metodologia de pesquisa ou os resultados de aprendizagem; (3) trabalhos não relacionados ao tema dessa pesquisa; e (4) trabalhos não disponíveis para download gratuito, não disponíveis através do acesso institucional universitário, e não disponíveis após solicitação aos seus autores.

A primeira seleção dos trabalhos foi feita com base no idioma (inglês), tipo de publicação, disponibilidade, títulos e resumos dos trabalhos. Foi feita uma segunda seleção a partir da leitura dos textos completos dos trabalhos para identificar a metodologia de pesquisa e os resultados para a aprendizagem. Os trabalhos selecionados foram incluídos e analisados.

Dos 747 trabalhos, 191 foram repetidos, 147 não eram trabalhos completos, 23 não estavam acessíveis e 11 não foram escritos em português ou inglês, o que impediram seu entendimento pela pesquisadora e não puderam ser incluídos nesta revisão. Os 375 trabalhos restantes foram avaliados na íntegra e 361 foram excluídos por uma ou mais das seguintes 
razões: não estavam relacionados a esta pesquisa; não utilizaram AVI com óculos de RV; amostra investigada não era de educação básica ou não avaliaram impactos na aprendizagem. Após a seleção, 14 trabalhos foram incluídos e, com base em suas referências, foram incluídos mais 10 trabalhos, resultando na análise de 24 artigos.

A fim de responder às questões de pesquisa, os estudos analisados foram categorizados em "referentes ao conhecimento formal", "referente a capacidades" e "referente a habilidades", que são as mesmas categorias usadas por Merchant, Goetz, Cifuentes, Keeney-Kennicutt (2014). Nesta categorização, os resultados relacionados ao conhecimento formal referem-se à recordação, compreensão e interpretação de conteúdos da educação formal. As categorias baseadas em capacidades estão relacionadas à motivação, engajamento, presença e dimensões afetivas, e as categorias baseadas em habilidades referem-se às habilidades cognitivas e motoras (Anderson, 1982; Schunk, 2012). O termo "referente a capacidades" é uma tradução livre do termo "abilities-based" utilizado na categorização de Merchant et al (2014), embora acredita-se que em português o melhor termo que representa esta categoria talvez seja "referente a afetividade" que, portanto, será utilizado daqui em diante. Os resultados dos estudos foram categorizados em "melhoria", "deterioração" e "nenhuma diferença significativa". Algumas pesquisas avaliaram mais dessas categorias.

Os trabalhos incluídos nesta revisão estão listados na Tabela 1. Embora não seja o foco aqui analisar os estudos sobre educação especial ou reabilitação, foram incluídos artigos que investigaram crianças com desenvolvimento atípico inseridas na educação básica e, portanto, seus resultados são importantes para entender o estado da arte do uso de AVI com óculos de RV em contextos de educação básica inclusiva (Mikropoulos \& Natsis, 2011). Além disso, esses 
estudos investigaram habilidades importantes para o sucesso acadêmico de crianças com deficiência auditiva, déficits cognitivos e autismo (Passig, 2015). Apenas dois estudos usaram AVI com óculos de RV de baixo custo (telefone celular inserido no adaptador de RV) e vídeo imersivo (Gelsomini, 2016; Rasheed et al., 2015); todos os outros estudos usaram óculos de RV dedicado e conteúdo interativo.

Tabela 1. Trabalhos revisados

\begin{tabular}{|c|c|c|}
\hline & Desenvolvimento típico & Desenvolvimento atípico \\
\hline Conhecimento & $\begin{array}{c}\text { (Adamo-Villani \& Wilbur, 2008; Häfner et al., } \\
2014 ; \text { Rasheed et al., 2015; Salzman et al., } \\
\text { 2006, 1996, 1995; Tamaddon \& Stiefs, 2017) }\end{array}$ & $\begin{array}{c}\text { (Adamo-Villani \& Wilbur, 2008; Gelsomini, } \\
\text { 2016) }\end{array}$ \\
\hline Capacidades & $\begin{array}{c}\text { (Casu et al., 2015; Parmar et al., 2016; Passig } \\
\text { et al., 2007) }\end{array}$ & \\
\hline Habilidades & (Eden \& Passig, 2007; Y. Huang et al., 2015; & (Cheng et al., 2015; Passig, 2009, 2015; \\
& $\begin{array}{c}\text { Passig, 2015; Passig et al., 2016a; Passig \& } \\
\text { Eden, 2010; Passig \& Schwartz, 2014; } \\
\text { Rasheed et al., 2015) }\end{array}$ & $\begin{array}{c}\text { 2010; Strickland et al., 1996) } \\
\end{array}$ \\
\hline
\end{tabular}

A seguir são apresentados os resultados de acordo com as perguntas de pesquisa desta revisão.

Pergunta 1: Quais são os resultados de aprendizagem do uso do AVI na educação básica? Estudos que investigaram o conhecimento formal: Embora haja significativa variabilidade entre as tarefas e experimentos entre os estudos, a maioria dos estudos que relataram resultados de aprendizagem de conhecimento formal (Adamo-Villani \& Wilbur, 2008; Gelsomini, 2016; Häfner et al., 2014; Rasheed et al., 2015; Salzman et al., 2006, 1996, 1995; Tamaddon \& Stiefs, 2017) relataram impactos positivos na aprendizagem. Um estudo relatou impacto positivo pouco significativo (Salzman et al., 1996) e um não relatou melhora no 
desempenho dos estudantes (Salzman et al., 1995) - este último estudo destaca aspectos a serem considerados quando se utiliza óculos de RV para o aprendizado do conhecimento conceitual, como a importância de uma equipe interdisciplinar para o desenvolvimento do AVI. Os dois estudos (Adamo-Villani \& Wilbur, 2008; Gelsomini, 2016) em educação especial relataram melhora no desempenho de crianças, embora um tenha relatado apenas uma pequena melhora (Gelsomini, 2016). O autor desse estudo sugere que isso pode se dever ao breve tempo da experiência no AVI - menos de 5 minutos (Gelsomini, 2016). Ambos estudos destacam a importância do período de adaptação antes das sessões experimentais.

Estudos que investigaram afetividade: os trabalhos analisados demonstraram que os estudantes que utilizaram óculos de RV relataram maior percepção da relevância do tópico estudado, maior autoconfiança em sua capacidade de aprender, mais satisfação com a aula e mais motivação e envolvimento na tarefa do que os estudantes que usaram outros contextos de aprendizagem (Casu et al., 2015; Parmar et al., 2016).

Em relação à consciência social e emocional, o estudo de Passig, Eden e Heled (Passig et al., 2007) com adolescentes, relatou que filmes assistidos em AVI e filmes em vídeo tradicional apresentaram resultados positivos porém significativamente diferentes entre si. Os autores acreditam que, como os participantes que assistiram ao filme em vídeo tradicional o assistiram em grupo e o mesmo apresentou imagens reais de pessoas, isso pode ter contribuído para a melhoria das habilidades sociais e emocionais dos participantes em comparação ao uso individual e de imagens gráficas utilizadas no AVI com uso de óculos de RV (Passig et al., 2007).

Estudos que investigaram habilidades: Todos os estudos que investigaram habilidades relataram melhora no desempenho dos alunos. Essas habilidades estão listadas na resposta da 
próxima pergunta de pesquisa. A maioria desses estudos investigou crianças com desenvolvimento atípico e mostrou uma contribuição relevante AVI com uso de óculos de RV para a educação inclusiva.

A maioria dos estudos que investigam o uso de óculos de RV para educação inclusiva relatou resultados positivos para a aprendizagem de habilidades avaliadas por meio de testes de inteligência (Passig, 2009, 2015; Passig \& Eden, 2000b, 2001, 2010). Estudos comparando impactos na aprendizagem de crianças com desenvolvimento atípico e com desenvolvimento típico indicam que os primeiros tiveram ganhos significativos e consideráveis ao que se refere à flexibilidade cognitiva e pensamento indutivo ao usar óculos de RV, a ponto de superar as diferenças nessas habilidades entre os grupos (Passig \& Eden, 2000a, 2000b).

Pergunta 2: Quais os tópicos, habilidades e capacidades a que os estudos se referem?

Os tópicos mais comuns investigados nos estudos com população típica de desenvolvimento são Ciências Naturais, Tecnologia, Engenharia e Matemática (com seis estudos encontrados no total), seguidos por habilidades envolvidas no desempenho medido em teste de inteligência (cinco estudos). Ciências Sociais (História), Esportes (futebol americano) e habilidades sociais e emocionais representam uma pequena parcela dos estudos analisados, com dois, um e um estudo, respectivamente.

Quatro estudos investigaram a consciência espacial (Adamo-Villani \& Wilbur, 2008; Y. Huang et al., 2015; Passig \& Eden, 2001; Rasheed et al., 2015), dois investigaram a atenção e o foco (Casu et al., 2015; Gelsomini, 2016), e dois investigaram habilidades sociais (Parmar et al., 2016; Passig et al., 2007) e flexibilidade cognitiva (Passig et al., 2016b; Passig \& Eden, 2000b) . As seguintes habilidades foram investigadas em um estudo cada: conexões de tempo (Passig \& 
Eden, 2010), percepção de tempo sequencial (Passig, 2009), analogias conceituais e perceptivas (Passig \& Schwartz, 2014), pensamento indutivo (Passig \& Eden, 2000a), e habilidades motoras e esportivas (Y. Huang et al., 2015).

Pergunta 3: O que os pesquisadores dos trabalhos analisados sugerem para estudos futuros?

Os pesquisadores referem-se à necessidade de estudos futuros que considerem um número maior de sujeitos e de sessões (estudos longitudinais) (Casu et al., 2015; Cheng et al., 2015; Gelsomini, 2016; Y. Huang et al., 2015; Tamaddon \& Stiefs, 2017), bem como de estudos que comparem uso de óculos de RV e de ambientes imersivos em geral com outras configurações instrucionais (como livros, vídeos 2D e aulas expositivas) para melhor compreensão dos resultados de aprendizagem do uso de AVI com uso de óculos de RV (Tamaddon \& Stiefs, 2017). Também sugerem que é importante considerar a facilidade de uso e a flexibilidade do sistema imersivo para permitir que os alunos personalizem seu AVI, e assim melhorar a imersão (Casu et al., 2015; Dede, 2009; Parmar et al., 2016; Salzman et al., 2006, 1995). Além disso, sugere-se o uso de mecanismos de avaliação de aprendizagem integrados ao AVI com intuito de aumentar a precisão dos resultados (Huang et al., 2015).

Alguns estudos enfatizam a importância de pesquisas futuras usarem grupos mais homogêneos e equilibrados (Häfner et al., 2014), utilização de sistemas multiusuários e AVI compartilhados (Parmar et al., 2016), desenho experimental incluindo grupos controle (Parmar et al., 2016) e avaliação prévia do conhecimento dos alunos a fim de determinar resultados de aprendizagem mais precisos (Tamaddon \& Stiefs, 2017). Diversos estudos enfatizam a necessidade de mais pesquisas sobre aplicação de AVI para educação especial (Eden \& Passig, 
2007; Passig, 2009, 2015; Passig et al., 2007, 2016a; Passig \& Eden, 2000a, 2010; Passig \& Schwartz, 2014) e alguns estudos sugerem investigar como as habilidades desenvolvidas em AVI com uso de óculos de RV podem prever conquistas dentro e fora do ambiente escolar (Passig et al., 2016a; Strickland et al., 1996).

Salzman, Loftin, Dede e McGlynn (1996) enfatizam a importância de uma equipe multidisciplinar no desenvolvimento do AVI. Os autores também sugerem a necessidade de estudos sobre "aprendizagem baseada em imersão multissensorial, coaching inteligente, motivação em ambientes virtuais e colaboração entre estudantes" (Salzman et al., 1996, p. 251). Desde a publicação deste estudo há mais de 20 anos, poucos estudos foram realizados investigando o impacto da imersão e de ambientes virtuais imersivos na aprendizagem, como pode ser visto na revisão sistemática de literatura feita pela pesquisadora. Dessa forma, ainda há necessidade de estudos futuros que investiguem o impacto dessas características dos ambientes de realidade virtual na aprendizagem.

Os estudos revisados revelam importantes contribuições do AVI com uso de óculos de RV na educação básica e educação inclusiva. Em geral, os estudos que investigaram habilidades apresentaram mais resultados positivos para a aprendizagem do que os estudos que investigaram o conhecimento formal. Os resultados relatados relacionados a atenção e engajamento foram bastante significativos nos estudos analisados. A maioria dos estudos que investigaram a aprendizagem de conhecimentos formais relataram resultados positivos para a aprendizagem, mas um deles não (Salzman et al., 1995).

A diferença nos resultados da aprendizagem de habilidades, conhecimento e afetividade pode ser devido ao fato de que a eficácia do ambiente no qual a aprendizagem ocorre depende 
também da natureza da tarefa (Moreno \& Mayer, 2007) e também porque os processos necessários para aprender cada uma dessas habilidades podem ser diferentes (Anderson, 1982; Kanfer \& Ackerman, 1989). Além disso, o conhecimento conceitual pode requerer relações mais explícitas a serem aprendidas do que as habilidades investigadas (Anderson, 1982).

Os resultados dos estudos que investigaram aquisição de conhecimento indicam que o AVI com uso de óculos de RV parece melhorar a retenção e a compreensão da informação quando comparado com ambientes tradicionais de educação ou computadores com monitor único (Rakkolainen et al., 2016; Rasheed et al., 2015). Entretanto, como são poucos estudos e eles variam entre si em relação a metodologia utilizada, mais estudos são necessários para se obter conclusões mais sólidas. Além disso, os estudos sugerem que uma combinação do uso de óculos de RV e de outros ambientes (tradicionais ou mesmo virtuais não imersivos) pode gerar resultados mais significativos de aprendizado do que o $\mathrm{AVI}$ ou métodos tradicionais isolados (Häfner et al., 2014; Rasheed et al., 2015). Essa combinação pode permitir que professores e alunos superem limitações de cada método, resultando em um ambiente mais rico e estimulante (Rasheed et al., 2015).

Em relação à afetividade, os resultados dos estudos que a investigaram com estudantes da educação básica são coerentes com estudos que investigam o uso de óculos de RV com estudantes adultos e de ensino superior (Bailenson et al., 2008; Blascovich et al., 2002). Por um lado, os alunos do ensino fundamental e médio podem encontrar um grande número de ambientes estimulantes e interessantes fora da escola, mesmo em ambientes virtuais projetados para fins de entretenimento (Dawley \& Dede, 2014), o que pode afetar seu envolvimento com atividades de educação formal que apresentam diferentes características (Moreno \& Mayer, 
2007). Por outro lado, engajamento, motivação e percepção de auto eficácia representam papéis importantes no desempenho do estudante (Bailenson et al., 2008; Fowler, 2015; Zimmerman, Bandura, \& Martinez-Pons, 1992). A capacidade de permanecer engajado e motivado para aprender é crucial para as conquistas dos estudantes (Bailey \& Bailenson, 2018; Salzman et al., 1996; Zimmerman et al., 1992). Estudos têm mostrado que tanto o envolvimento comportamental quanto o emocional podem predizer o desempenho acadêmico (Lee, 2014). Neste contexto, o uso de óculos de RV parece contribuir significativamente para a educação básica ao melhorar a motivação, atenção e envolvimento dos alunos (Bailenson et al., 2008; Dalgarno \& Lee, 2010; Dede, 2009; Salzman et al., 1996).

Quanto às habilidades, os estudos nesta área sugerem que o uso de óculos de RV pode melhorar significativamente as habilidades cognitivas que são importantes para o desempenho acadêmico ao longo da vida, como flexibilidade cognitiva e analogias conceituais, abrindo caminho para aplicações que enriqueçam a educação básica, desenvolvendo habilidades cognitivas dos alunos e reduzindo suas falhas (Passig, 2015; Passig et al., 2016a). Ainda, os resultados sugerem que o uso de óculos de RV pode contribuir significativamente para a educação de crianças com necessidades especiais, indicando alternativas metodológicas para o aprimoramento da educação inclusiva (Cheng et al., 2015).

Os tópicos investigados nos estudos são semelhantes aos relatados em revisões anteriores da literatura de estudos sobre AVI na educação (educação básica, ensino superior e profissional) (Freina \& Ott, 2015; Mikropoulos \& Natsis, 2011). Talvez as disciplinas de exatas e ciências naturais sejam mais adequadas para a criação de ambientes virtuais, uma vez que o conteúdo dessas áreas de estudo e as simulações no AVI permitem que os alunos explorem e 
experimentem situações sem os perigos e os altos custos de um experimento real (Bailenson et al., 2008; Dalgarno \& Lee, 2010).

Bailenson e colaboradores (2008) sugerem que os óculos de RV devem ser usados especialmente em situações que no mundo real seriam perigosas, impossíveis, contra produtivas e/ou muito onerosas. Os autores afirmam que a possibilidade de imersão e interatividade permitem trazer ambientes e experiências como essas mais próximas psicologicamente dos usuários, permitindo assim uma experiência mais próxima do real do que outras mídias podem oferecer.

Nesse sentido, considerando a possibilidade dos óculos de RV imergirem os sentidos dos usuários em qualquer cenário (criado sinteticamente), os óculos de RV parecem uma boa ferramenta para o ensino de história, por exemplo, bem como de assuntos que dependam da descrição de ambientes e eras (Casu et al., 2015). Este resultado indica que os estudos referentes a outros temas do currículo do ensino médio, como artes e geografia, por exemplo, são escassos e devem ser considerados em pesquisas futuras.

Para estudos futuros, os autores dos trabalhos analisados destacam não apenas as tendências na aplicação do AVI com uso de óculos de RV, que podem fornecer novas ideias sobre pesquisas neste campo, mas também identificam as limitações atuais dos estudos existentes. Eles pontuam que limitações metodológicas podem ter impactado os resultados de alguns estudos (Slavin \& Smith, 2009), limitando a generalização dos resultados relatados. 
1.4.2. Pesquisas e artigos científicos em Realidade Virtual no Brasil

A fim de traçar um panorama atual das pesquisas em Realidade Virtual no Brasil, especialmente aquelas voltadas para a Educação, a pesquisadora fez um levantamento dos grupos de pesquisa cadastrados no Diretório de Grupos de Pesquisa da Plataforma Lattes do Conselho Nacional de Pesquisa (CNPq) que possuem em seu nome, linha de pesquisa ou palavrachave da linha de pesquisa o termo "realidade virtual" e também os artigos que continham essa mesma palavra-chave nas bases de dados Scielo, Bireme, Sumários.org e Revista Brasileira de Informática na Educação (RBIE). Essas bases de dados foram escolhidas por serem as mais relevantes na intersecção Psicologia, Tecnologia e Educação.

A busca com o termo "realidade virtual" na base de dados Scielo resultou em 155 artigos e na Bireme, com o filtro de publicações nacionais, em 71 artigos. Na base de dados Sumários.org foram encontradas 16 publicações e também 16 na RBIE. Estes foram classificados de acordo com a área do tema da pesquisa, conforme Tabela 2:

Tabela 2. Quantidade de publicações de acordo com a área de pesquisa.

\begin{tabular}{|l|c|c|c|c|c|}
\hline \multicolumn{1}{|c|}{ Área de pesquisa / Base de dados } & Scielo & Bireme & Sumários.org & RBIE & Total \\
\hline Administração e Marketing & 9 & - & 1 & - & $\mathbf{1 0}$ \\
\hline Arquitetura e Urbanismo & 3 & - & - & - \\
\hline Artes produção de & 2 & - & 1 & $\mathbf{3}$ \\
\hline Atividade física & 4 & - & - & - & $\mathbf{4}$ \\
\hline $\begin{array}{l}\text { Atributos técnicos de } \\
\text { conteúdos em RV }\end{array}$ & 8 & - & 2 & $\mathbf{1 2}$ \\
\hline Biblioteconomia & 4 & - & - & - & $\mathbf{4}$ \\
\hline Biologia & 1 & $1 *$ & - & - & $\mathbf{1}$ \\
\hline Ciências Sociais & 25 & 17 & - & - & $\mathbf{4 2}$ \\
\hline Cognição & - & 1 & - & $\mathbf{1}$ \\
\hline
\end{tabular}




\begin{tabular}{|l|c|c|c|c|c|}
\hline Comunicação & 3 & - & 6 & - & $\mathbf{9}$ \\
\hline Educação & 30 & $4\left(1^{*}\right)$ & 5 & 13 & $\mathbf{5 1}$ \\
\hline Estatística & 1 & - & - & - & $\mathbf{1}$ \\
\hline Ética & 1 & - & - & - & $\mathbf{1}$ \\
\hline Filosofia & - & - & 1 & - & $\mathbf{1}$ \\
\hline Fonoaudiologia & 1 & - & - & - & $\mathbf{1}$ \\
\hline Sentimento de Presença em RV psicanálise, & 3 & - & - & - & $\mathbf{3}$ \\
\hline $\begin{array}{l}\text { Psicologia (identidade, } \\
\text { relações humanas) }\end{array}$ & - & 24 & - & - & $\mathbf{2 4}$ \\
\hline Psicoterapia & 7 & 5 & - & - & $\mathbf{1 2}$ \\
\hline Reabilitação & 19 & 8 & - & - & $\mathbf{2 7}$ \\
\hline Medicina & 28 & 11 & - & - & $\mathbf{3 9}$ \\
\hline Não relacionado & 6 & - & - & 1 & $\mathbf{7}$ \\
\hline
\end{tabular}

Os artigos foram classificados separadamente em Psicologia ou Psicoterapia, pois os primeiros referem-se a discussões teóricas sobre o uso da realidade virtual e suas implicações na formação da identidade, principalmente sob o enfoque da Psicanálise e das Relações Humanas. Já os artigos classificados em Psicoterapia, relatam aplicações práticas da Realidade Virtual no tratamento psicológico. Ainda, embora o sentimento de presença em Realidade Virtual seja bastante estudado pelo campo da Psicologia, este foi classificado separadamente, pois é prioritariamente um estudo interdisciplinar, dos campos da Psicologia, Neurociências, Comunicação e Ciências Sociais (Tori et al., 2006).

Foram encontradas publicações repetidas entre as bases de dados, sendo uma repetição em Biologia e uma em Educação. As publicações que abordam a Educação foram classificadas de acordo com objetivo e nível educacional do uso da Realidade Virtual nesse campo, como mostrado na Tabela 3: 
Tabela 3. Quantidade de artigos de acordo com o objetivo e nível educacional.

\begin{tabular}{|l|c|c|c|c|c|}
\hline Tema em Educação / Base de dados & Scielo & Bireme & Sumários.org & RBIE & Total \\
\hline Educação Geral & 6 & 2 & 1 & 1 & $\mathbf{1 0}$ \\
\hline Avaliação de Aprendizagem & 2 & - & - & - & $\mathbf{2}$ \\
\hline Educação à Distância & 1 & - & - & 2 & $\mathbf{3}$ \\
\hline Educação Básica & 2 & - & - & 5 & $\mathbf{7}$ \\
\hline Ensino Superior & 12 & 2 & 4 & 3 & $\mathbf{2 1}$ \\
\hline Educação Especial & 6 & - & - & 2 & $\mathbf{8}$ \\
\hline Educação Corporativa & 1 & - & - & - & $\mathbf{1}$ \\
\hline
\end{tabular}

Os dados dos levantamentos feitos indicam que há poucas publicações disponíveis na revista RBIE e nas bases de dados pesquisadas sobre a aplicação da Realidade Virtual na Educação no Brasil, principalmente ao que se refere à Educação Básica. Os estudos publicados são baseados principalmente na utilização de simulações e ambientes virtuais de aprendizagem, projetados por meio de uma tela de computador, console de vídeo game ou televisão, com raros estudos abordando o uso de óculos de realidade virtual e vídeos 360 graus. Como os dispositivos de Realidade Virtual são caros e sua acessibilidade é recente (Armstrong, 2017; Rosedale, 2017), entende-se que esse baixo número de publicações seja resultado do recente uso e acesso aos dispositivos e programas que permitem a criação de ambientes de realidade virtual. Espera-se que este número de estudos e publicações aumente significativamente nos próximos anos, em decorrência do maior uso doméstico da Realidade Virtual.

A análise das linhas de pesquisa cadastradas no Diretório de Grupos de Pesquisa (DGP) da Plataforma Lattes do CNPq voltadas para o estudo da Realidade Virtual (144), refletem um panorama mais atual das pesquisas conduzidas no Brasil e indicam que há interesse no conhecimento sobre a aplicação de ambientes virtuais imersivos na educação, sendo que $33 \%$ dessas linhas são voltadas para a aplicação da RV na Educação. Entretanto, estes estudos ainda 
são recentes e seus resultados pouco divulgados por meio de publicação científica. 0 levantamento completo encontra-se descrito na seção a seguir.

A pouquíssima pesquisa em Educação Corporativa (apenas 1 artigo e 1 linha de pesquisa com esse objetivo) pode ser explicada pela dificuldade de acesso ao ambiente corporativo por parte da academia (Chaddad \& Andreassi, 2002). Além disso, muitas organizações conduzem suas próprias pesquisas, sem necessariamente publicá-las em bases de dados científicas (Alperstedt, 2001; M. W. Silva \& Balzan, 2007).

O uso da Realidade Virtual na Educação à Distância parece promissor, uma vez que permite a criação de ambientes imersivos e maior engajamento dos alunos, aproximando-se do ambiente presencial de sala de aula, porém com vantagens, como flexibilidade e dinamismo de conteúdo (Monahan et al., 2008). Embora poucas publicações pesquisem esta aplicação (apenas 3), o número de linhas de pesquisa (10) com este objetivo indica que há interesse por parte das instituições de ensino superior em investigar o uso da Realidade Virtual nesse campo.

No campo da Educação Especial, a Realidade Virtual pode atender a uma demanda importante e crescente - como apontado por Oliveira (2016) - além de criar ambientes de aprendizagem mais específicos voltados para as necessidades de cada aluno, o que é difícil num ambiente presencial de sala de aula.

Os resultados indicam que há poucos grupos de pesquisa com esse enfoque (apenas 3) e poucas publicações sobre o uso da RV na Educação Especial (8), o que indica uma área de pesquisa que muito pode crescer no Brasil, uma vez que estudos internacionais tem mostrado bons resultados com a utilização da RV na Educação Especial (Brown et al., 1997; Lányi et al., 
2006; S. Parsons \& Cobb, 2011; Passig, 2015; Passig et al., 2016b; Passig \& Eden, 2000a; Queiroz, Tori, et al., 2018).

Como limitações para essas pesquisas, pode-se citar os efeitos de náusea, desequilíbrio motor e excesso de estimulação advindos do uso dos óculos de realidade virtual, que exigem um maior cuidado tanto no delineamento das pesquisas bem como no desenvolvimento das imagens a serem utilizadas e na condução do experimento. Essas limitações podem atrasar o andamento e os resultados de tais pesquisas, além de exigir um maior investimento para utilização de equipamentos de realidade virtual com melhor capacidade computacional e gráfica. Portanto, é importante que estudos futuros considerem essas limitações e utilizem conteúdos e métodos apropriados à Educação Especial.

Considerando a educação básica (ensino infantil, fundamental e médio), a escassez de pesquisas com o uso de ambientes mais imersivos de realidade virtual voltadas para esse nível educacional talvez se deva ao alto custo dos equipamentos necessários para a criação destes ambientes até pouco tempo atrás. A redução do custo e maior acessibilidade a óculos de realidade virtual e smartphones, que permitem a criação de ambientes imersivos móveis mais baratos, é um fato recente (Ladendorf et al., 2019; Rosedale, 2017), e portanto, acredita-se que as pesquisas sobre a sua utilização estejam em andamento e não tenham resultado em produção bibliográfica publicada ainda.

Além disso, as pesquisas com estudantes dessa faixa etária são mais demoradas, exigem maior cuidado no delineamento experimental, precisam de autorização dos pais (pois a maior parte dos alunos é menor de 18 anos) e dependem da colaboração de escolas, o que dificulta e 
atrasa a divulgação dos resultados da pesquisa. Nesta direção, Lüdke \& Cruz (2005) apontam como fatores que dificultam o estudo com a população estudantil: questões metodológicas, culturais e de formação docente, como por exemplo, dificuldade de acesso ao público infantil, bem como necessidade de autorização dos pais e da escola para a participação de alunos em pesquisas.

É nítida a prevalência de estudos de Realidade Virtual voltados para a Educação Superior conforme mostra a Tabela 3. Isso pode ser devido ao fato de pesquisas serem conduzidas por instituições de ensino superior, o que facilita o delineamento de experimentos considerando o maior acesso aos estudantes universitários como sujeitos experimentais (Sears, 1986). Além disso, há de se ressaltar o interesse do próprio corpo docente nos impactos da realidade virtual em seu ambiente de trabalho e prática profissional.

Outro fator que deve ser levado em consideração é a idade mínima para o uso dos dispositivos de realidade virtual imersivos, como óculos de realidade virtual. Os fabricantes indicam que os mesmos devem ser usados por pessoas acima de 13 anos e alertam sobre a possível ocorrência de náuseas e outros sintomas adversos consequentes da sua utilização (Guarino, 2016). Isso implica em limitações de pesquisas para a educação básica e justifica a prevalência de estudos e publicações voltadas para o ensino superior, reabilitação de adultos e idosos e psicoterapia de jovens e adultos.

Com intuito de expandir essa revisão de literatura sobre os estudos que utilizam realidade virtual no Brasil, foi feita uma revisão sistemática dos grupos de pesquisa cadastrados no CNPq 
que investigam o uso de realidade virtual na educação. Esta revisão encontra-se na próxima seção.

1.4.3. Grupos de pesquisa sobre Realidade Virtual na Educação no Brasil

Foi feita uma pesquisa utilizando a base de dados disponibilizada pelo Diretório de Grupos de Pesquisa (DGP), integrante da Plataforma Lattes do Conselho Nacional de Desenvolvimento Científico e Tecnológico (CNPq) com intuito de identificar e categorizar os grupos de pesquisa no Brasil em Realidade Virtual aplicada à Educação.

O levantamento dos grupos de pesquisa foi feito utilizando-se a palavra-chave "Realidade Virtual" no campo "termo de busca" do site de busca parametrizada do Censo 2016 do DGP, com o filtro "consulta por grupo" e com aplicação do termo nos campos "nome do grupo", "nome da linha de pesquisa" e "palavras-chave da linha de pesquisa" na data de 20 de Abril de 2017. Foram considerados apenas os grupos certificados, que totalizaram 126 grupos. Em seguida, os perfis desses grupos foram traçados em termos de distribuição geográfica, maturidade, área do conhecimento predominante e grau de formação acadêmica dos integrantes.

Com o objetivo de fazer o recorte das linhas de pesquisa voltadas para a Educação, buscou-se o termo "Realidade Virtual” com consulta por "linha de pesquisa" e aplicação do termo nos campos "nome da linha de pesquisa" e "palavras-chave da linha de pesquisa". Foi utilizado o filtro avançado "Filtro para área do conhecimento e setor de aplicação", selecionando-se a opção 
"Educação". Esta busca retornou 55 itens, sendo 48 linhas de pesquisa certificadas e, portanto, consideradas para este estudo.

Os perfis dos grupos dessas linhas de pesquisa em RV voltadas à Educação foram traçados e comparados com os grupos de pesquisa em RV não aplicadas à Educação. As linhas de pesquisa em RV voltadas à Educação foram analisadas de acordo com as categorias, estabelecidas pelos autores: Domínio do Conhecimento, Finalidade (Teoria, Metodologia, Desenvolvimento, Avaliação e Aplicação), Modalidades (Educação a Distância [EaD], Treinamento, Reabilitação e Não Especificado) e Nível Educacional (Ensino Infantil, Educação voltada para Necessidades Especiais, Ensino Fundamental, Ensino Médio, Ensino Técnico, Ensino Superior ou Educação Corporativa).

A região brasileira com maior número de grupos de pesquisa em Realidade Virtual é a Sudeste, com 60 grupos, sendo que 22 desses pesquisam a RV aplicada à Educação. As regiões com menor número de grupos são Centro-Oeste e Norte, com 9 e 4 grupos, respectivamente, sendo que na região Centro-Oeste dois desses grupos pesquisam a RV aplicada à Educação e na Região Norte três, conforme Figura 4:

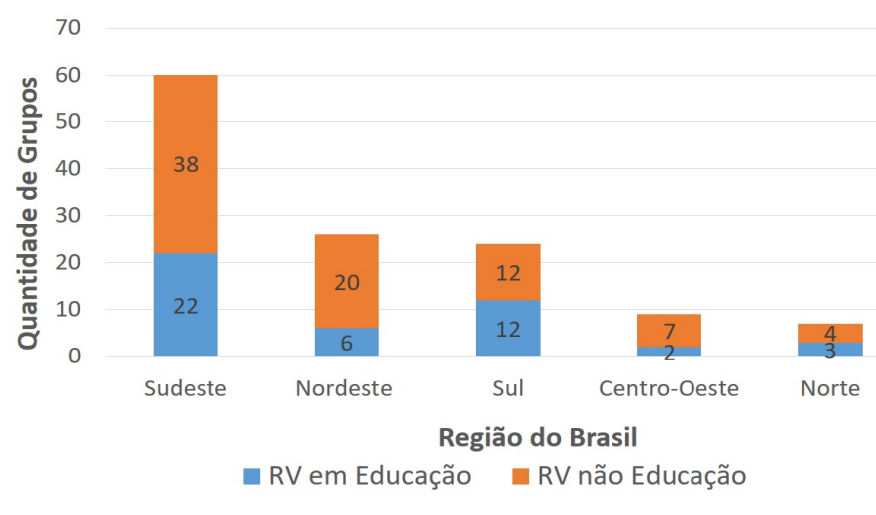

Figura 4. Distribuição geográfica dos grupos de pesquisa. 
Embora todas as regiões brasileiras apresentem grupos que pesquisam RV aplicada à Educação, tais grupos encontram-se concentrados nas regiões Sudeste e Sul, que juntas abrigam aproximadamente $75 \%$ deles. A Região Nordeste, que apresenta número significativo de grupos de pesquisa em RV (26 no total; a maior quantidade depois da Região Sudeste) não mantém a mesma representatividade quando feito o recorte de aplicação de RV na Educação, apresentando apenas 6 grupos com esse enfoque.

Essa concentração de grupos de pesquisa na Região Sul e Sudeste coincide com as principais regiões econômicas do país. Entretanto, nas regiões mais longínquas e com menos recursos, como na Região Norte, a RV aplicada à Educação pode contribuir sobremaneira ao permitir que alunos que não teriam acesso a certos ambientes reais, como por exemplo, museus ou laboratórios de alta tecnologia, interajam com versões virtuais desses ambientes. Parcerias com grupos de outras regiões e políticas de incentivo de apoio a pesquisas nessa área, aproveitando-se da facilidade de importação de equipamentos de RV via Zona Franca de Manaus e leis de incentivo da indústria de informática, por exemplo, podem ser estratégias que ajudem a reduzir essa distância.

O grupo mais antigo de pesquisa em RV foi formado em 1980, mas só a partir de 2002 que o interesse pelo tema RV tem crescido significativamente. Os anos com maior formação de grupos de pesquisa da RV na Educação foram 2002 e 2007, seguidos de 2016, como pode ser visualizado na Figura 5. 


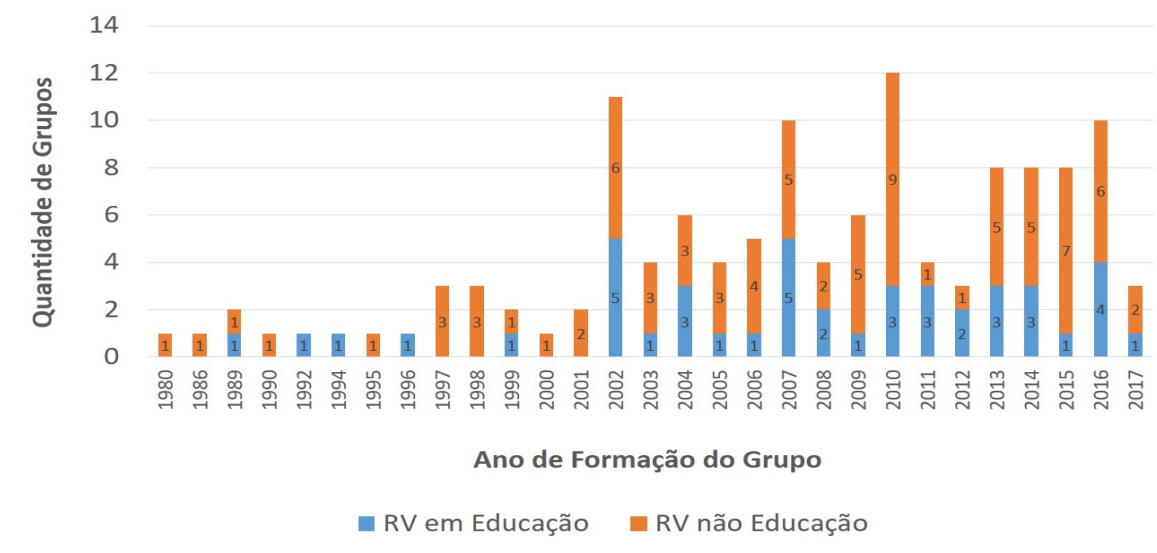

Figura 5. Ano de Formação dos Grupos de Pesquisa

Esses dados indicam que embora existam grupos formados há mais de 30 anos, que hoje pesquisam RV na Educação, são os mais recentes que demonstram maior interesse em RV, seja na Educação ou não. Provavelmente a popularização da RV, viabilizada pela maior acessibilidade e redução de custos dessa tecnologia (Ladendorf et al., 2019; Rosedale, 2017), motivou a criação de vários grupos com o interesse em RV.

As pesquisas tanto dos grupos que aplicam a RV à Educação, quanto dos que não tem esse objeto, são conduzidas em sua maioria por pesquisadores doutores, como pode ser visualizado na Figura 6. 


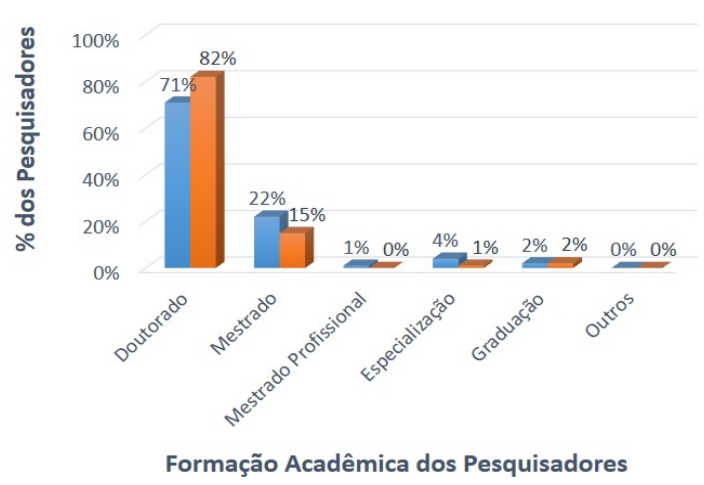

- RV em Educação

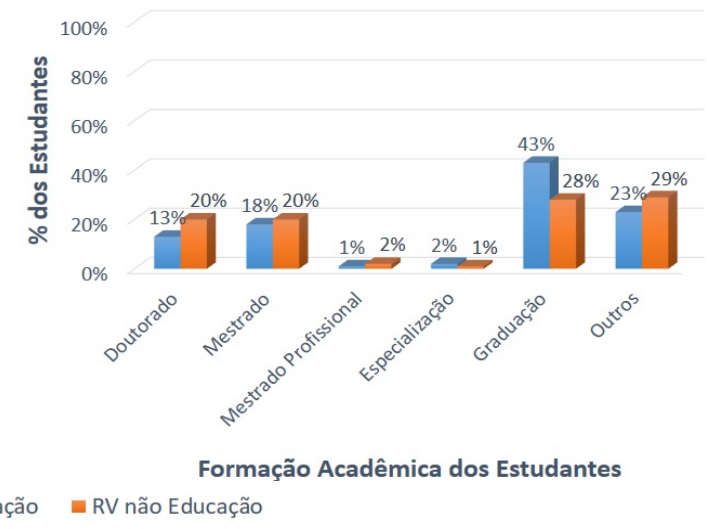

Figura 6. Formação Acadêmica dos Pesquisadores e Estudantes

Percebe-se que o percentual de pesquisadores mestres em grupos que pesquisam RV na Educação, comparado ao dos grupos que pesquisam RV não aplicada à Educação, é significativamente maior. Como grande parte das linhas de pesquisa é de Computação (vide Figura 7), é de se esperar que haja mais interesse e desafios tecnológicos nessa área em pesquisas relacionadas ao desenvolvimento e inovação da tecnologia de RV do que em sua aplicação em Educação. Essa pode ser a explicação para uma proporção maior de doutores em relação aos mestres nas pesquisas de RV não aplicadas à Educação. Essa mesma tendência é observada na análise do nível de formação dos estudantes dos grupos, com maior proporção de alunos de graduação nos grupos que pesquisam RV na Educação.

Sobre o domínio do conhecimento a que cada linha de pesquisa em RV aplicada à Educação pertence, identificou-se que a maior parte delas é da área da Computação (47\%), seguida da área de Educação e de Saúde, com 17\% das linhas cada uma, como apresentado na Figura 7. Este resultado é esperado, como dito anteriormente, por tratar-se de uma tecnologia relativamente nova e primariamente desenvolvida na área de Computação. 


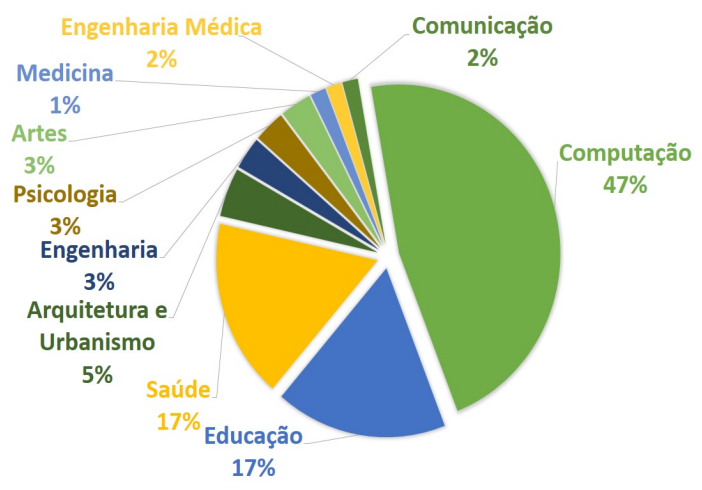

Figura 7. Domínio do Conhecimento das Linhas de Pesquisa em RV aplicada à Educação

A maior concentração de linhas de pesquisa na área da Computação indica que o uso da tecnologia de RV ainda está no estágio de soluções na busca de problemas, ou seja, primeiro desenvolve-se a tecnologia e depois busca-se a aplicação dela e não o inverso. Zorzal e Nunes (2014) identificam situação semelhante quanto à aplicação da Realidade Aumentada na área da Saúde. Espera-se que no decorrer dos anos haja um equilíbrio com o aumento nas pesquisas na área de Educação, para a consequente comprovação da validade da aplicação da RV nessa área. Uma recomendação que se pode fazer é de que haja maior divulgação e incentivo para pesquisas de RV em outras áreas, além da computação. Ações como a aproximação entre dois importantes eventos científicos, o CIAED (promovido pela Associação Brasileira de Educação a Distância), com foco e participantes mais voltados para a Educação, e SBIE (promovido pela Sociedade Brasileira de Computação) devem contribuir nesse sentido. Espera-se que SVR e SBGames (promovidos pela $\mathrm{SBC}$ ), com focos respectivamente em realidade virtual/aumentada e jogos digitais, também busquem essa aproximação com a comunidade de Educação. 
Quanto à finalidade das pesquisas, a maior parte é destinada a Desenvolvimento e Metodologia, como pode ser visto na Figura 8.

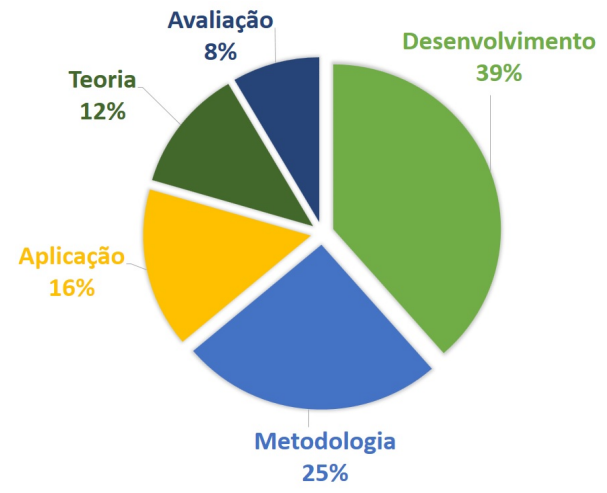

Figura 8. Finalidade das Pesquisas das Linhas em RV aplicada à Educação

Esse resultado é esperado ao se considerar que a maior parte dos grupos de pesquisa é da área de Computação, sendo natural que o principal enfoque não seja na aplicação e sim no desenvolvimento da tecnologia.

Observando-se as modalidades de ensino explicitadas nas ementas das linhas de pesquisa identificadas, a maior parte não faz referência à modalidade de ensino, havendo ainda referência a duas outras: EaD, Treinamento e Reabilitação, como pode ser visto na Figura 9. 


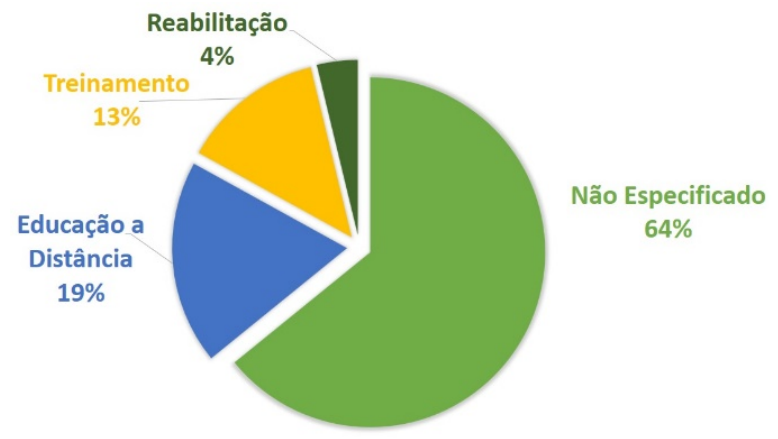

Figura 9. Modalidade das Pesquisas das Linhas em RV aplicada à Educação

O fato de a maior parte das linhas de pesquisa não especificar a qual modalidade de ensino se destina pode talvez ser atribuída ao fato de terem apenas reportado modalidades diferentes da modalidade presencial, por essa modalidade ser considerada a mais comum, e portanto, não ser necessária a sua especificação por parte dos pesquisadores, uma vez que nenhuma linha de pesquisa cita a modalidade presencial.

Finalmente, as linhas de pesquisa foram classificadas de acordo com o nível educacional ao qual suas pesquisas se destinam. As linhas de pesquisa voltadas ao Ensino Superior são as mais numerosas, que correspondem a $39 \%$ das linhas, enquanto apenas $2 \%$ destinam-se à Educação Corporativa, conforme visualizado na Figura 10: 


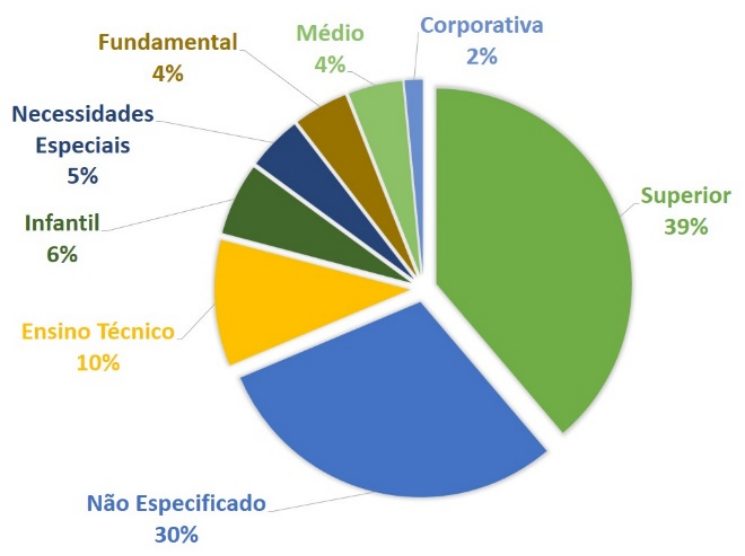

Figura 10. Distribuição das Linhas de Pesquisa em RV aplicada à Educação de acordo com o nível educacional a que se destinam.

A prevalência de linhas de pesquisa voltadas para aplicação da RV na Educação Superior pode ser devido à facilidade de acesso a estudantes universitários como sujeitos nas pesquisas, como mencionado anteriormente, uma vez que as mesmas são conduzidas por instituições de ensino superior, o que facilita o delineamento e andamento dos experimentos (Sears, 1986).

Por meio deste levantamento, identificou-se que há um interesse crescente dos grupos de pesquisa em estudar a aplicação da RV na Educação, principalmente por parte daqueles criados a partir de 2002, e que o Brasil apresenta número expressivo de iniciativas de pesquisas nessa área. Tais pesquisas, contudo, estão muito concentradas nas áreas de Computação e Exatas, bem como nas Regiões Sudeste e Sul, o que demonstra a importância da expansão das pesquisas para outras áreas do conhecimento e regiões brasileiras.

Ainda há muitas lacunas na aplicação da RV quanto ao nível educacional, com apenas uma linha de pesquisa voltada para a Educação Corporativa e poucas para Ensino Fundamental, Médio 
e para Necessidades Especiais, o que mostra a necessidade e direção para os estudos futuros, planejamentos pedagógicos e de políticas públicas para a aplicação da Realidade Virtual em Educação.

1.5. Avaliação da aprendizagem em Ambientes Virtuais Imersivos

Avaliar a aprendizagem é fundamental no processo de ensino-aprendizagem, uma vez que é tanto a forma de identificar os resultados do processo de ensino-aprendizagem, quanto ponto de partida para a revisão dos objetivos deste processo (Edwards et al., 2014; Luckesi, 2014; Pozo, 2016; Suskie, 2018).

A avaliação no ambiente escolar por muito tempo pautou-se somente em avaliações quantitativas do desempenho do aluno, por meio de provas ou trabalhos escritos. Este formato de avaliação é descrito por Luckesi (2014) como baseado mais em exames escolares do que na aprendizagem do aluno. Entretanto, a forma de avaliar a aprendizagem tem ganhado atenção, sido questionada e remodelada no ambiente escolar (Luckesi, 2014).

Salzman, Loftin, Dede and McGlynn (1996) recomendaram em 1996 que os estudos que objetivam investigar como o uso de AVIs pode impactar a aprendizagem devem levar em consideração variáveis de avaliação da aprendizagem, da tecnologia e da natureza da tarefa, entre outros elementos. Mais de quinze anos após esta publicação, um estudo de Jia, Bhatti e Nahavandi (2014) identificou que a maior parte dos estudos sobre o uso de AVIs na educação 
investigam fatores de interação e usabilidade do AVI (como engajamento e efeitos adversos do uso do AVI), com poucos estudos voltados para a avaliação da aprendizagem.

Diante da necessidade descrita na literatura de estudos que investiguem o uso de AVIs e a avaliação da aprendizagem, e, da importância desta avaliação tanto para o desenvolvimento de AVIs quanto para sua aplicação na educação, foi feita uma revisão sistemática de literatura para traçar o estado da arte sobre o referido tema.

Tal como no estudo realizado por Freina e Ott (Freina \& Ott, 2015) - que investigou o uso de capacetes de realidade virtual na educação - foi escolhida a base de dados Scopus, em função de suas ferramentas de análise e grande amplitude de títulos (aproximadamente 70 milhões de publicações) e periódicos (aproximadamente 5 mil), muitos reconhecidos pela comunidade científica nas principais áreas de conhecimento relacionadas ao tema desta pesquisa (Psicologia, Educação, Computação e Engenharias).

Após uma breve pesquisa exploratória para escolha de palavras-chave, a chave de busca utilizada nos campos título, resumo e palavras-chave foi: ("immersive virtual environment" AND "assessment"). Os 84 registros retornados na busca foram categorizados de acordo com o uso do AVI: se este foi utilizado como "avaliação do AVI" ou "avaliação do aprendizado" ou "outro tipo de avaliação". Foram excluídos os estudos em que foi avaliado apenas o AVI, sendo, portanto, este um dos critérios de exclusão. Outros critérios de exclusão foram: trabalhos duplicados, trabalhos completos não disponíveis e trabalhos que pesquisaram outro tipo de avaliação. 0 fluxo de busca e seleção dos trabalhos pode ser observado na Figura 11. 
Foram incluídos e analisados em sua completude os trabalhos que investigaram a avaliação da aprendizagem em função do uso de AVIs (44 trabalhos). Destes, foram extraídos os dados de ano de publicação, país de afiliação dos autores e subárea do conhecimento da pesquisa. As subáreas do conhecimento da pesquisa foram agrupadas de acordo com a área correspondente.

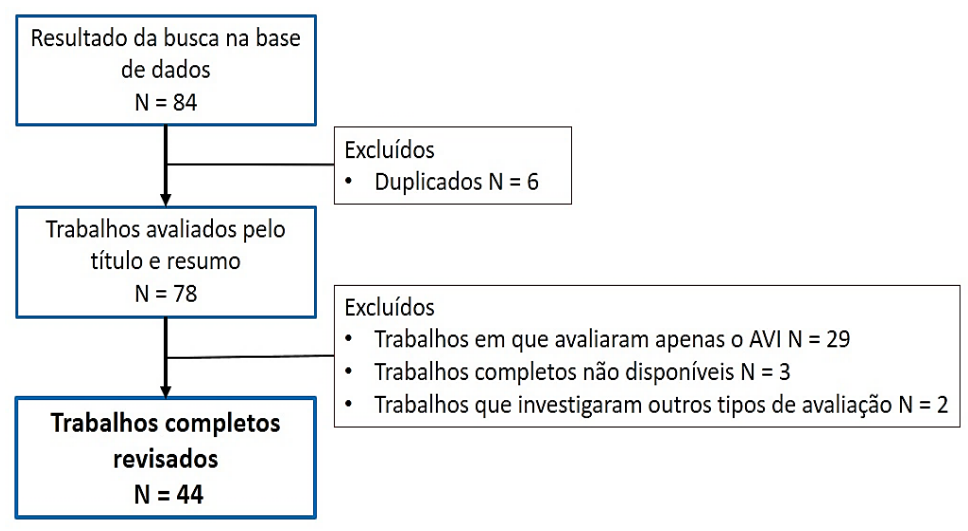

Figura 11. Fluxograma da revisão sistemática de literatura

As informações dos estudos foram categorizadas de acordo com os elementos encontrados na análise dos trabalhos, descritas a seguir:

a. Tipo de Conhecimento (Conceitual ou Procedural). O conhecimento conceitual é o que conecta elementos mais básicos que já foram organizados e explicados (Anderson et al., 2001; Krathwohl, 2002). Envolve o conhecimento de classificação e categorização, de princípios e generalizações e de teorias, modelos e estruturas. Este tipo de conhecimento se relaciona com a explicitação do que se sabe e foi aprendido. Já o conhecimento procedural refere-se à utilização de critérios e métodos na solução de problemas. Engloba o conhecimento de técnicas, 
habilidades e métodos específicos, bem como a percepção de como e quando usar determinado procedimento (Anderson et al., 2001; Krathwohl, 2002);

b. Tipo de Imersão (Visual, Auditiva ou Háptica). Para imersão considerou-se como fonte de estímulo visual: monitor único, diversos monitores, caverna virtual, video wall (parede de vídeo, em tradução livre) ou adaptador de realidade virtual (HMD). Para imersão auditiva considerou-se a fonte do áudio como mono ou estéreo fônico, ou tridimensional. Quanto à imersão háptica, considerou-se apenas a sua utilização ou não. Esta categorização seguiu a mesma utilizada por Queiroz et al. (2018);

c. Tipo de Habilidades (Motora, Cognitiva ou Emocional). A habilidade motora envolve atividade física ou de coordenação motora. A habilidade cognitiva é aquela que depende de atenção, memória, processamento e manipulação de informação para sua aquisição. Em habilidade emocional são enquadrados os casos em que se avaliam os sentimentos e as respostas emocionais dos participantes.

d. Contexto (Fundamental, Médio, Superior, Saúde, Corporativo ou Outro). O contexto se refere ao tipo e/ou nível de ensino, se formal (fundamental, médio ou superior), se no âmbito corporativo ou em outro contexto, como educação de adultos ou cursos livres. Os estudos foram categorizados de acordo com a descrição apresentada nos trabalhos sobre os participantes;

e. Técnicas de avaliação (Padrões, Métricas ou Inteligência Artificial). As técnicas baseadas em padrões pautam a avaliação na análise de comportamentos, movimentos, decisões, discurso ou algum outro aspecto apresentado pelo aprendiz antes, durante ou após o uso do AVI, que possibilite comparação com um ou mais padrões de referência. Para análise métrica 
considerou-se a avaliação feita por meio da obtenção de medidas numéricas de desempenho, como por exemplo amplitude de movimentos, quantidade de respostas corretas, frequência de comportamentos, entre outros. Inteligência Artificial (IA) engloba o uso de técnicas como mineração de dados e aprendizagem de máquina (Michie et al., 1994) para obtenção e análise de dados de aprendizagem.

f. Processos de avaliação (Automático, Semiautomático ou Humano). A avaliação automática refere-se àquelas processadas computacionalmente, sem necessidade de participação humana no processo. A avaliação semiautomática foi considerada nos casos em que parte do processo de avaliação foi feita computacionalmente e parte foi realizado por pessoas. A avaliação humana refere-se às avaliações que dependem exclusivamente de interação humana para obtenção e análise de dados de aprendizagem.

g. Formas de avaliação (Quantitativa ou Qualitativa). Como avaliação quantitativa foram consideradas aquelas baseadas em resultados numéricos, utilizadas posteriormente em análises estatísticas para determinar o desempenho dos aprendizes. A avaliação qualitativa, referiu-se às avaliações pautadas em perguntas abertas, entrevistas, relatos e observações analisadas por alguém (análise humana).

A Figura 12 ilustra a distribuição dos 44 estudos pela data de publicação e uma linha de tendência (regressão linear). Identificou-se que a maior parte (23) dos trabalhos foram publicados a partir de 2014. O R² da linha de tendência excluindo-se o ano 2018 (por não estar completo) foi de 0,52 , o que mostra que mais da metade da variância do número de publicações é explicada pela variável "ano", indicando uma tendência de crescimento ao longo dos anos. 


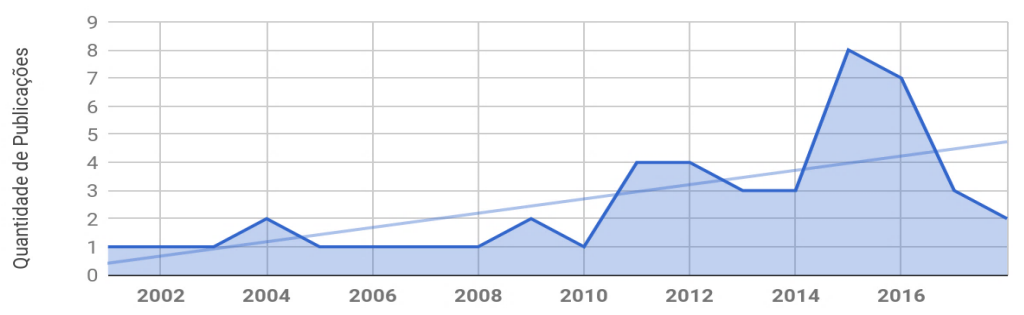

Figura 12. Quantidade de publicações por ano

Apesar da heterogeneidade dos países de origem dos estudos (Figura 13), quase metade (20) dos estudos foram desenvolvidos por pesquisadores vinculados a instituições de ensino dos Estados Unidos. Percebe-se também uma grande concentração destas pesquisas nos países desenvolvidos.

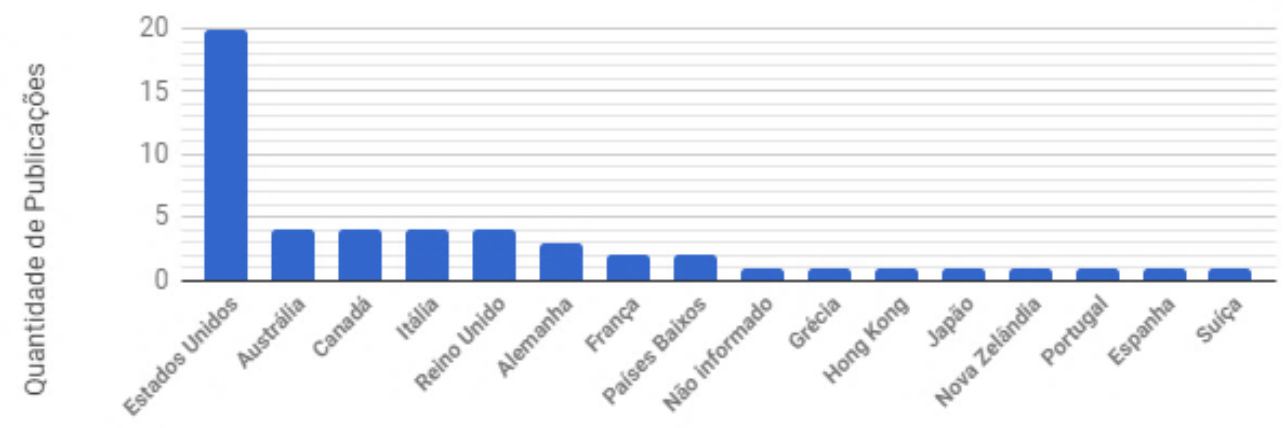

Figura 13. Quantidade de publicações por país de afiliação

Quanto à área de conhecimento, predominam os estudos em Ciências Agrárias e Biológicas, Ciência da Computação e Medicina (estas três áreas juntas contam com 52\% dos estudos). Em seguida, identifica-se número significativo de estudos nas áreas de Ciências Sociais, Engenharia e Psicologia, como pode ser visto na Figura 14. 


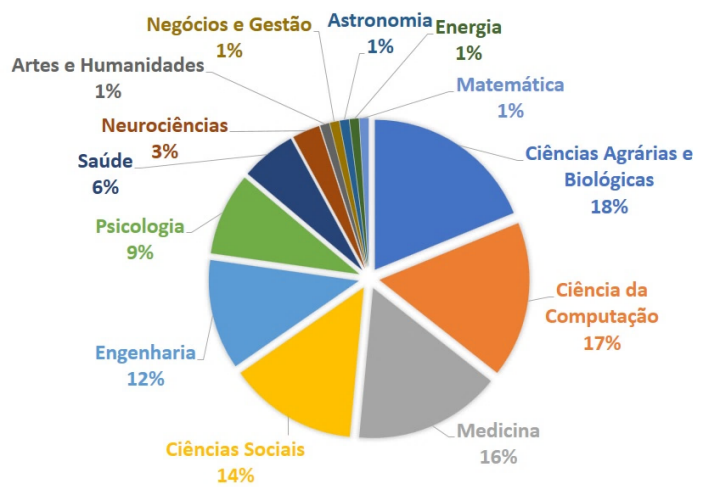

Figure 14. Áreas de conhecimento

Quanto ao tipo de conhecimento abordado nos estudos, identifica-se que a maior parte investigou o conhecimento procedural (66\%), seguido de estudos que investigaram os dois tipos de conhecimento (procedural e conceitual, 20\%) e conceitual apenas (14\%). Considerando as habilidades aprendidas, a maioria dos estudos pesquisou habilidades cognitivas (56\%), seguido de habilidades emocionais (27\%) e habilidades motoras (17\%).

Entre as habilidades cognitivas, foram avaliadas principalmente: atenção (CohenBendahan et al., 2015; Edmans et al., 2009; T. D. Parsons et al., 2009; Stavrinos et al., 2011), memória (Baker et al., 2016a; Brooks \& Rose, 2003; Daniel Cohen et al., 2013; Ketelhut \& Shelton, 2012; Nelson et al., 2014) e resolução de problemas (R. S. Baker et al., 2016b; D. Cohen et al., 2013; S. Colombo et al., 2014; Simone Colombo \& Golzio, 2016; Jiang et al., 2018; Ketelhut et al., 2014a).

Quanto às habilidades emocionais, houve grande variabilidade entre os estudos, sendo investigado, por exemplo: sentimento de presença (Bailenson et al., 2005; Bessa et al., 2016), 
sensação de dor (Hoffman et al., 2004), confiança (Van den Brule et al., 2014), reações diante situações de violência (Jouriles et al., 2016), percepção de auto eficácia (Bergey et al., 2015), percepção de imagem corporal (Purvis et al., 2015) e autoestima (Nosek et al., 2016).

Dentre as habilidades motoras, destacam-se os estudos que investigaram: locomoção e equilíbrio (Gérin-Lajoie et al., 2008; Sinitksi et al., 2012) e coordenação motora fina (Xianwei Huang et al., 2018; Palacios-Navarro et al., 2016; Vosniakos et al., 2017).

Com relação aos estudos que investigaram o conhecimento conceitual, todos utilizaram método experimental para avaliar a aprendizagem após o uso de AVI. Sete destes estudos investigaram a aprendizagem de conceitos de Biologia (como mutações genéticas e relações existentes em ecossistemas) com participantes entre 12 e 14 anos de idade (Baker et al., 2016b; Bergey et al., 2015; Jiang et al., 2018; Ketelhut, Nelson, Bergey, \& Ryu, 2014b; Ketelhut, Nelson, Schifter, \& Kim, 2010; Ketelhut \& Shelton, 2012; Nelson, Kim, \& Slack, 2016). Estes estudos utilizaram principalmente a plataforma de ensino de ciências SAVE Science ${ }^{1}$, desenvolvida com apoio do National Science Foundation dos Estados Unidos. Esta plataforma oferece diversos módulos, sendo estes compostos por desafios que o aluno precisa desvendar ao explorar o AVI. Testes são inseridos ao contexto explorado e a partir da resposta do aluno, ele prossegue no desafio. As respostas são registradas automaticamente pelo sistema e posteriormente analisadas pelos pesquisadores. Em alguns destes estudos, além da análise do desempenho durante o uso do AVI, também foram aplicados testes para verificação da percepção de auto eficácia (Bergey

\footnotetext{
${ }^{1}$ Disponível em http://www.savescience.net/, acessado em 20 de Agosto de 2018.
} 
et al., 2015), do uso de estratégias de aprendizado (Jiang et al., 2018) e percepção de carga cognitiva (Nelson, Kim, \& Slack, 2016).

Três estudos investigaram a aprendizagem de conceitos de operações industriais, com funcionários de indústrias, no qual foram abordados conceitos de segurança, de operação de máquinas em campo e da sala de operações (Colombo et al., 2014, 2013; Colombo \& Golzio, 2016). Estes estudos utilizaram o sistema Plant Simulator e tiveram como objetivo avaliar a efetividade deste $\mathrm{AVI}$ no treinamento tanto de funcionários que operam máquinas presencialmente quanto dos que as operam virtualmente, a partir da sala de operações. Os seguintes temas foram abordados em apenas um estudo cada: história da humanidade (Ketelhut et al., 2014b), logística e cadeia de suprimentos (Reiners \& Wood, 2013), padrões de composição de fármacos (Patel et al., 2011), distúrbio da imagem corpórea (Purvis et al., 2015) e neurocirurgia (Watanuki \& Hou, 2011).

Todos os estudos utilizaram algum tipo de imersão visual, sendo o monitor único e o capacete de realidade virtual os mais frequentes (Figura 15). A imersão auditiva foi utilizada em $70 \%$ dos estudos, sendo que em $68 \%$ foi usada uma fonte mono ou estéreo fônica e em apenas um estudo (2\%) utilizou a imersão auditiva tridimensional. Apenas $16 \%$ dos estudos utilizaram a imersão háptica. 

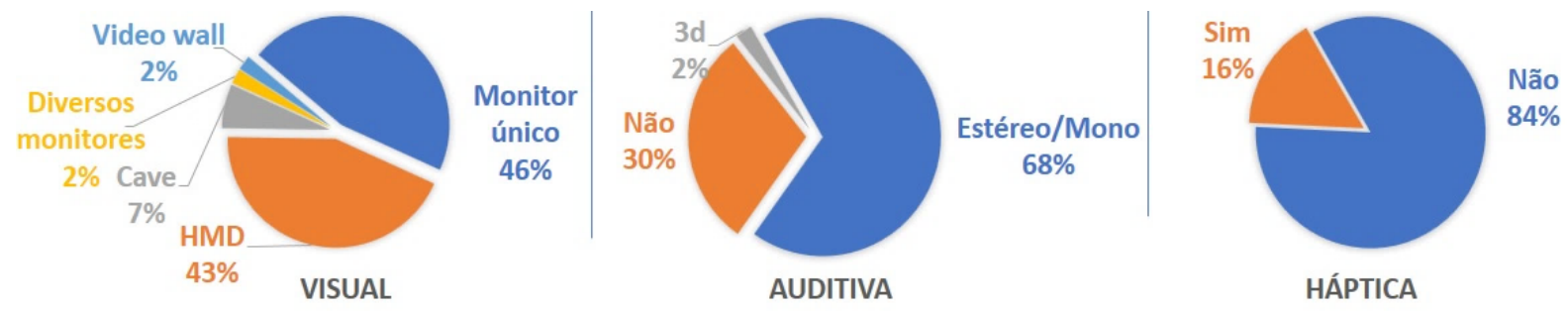

Figura 15. Tipos de Imersão

O contexto dos participantes investigados nestes estudos é bastante diversificado, sendo composto de público em geral (25\%), pacientes ou profissionais da saúde (23\%), alunos do ensino superior (20\%), alunos do ensino fundamental (14\%), contexto corporativo (14\%) e apenas $2 \%$ do ensino médio.

Quanto às técnicas de avaliação utilizadas, a maior parte dos estudos utilizou a avaliação métrica, seguida da análise de padrões. Apenas dois estudos (3\%) utilizaram técnicas de IA para a avaliação da aprendizagem. O processo de avaliação automático foi o mais frequente, sendo utilizado por $44 \%$ dos estudos, seguido do processo humano de avaliação, presente em $41 \%$ dos estudos. A maioria dos estudos (84\%) utilizou somente a forma de avaliação quantitativa, conforme mostrado na Figura 16.
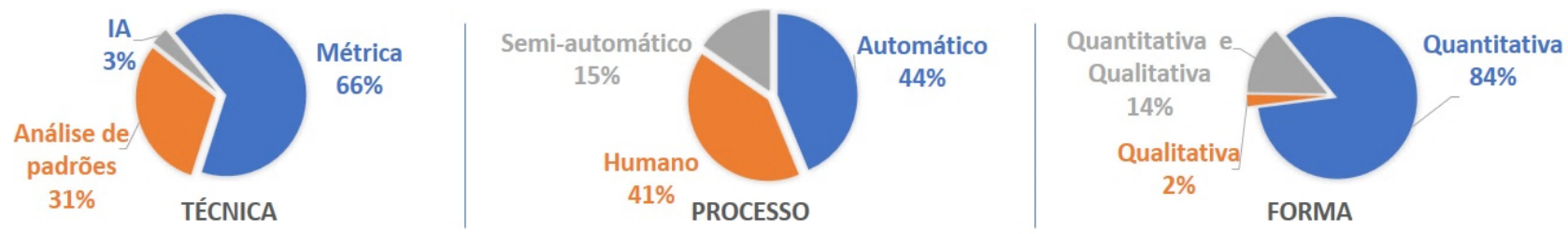

Figura 16. Técnicas, processos e formas de avaliação

Diante deste levantamento, foi identificada uma tendência de crescimento nas publicações sobre o tema. Isto é esperado se considerarmos que inicialmente se desenvolve a 
tecnologia, para depois esta ser difundida e aplicada em diversos campos de pesquisa (Queiroz et al., 2017). No caso dos AVIs, apesar da idealização e as investigações de seus usos em educação não serem recentes, as mudanças na acessibilidade e no amadurecimento destas tecnologias parecem ter influenciado o número de publicações (Burke et al., 2018; Cook et al., 2017).

Evidencia-se a concentração de pesquisas em países desenvolvidos. Este fato corrobora estudos recentes de Queiroz, Nascimento, Tori e Leme, (2018) e Queiroz, Kamarainen, Preston e Leme (2018) e talvez deva-se à questão da acessibilidade às tecnologias (Das, 2016; Walsham \& Sahay, 2006). Assim, é esperado um atraso nas publicações de pesquisas de países com menor poder financeiro e distribuição desigual de recursos. Neste sentido, talvez estejamos num ponto de inflexão e espera-se o aumento de pesquisas em países com recursos menos abundantes, já que estas tecnologias passaram por uma significativa redução de custo e aumento da competição (Burke et al., 2018).

Ainda, percebe-se que há poucos estudos que avaliam o uso de AVI e a aprendizagem conceitual. Isto corrobora Jia, Bhatti e Nahavandi (Jia et al., 2014) que apontam a necessidade de pesquisas sobre o uso de AVI para ensino instrucional tradicional e conceitual. Este é um ponto muito importante que precisa ser discutido pela comunidade científica para viabilizar próximos passos sólidos na adoção de AVI na educação, sendo fundamental para a agenda de pesquisa futura.

Foi também identificada escassez de estudos que consideram a avaliação qualitativa da aprendizagem. Avaliações qualitativas normalmente demandam mais tempo e profissionais especializados para serem realizadas (Marton \& Säaljö, 1976) e talvez por isto publicações com 
este foco sejam menos frequentes (Karabulut-Ilgu et al., 2018). Por outro lado, o uso de AVI permite o registro automático do comportamento do usuário, o que facilita posteriores análises qualitativas (Passig et al., 2016b). Neste ponto, identifica-se um subaproveitamento desta facilidade nos estudos analisados.

O melhor aproveitamento das coletas de dados automáticas pode aumentar o número de estudos e o poder de resolução de análises qualitativas em estudos futuros. Percebe-se uma necessidade de estudos longitudinais que avaliem, por exemplo, o desempenho dos alunos que tiveram habilidades adquiridas utilizando AVIs ao longo do tempo, comparando-se com os métodos de ensino tradicionais e outros alternativos, o que corrobora Queiroz, Tori, Nascimento e Leme (2018), Tamaddon e Stiefs (2017), Gelsomini (2016) e Salzman, Loftin, Dede e McGlynn (1996).

Apenas dois estudos utilizaram técnicas de IA para a avaliação da aprendizagem. A utilização de técnicas de IA baseadas em aprendizado de máquina trazem um potencial enorme para a avaliação da aprendizagem (Spector et al., 2016). Sofisticadas técnicas como o aprendizado profundo permitem que a relações complexas e não lineares entre múltiplas variáveis sejam identificadas, o que viabiliza, por exemplo, que as causas de problemas na aprendizagem em alguns tópicos por parte de alguns alunos sejam identificadas (Cope \& Kalantzis, 2016). Adicionalmente, tais técnicas permitem reduzir o tempo de análises, bem como a utilização de mineração de dados permite o aumento do poder de descoberta de informações implícitas nos dados coletados em intervalos menores de tempo de análise (Spector et al., 2016). Assim, sugere-se a integração destas técnicas como coadjuvantes nas pesquisas futuras. 
O pequeno número de estudos encontrados com participantes do ensino básico aponta uma lacuna de pesquisas com este público, necessitando ser preenchida. Durante o ensino médio há muitos conceitos abstratos que precisam ser assimilados e dominados pelos alunos (Libâneo \& Alves, 2017). O uso de AVI na educação tem mostrado significativo aumento da motivação e engajamento dos alunos (Bailenson et al., 2008; Bricken, 1991; Dalgarno \& Lee, 2010; Dede, 2009; Dede et al., 2017; Wickens, 1992). Quando voltado para a aprendizagem de conceitos, os estudos tem mostrado resultados encorajadores (Kamarainen et al., 2018; Ketelhut et al., 2010; Salzman et al., 1999), porém ainda são poucos os estudos com este objetivo, o que sugere um importante campo de pesquisa a ser explorado.

Dessa forma, ao mesmo tempo que se identifica um grande interesse pelo uso de tecnologias imersivas na educação - tanto por permitir a imersão dos sentidos em um ambiente virtual, o que tem mostrado aumentar o engajamento e motivação dos aprendizes, como por permitir a criação de conteúdos digitais diversos, que podem ser não apenas observados, mas experienciados pelos alunos - ainda há muitas lacunas sobre a efetividade destas tecnologias para a aprendizagem.

Ao examinar a literatura sobre o tema, encontra-se consistência entre os estudos que investigam os aspectos afetivos da aprendizagem, como motivação, percepção de auto eficácia e engajamento, indicando que o aumento do nível de imersão favorece estes aspectos afetivos. Quando se compara os resultados de estudos voltados para a aprendizagem procedural com estudos voltados ao aprendizado conceitual, percebe-se que o impacto do nível de imersão parece favorecer a aprendizagem procedural, por permitir tanto a exploração do ambiente 
virtual, a execução de movimentos físicos para interagir com o ambiente e a repetição de procedimentos. Os estudos voltados para o aprendizado conceitual são mais escassos do que os demais, e seus resultados variam consideravelmente, o que ainda não permite que tenhamos conclusões sólidas sobre o impacto de AVIs na aprendizagem conceitual.

Diante disso, considerando a crescente integração de tecnologias imersivas nas salas de aula, a importância dos aspectos afetivos e do aprendizado conceitual na educação, é importante investigar os impactos dessas tecnologias nos aspectos afetivos da aprendizagem e no aprendizado conceitual antes da adoção em escala dessas tecnologias no ensino formal, de forma a desenvolver e planejar o uso efetivo das mesmas. 
1.6. Objetivos e Hipóteses

\subsubsection{Objetivos}

\subsubsection{Objetivo Geral}

- Identificar a existência de diferenças na aprendizagem e percepção de auto eficácia de alunos do ensino básico resultantes da exposição a conteúdos curriculares em AVI versus a exposição do mesmo conteúdo em formato de vídeo tradicional.

\subsubsection{Objetivos específicos}

- Caracterizar os resultados de aprendizagem do conteúdo apresentado em RV e em vídeo tradicional;

- Identificar por meio de auto avaliação, a percepção de auto eficácia e motivação para aprender ciências;

- Identificar possíveis efeitos mediadores da percepção de auto eficácia e presença entre os meios de apresentação do conteúdo e a aprendizagem.

\subsection{Hipóteses}

Pesquisas que investigam os efeitos de AVI na educação relataram um aumento significativo no aprendizado após o uso de experiências educacionais em realidade virtual imersiva (Alhalabi, 2016; Dede et al., 1997; Jensen \& Konradsen, 2017; Markowitz et al., 2018; Parong \& Mayer, 2018; Queiroz et al., 2018; Webster, 2016). No entanto, ao comparar os ganhos 
de aprendizagem do uso de RV imersiva com o computador de mesa, os resultados de estudos anteriores variam significativamente. Alguns estudos relatam maiores ganhos de aprendizagem ao usar RV imersiva e outros relatam o contrário, como mencionado no primeiro capítulo (Jensen \& Konradsen, 2017; Parong \& Mayer, 2018). Considerando esses resultados, temos como primeira hipótese:

H1. Participantes que assistirem a vídeos imersivos usando óculos de RV e os participantes que assistirem ao mesmo conteúdo usando um monitor de computador apresentarão ganhos de aprendizado semelhantes.

Considerando os estudos que investigaram o impacto da RV imersiva na percepção de auto eficácia, o aumento da imersão tem demonstrado um efeito positivo na percepção de auto eficácia (Makransky et al., 2019; Meyer et al., 2019). Ainda assim, é importante observar que, até o momento, existem apenas poucos estudos comparando esses efeitos entre vídeos imersivos e vídeos tradicionais (2D). Levando estes achados em consideração, temos como segunda hipótese:

H2. Participantes que assistirem a um vídeo imersivo com óculos de RV relatarão maior percepção de auto eficácia (no que se refere especificamente ao aprendizado de ciência) em comparação com os participantes que assistirem o mesmo conteúdo em um monitor de computador.

Com base em descobertas anteriores, sugerindo que níveis aumentados de imersão resultam em sentimentos de presença mais elevados (Sanchez-Vives \& Slater, 2005), formulamos a terceira hipótese: 
H3. participantes que assistirem a vídeos imersivos usando óculos de RV relatarão sentimentos de presença mais intensos do que os participantes que assistirem o mesmo conteúdo usando um monitor de computador.

Além disso, não foi encontrado nenhum estudo publicado investigando o efeito da mediação do sentimento de presença nos ganhos de aprendizagem e na percepção de auto eficácia usando vídeos imersivos com óculos de RV. Makransky e Lilleholt (2018) tiveram como objetivo entender como o nível de imersão afeta a aprendizagem percebida e descobriram que o sentimento de presença teve um efeito de mediação nos resultados percebidos da aprendizagem. No entanto, seu desenho experimental não mediu os ganhos reais de aprendizado, apenas a percepção de aprendizagem. Assim, como o sentimento de presença apresentou mediar o efeito entre imersão e aprendizagem percebida, e pesquisas anteriores sugerem correlações positivas significativas entre o nível de imersão e o envolvimento com o conteúdo da aprendizagem (Bailenson et al., 2008; Parong \& Mayer, 2018), entre engajamento e percepção de auto eficácia (Bandura \& Cervone, 1986; Linnenbrink \& Pintrich, 2003) e entre presença e emoções (Riva et al., 2007), temos como hipóteses:

H4. O sentimento de presença mediará a percepção de auto eficácia e os ganhos de aprendizagem e

H5. A percepção de auto eficácia mediará a relação entre a condição (RV ou computador) e os ganhos de aprendizagem. 


\section{Estudos Empíricos}

\subsection{Estudo 1}

Esta pesquisa é composta por dois estudos. Ambos estudos utilizaram um delineamento quasi-experimental, com pré-teste, pós-teste e medidas repetidas (Ary et al., 2013; D. T. Campbell \& Stanley, 2015; Cozby, 2003), de acordo com descrição a seguir.

\subsubsection{Método}

A pesquisadora trabalhou com o professor de ciências dos participantes para definir a logística do experimento e a redação dos questionários utilizados. A totalidade do estudo ocorreu antes dos participantes abordarem qualquer material de aprendizagem relacionado ao conteúdo abordado nos materiais de ensino apresentados (acidificação do oceano e recifes de coral).

\subsubsection{Participantes}

Os participantes foram recrutados em uma escola de ensino fundamental II exclusiva para meninas na cidade de Palo Alto, nos Estados Unidos. A participação foi voluntária. Uma amostra inicial de 55 alunas da 8a série respondeu ao pré-teste usando um computador MacBook Air. Duas participantes não conseguiram concluir uma das partes do estudo e foram excluídas da amostra. A amostra final foi composta por 53 participantes do sexo feminino.

\subsubsection{Material}

\subsection{Vídeos}


O material instrucional consistiu em dois vídeos imersivos em 360 graus, intitulados: The Crystal Reef (O recife de Cristal, em tradução livre) e Coral Compass.(Bússola de Coral, em tradução livre). Ambos foram desenvolvidos pelo Virtual Human Interaction Lab em colaboração com o Centro de Soluções Oceânicas, localizados na Universidade de Stanford.

Os vídeos mostram como as ações humanas afetam negativamente o oceano. The Crystal Reef tem aproximadamente 6 minutos e concentra-se no processo da acidificação do oceano e em como o dióxido de carbono $\left(\mathrm{CO}_{2}\right)$, emitido em decorrência de atividades humanas, o afeta negativamente. O vídeo apresenta uma cientista (Fio Michelli) que mergulha em um local específico no Mar Mediterrâneo onde aberturas naturais no solo oceânico lançam $\mathrm{CO}_{2}$ na água. A alta concentração de $\mathrm{CO}_{2}$ na água diminui o pH da mesma, resultando num ambiente hostil para a vida e, consequentemente, menor biodiversidade. Imagens deste vídeo são mostradas na Figura 17.

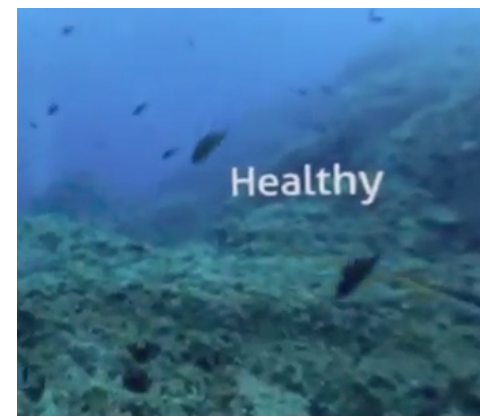

(a)

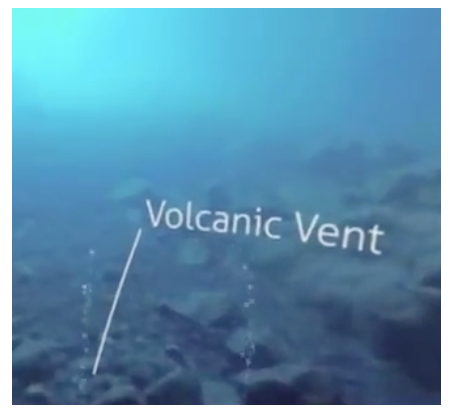

(b)

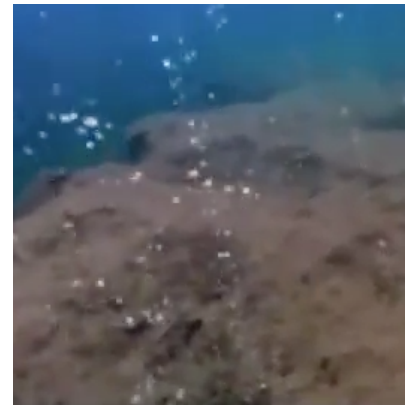

(c)

Figura 17. Imagens do vídeo The Crystal Reef. (a) Imagem de um recife de corais saudável. (b) Imagem de aberturas no solo oceânico emitindo CO2. (c) Imagem da região oceânica com reduzida biodiversidade por conta da redução do ph da água. 
O vídeo Coral Compass tem aproximadamente 6 minutos e retrata como as atividades humanas têm impactado os recifes de coral em Palau, uma pequena ilha no Pacífico Ocidental. O vídeo é narrado por um cientista (Rob Dunbar) e apresenta como o turismo e as práticas terrestres afetam a saúde dos recifes de coral. Ainda, o vídeo mostra como o governo do país está agindo para reduzir o impacto negativo no oceano. Ambos os vídeos são gratuitos para download online e sugerem ações que podem ser tomadas para reduzir o impacto negativo da humanidade no oceano. Imagens deste vídeo são mostradas na Figura 18.

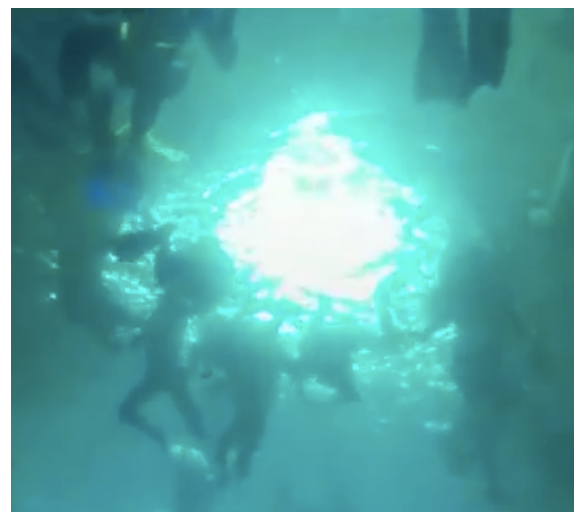

(a)

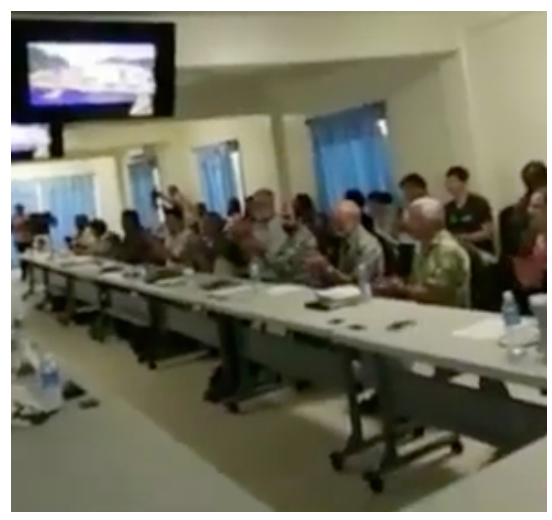

(b)

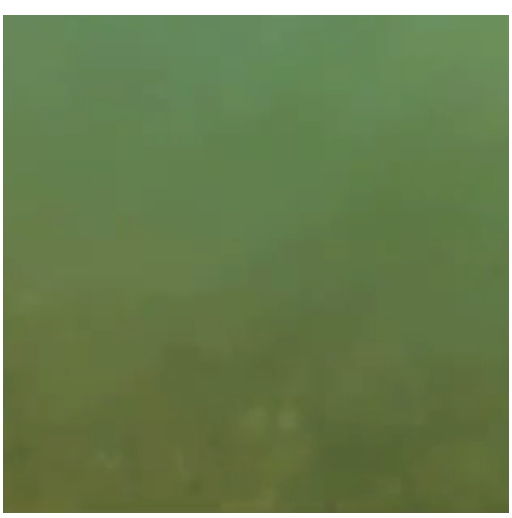

(c)

Figura 18. Imagens do vídeo Coral Compass. (a) Turistas nadando num recife de coral em Palau. (b) governantes e pesquisadores discutindo medidas para preservação dos recifes de coral em Palau. (c) região do recife de corais afetada por resíduos terrestres resultantes de práticas inadequadas de plantio.

Os vídeos originais foram desenvolvidos em 360 graus, para serem assistidos com o uso de óculos de RV. Uma versão em 2D (vídeo tradicional) foi criada pela pesquisadora, utilizando o software de captura de tela FRAPS. A pesquisadora assistiu aos vídeos usando óculos de RV ligado a um computador e capturou as imagens da tela e sons do vídeo no formato 2D. Esse processo garantiu que as duas versões (imersiva e tradicional) apresentassem exatamente o mesmo conteúdo. 


\subsection{Equipamentos}

Dependendo de qual condição os participantes foram designados, eles assistiram aos dois vídeos na tela de computador portátil, modelo Mac-Book Air Pro (condição computador) ou assistiram à versão imersiva dos vídeos usando óculos de RV, modelo Lenovo Mirage Solo (condição AVI). Estes equipamentos estão demonstrados na Figura 19. Os participantes das duas condições ouviram o áudio dos vídeos usando fones de ouvido. Os sons e a narrativa eram exatamente os mesmos nas condições de AVI e computador.
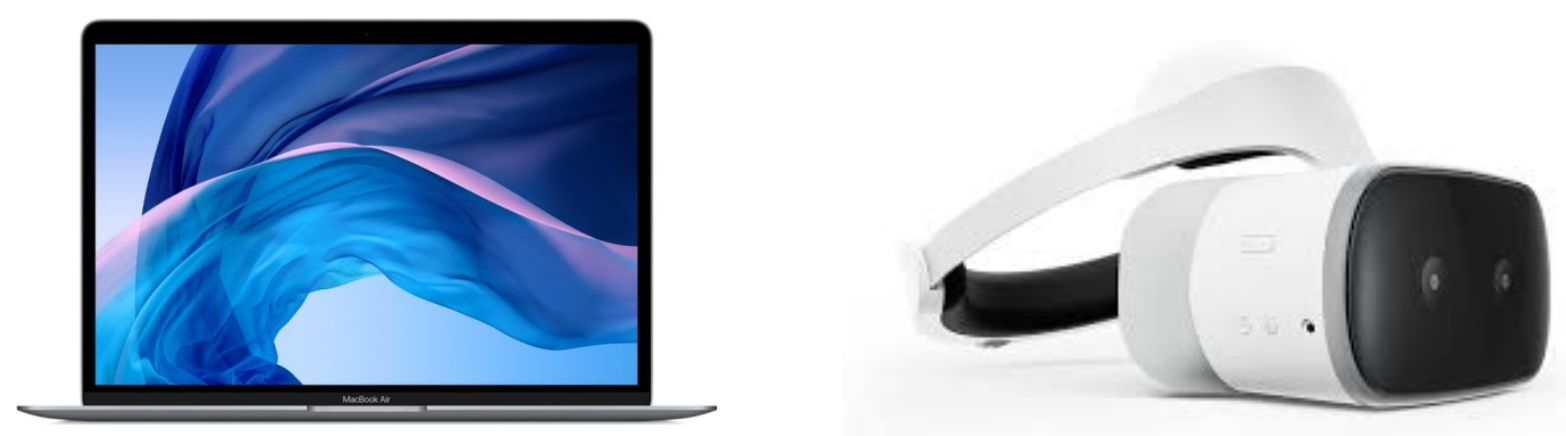

Figura 19. Equipamentos utilizados. (a) Computador da marca MacBook Air. (b) Óculos de RV da marca Lenovo Mirage.

\subsection{Instrumentos de avaliação}

O questionário completo utilizado neste estudo encontra-se no Anexo 1 (versão em português) e Anexo 2 (versão em inglês).

Presença. Três itens adaptados de Nowak e Biocca (2003) avaliaram sentimentos de presença usando uma escala Likert de 5 pontos sobre o quanto as participantes se sentiram presentes no ambiente digital ( 1 = nada, 5 = extremamente). Esses itens foram: “Até que ponto você se sentiu dentro da experiência virtual?"; "Até que ponto você se sentiu imerso na 
experiência virtual?" e "Quanto você sentiu como se tivesse visitado outro lugar?". As participantes responderam a essas três perguntas durante o pós-teste, imediatamente após assistir a cada um dos vídeos.

Perguntas abertas para avaliação de aprendizado. Seis perguntas abertas foram criadas com base na teoria do pensamento crítico e na revisão da taxonomia de Bloom para avaliação da aprendizagem, com foco no entendimento, aplicação e criação de conhecimento (Anderson et al., 2001; Mayer et al., 2001). As perguntas utilizadas foram:

- Explique o que você sabe sobre como as atividades humanas alteram a química do oceano.

- Como nossa sociedade pode reduzir a acidificação dos oceanos? Sugira o maior número soluções que você puder.

- Poucas pessoas sabem sobre a acidificação do oceano. Proponha e detalhe estratégias para aumentar o conhecimento e engajamento do público sobre a acidificação dos oceanos.

- Os recifes de coral em Palau, no Oceano Pacífico, são considerados uma das "Sete Maravilhas Subaquáticas do Mundo". Que ações o governo de Palau está tomando para reduzir os danos aos recifes de coral?

- Como as ações do governo de Palau para proteger os recifes de coral podem ser aplicadas a outras questões ambientais, como por exemplo, a rápida erosão das praias do sul da Califórnia? 
- Considerando os esforços do governo de Palau para proteger os recifes de coral, pense em um problema da sua comunidade que precisa de atenção imediata. Proponha um plano de ação detalhado que possa ajudar a resolver esse problema.

As respostas foram pontuadas por dois pesquisadores, que classificaram as respostas de cada uma das participantes usando um intervalo de 0 a 5 pontos. Foi desenvolvida e utilizada uma rubrica de acordo com Saxton, Belanger e Becker (Saxton et al., 2012). A taxa média de concordância entre os pesquisadores foi de $89,27 \%$ no pré-teste e $88 \%$ no pós-teste. Quando os pesquisadores tiveram uma discordância inicial sobre a pontuação, foi buscado o consenso e uma pontuação única para cada resposta foi considerada. A pontuação para as perguntas abertas foi a média das pontuações das perguntas individuais.

As perguntas em seguida foram agrupadas de acordo com a taxonomia dos objetivos de aprendizagem proposta por Bloom (entendimento, aplicação e criação de conhecimento; Anderson et al., 2001; Mayer et al., 2001) para identificação do desempenho dos participantes em cada um desses níveis.

Perguntas de múltipla escolha para avaliação da aprendizagem. Quatro perguntas sobre acidificação do oceano e sobre recifes de coral foram adaptadas de Fauville, Strang, Cannady e Chen (Fauville et al., 2019). Duas perguntas sobre as ações do governo de Palau em relação aos recifes de coral foram criadas por pesquisadores marinhos. As participantes receberam um ponto para cada resposta correta e zero ponto para respostas incorretas. A pontuação final dos participantes foi a soma de todas as respostas corretas. Por exemplo, uma das perguntas foi: "Selecione a prática da terra que pode ajudar muito a proteger os recifes de coral em Palau", e as participantes poderiam selecionar a resposta correta entre quatro opções. 
Preocupação com o oceano. Uma pergunta adaptada de Capstick et al., (2016) investigou o quanto as participantes estavam preocupadas com a saúde do oceano, usando uma escala Likert de 5 pontos ( 1 = nada, 5 = extremamente). A pergunta utilizada foi: "Quão preocupada você está, se é que você está, com a saúde do oceano?".

Crenças sobre as causas da acidificação do oceano. Foi solicitado às participantes que completassem a seguinte frase: "Você acha que o aumento da quantidade de dióxido de carbono na atmosfera foi causado..." selecionando uma das seguintes respostas: "principalmente por coisas que as pessoas fizeram"; "Principalmente por causas naturais" ou "igualmente por coisas que as pessoas fizeram e causas naturais". Esta pergunta foi criada especificamente para avaliar a crença da participante sobre o que causa acidificação do oceano e avaliar até que ponto o nível de imersão poderia impactar a crença das participantes sobre as causas da acidificação do oceano.

Seriedade da acidificação do oceano. Foi criada a pergunta "Quão sério você acha que é o problema do aumento da quantidade de dióxido de carbono na atmosfera para a saúde do oceano?" usando uma escala Likert de 5 pontos ( 1 = nada sério, 5 = extremamente sério). Esta pergunta foi usada para avaliar a opinião das participantes sobre a gravidade da acidificação do oceano.

Auto eficácia e motivação para aprender ciências. Doze perguntas foram selecionadas e adaptadas dos questionários desenvolvidos por Tuan, Chin e Shieh (2005), Pekrun, Goetz e Perry (2005) e Pekrun, Goetz, Frenzel, Barchfeld e Perry (2011). As questões usaram escala Likert de 5 pontos ( 1 = discordo totalmente, 5 = concordo totalmente). 


\subsubsection{Procedimento}

As participantes foram convidadas pelo seu professor de ciências para participar deste estudo. Antes do início da coleta de dados, a pesquisadora e o professor de ciências explicaram como seria a participação das alunas na pesquisa e esclareceram possíveis dúvidas. As participantes foram informadas que sua participação era voluntária e que elas poderiam deixar o experimento a qualquer momento sem nenhum prejuízo. Ainda, a pesquisadora explicou aos pais das alunas que a participação delas não teria relação com notas ou avaliações escolares.

As participantes que aceitaram participar da pesquisa receberam o termo de consentimento livre e esclarecido que foi assinado pelos seus responsáveis, e o termo de assentimento que foi assinado pelas participantes. As participantes autorizadas pelos seus responsáveis a participar da pesquisa responderam ao pré-teste online durante a aula de ciências. O pré-teste continha seis perguntas abertas e seis perguntas de múltipla escolha para medir o conhecimento sobre os temas abordados nos vídeos, 12 questões para medir percepção de auto eficácia, três perguntas sobre sua preocupação ambiental e crenças sobre acidificação.

Três semanas após as participantes responderem ao pré-teste, a pesquisadora visitou a escola para realizar as sessões de intervenção durante as quais as participantes foram aleatoriamente designadas para a condição de AVI $(\mathrm{N}=28)$ ou para a condição computador $(\mathrm{N}=$ 25).

Especialmente durante o uso dos óculos de Realidade Virtual, a pesquisadora solicitou que os participantes reportassem qualquer mal-estar, situação em que haveria interrupção imediata do seu uso. Os equipamentos (fones de ouvido e óculos de RV) foram higienizados antes 
de cada uso, sendo que as alunas os receberam sempre limpos. Nenhuma aluna relatou desconforto durante o experimento.

Na condição AVI, as participantes assistiram às versões imersivas dos vídeos The Coral Reef e Coral Compass usando fones de ouvido e óculos de RV, enquanto as participantes no grupo computador assistiram às versões 2D dos vídeos usando um computador e fones de ouvido em uma sala separada. A sessão de intervenção e o pós-teste ocorreram durante um período de 90 minutos nas aulas de ciências. Para reduzir o efeito da ordem de apresentação dos vídeos, metade das participantes de cada condição assistiu ao vídeo The Crystal Reef primeiro, enquanto a outra metade começou com o vídeo Coral Compass.

Ainda, para reduzir o efeito do cansaço, depois que as participantes assistiram ao primeiro vídeo, a pesquisadora pediu às alunas que removessem o fone de ouvido (ambas condições) e os óculos de RV (condição AVI apenas) e respondessem a três perguntas avaliando o sentimento de presença, três perguntas abertas e três de múltipla escolha para avaliar os resultados da aprendizagem. Todas usaram um computador para responder a estes questionários.

Quando as participantes terminaram de responder os questionários, a pesquisadora ajudou os participantes na condição $\mathrm{AVI}$ a recolocar os óculos de RV e iniciou a reprodução do segundo vídeo. Os participantes na condição computador foram orientados a colocar os fones de ouvido e iniciar o próximo vídeo em seus computadores. Após o segundo vídeo, os participantes responderam novamente às três perguntas que avaliam a presença, três perguntas abertas e três de múltipla escolha que avaliam o aprendizado, além de três perguntas adicionais sobre preocupação ambiental, conhecimento sobre acidificação do oceano e doze perguntas sobre auto eficácia. 
Finalmente, depois que todas as alunas concluíram o experimento, elas foram informadas sobre o objetivo do estudo e a pesquisadora respondeu às suas perguntas.

\subsubsection{Análise dos dados}

Todas as análises estatísticas foram realizadas no software RStudio Versão 1.1.463. A medida de presença foi realizada no pós-teste apenas e foi realizado um teste t de Welch para duas amostras para comparar os resultados entre as condições. As crenças sobre as causas da acidificação do oceano foi uma variável categórica nominal e para sua análise foi realizado um teste Qui-quadrado (Campbell, 2007) para comparar as proporções entre as condições no préteste e no pós-teste. A confiabilidade foi estimada através do coeficiente ômega, que demonstrou fornecer uma aproximação mais precisa de confiabilidade de escalas do que o alfa de Cronbach (Revelle \& Zinbarg, 2009). A confiabilidade para auto eficácia e motivação para aprender foi $\omega=0,84$ no pré-teste e $\omega=0,89$ no pós-teste, e no questionário de presença foi $\omega$ = 0,98 (medida apenas no pós-teste).

\subsubsection{Resultados}

Embora os participantes tenham sido distribuídos aleatoriamente para cada condição, foram encontradas diferenças significativas entre as condições no pré-teste para a avaliação da aprendizagem de múltipla escolha $(t(50,69)=3,16 ; p=0,003$; intervalo de confiança de $95 \%$ (IC) $[0,36,1,59], d=0,86)$, bem como percepção de auto eficácia $(t(44,49)=2,27, p=0,028, I C 95 \%$ $[3,52,3,20], d=0,63)$. Não foi encontrada diferença significativa entre as condições no pré-teste para a avaliação da aprendizagem das questões abertas (t $(42,37)=-0,36 ; p=0,718 ;$ IC 95\% [- 
$0,26,0,18], d=0,10)$, preocupação com a oceano (t $(48,71)=1,28 ; p=0,207 ;$ IC $95 \%[-0,14,0,67]$, $d=0,35)$, seriedade da acidificação do oceano (t $(50,42)=0,96 ; p=0,341 ;$ IC $95 \%[-0,18,0,52]$, $d=0,26)$ e crenças sobre acidificação do oceano $\left(X^{2}(1)=4,6-31, p=0,4247\right.$, IC $95 \%[-0,18,1,0]$, $d=0,22$ ). As estatísticas descritivas para cada variável medida no pré-teste (tempo 0) e pós-teste (tempo 1) são mostradas na Tabela 4.

Tabela 4 Médias e desvio-padrão no pré-teste e no pós-teste no estudo 1.

\begin{tabular}{|c|c|c|c|c|c|c|c|c|}
\hline \multirow{3}{*}{ Medidas } & \multicolumn{4}{|c|}{ Computador $(\mathrm{N}=25)$} & \multicolumn{4}{|c|}{$A V I(N=28)$} \\
\hline & \multicolumn{2}{|c|}{ Pré-teste } & \multicolumn{2}{|c|}{ Pós-teste } & \multicolumn{2}{|c|}{ Pré-teste } & \multicolumn{2}{|c|}{ Pós-teste } \\
\hline & $M$ & $D P$ & $M$ & $D P$ & $M$ & $D P$ & $M$ & $D P$ \\
\hline $\begin{array}{c}\text { Aprendizagem } \\
\text { (múltipla escolha) }\end{array}$ & 0,370 & 0,170 & 0,750 & 0,210 & 0,540 & 0,200 & 0,870 & 0,150 \\
\hline $\begin{array}{c}\text { Aprendizagem } \\
\text { (questões abertas) }\end{array}$ & 1,100 & 0,464 & 2,540 & 0,866 & 1,060 & 0,325 & 2,625 & 0,512 \\
\hline Auto eficácia & 3,200 & 0,574 & 3,123 & 0,711 & 3,521 & 0,435 & 3,652 & 0,500 \\
\hline Preocupação & 3,880 & 0,781 & 3,840 & 0,624 & 4,143 & 0,705 & 4,250 & 0,585 \\
\hline Seriedade & 4,080 & 0,640 & 4,560 & 0,583 & 4,250 & 0,645 & 4,536 & 0,508 \\
\hline Presença & - & - & 2,207 & 0,790 & - & - & 4,048 & 0,577 \\
\hline
\end{tabular}

Um modelo de curva de crescimento linear com efeito fixo da condição (computador versus AVI) e tempo (pré-teste versus pós-teste) foi utilizado para analisar os resultados para as medidas de aprendizagem (questões abertas apenas), medidas de preocupação com o oceano e de seriedade da acidificação do oceano (Tabela 2). O efeito aleatório dos indivíduos na interceptação e na inclinação da curva também foi incluído nos modelos (Bates et al., 2014). Dado o desenho experimental de pré-teste e pós-teste, esta análise da modelagem da curva de crescimento foi escolhida, uma vez que ela leva em consideração a variabilidade entre participantes e intra participantes dos padrões de mudança ao longo do tempo. Dada a diferença 
significativa no pré-teste, para as medidas de aprendizagem em múltipla escolha e para a medida de auto eficácia, foi utilizado o teste ANOVA sobre a diferença de pontuação entre o pré-teste e o pós-teste (Morgan \& Winship, 2015).

Tabela 5 Resultados dos modelos lineares de curva de crescimento no estudo 1

\begin{tabular}{|c|c|c|c|c|c|c|c|c|c|}
\hline \multirow{2}{*}{ Medidas } & \multirow{2}{*}{ Estimativa } & \multirow{2}{*}{$S E$} & \multicolumn{2}{|c|}{$95 \%$ IC } & \multirow{2}{*}{$t$} & \multirow{2}{*}{$p$} & \multirow{2}{*}{$\begin{array}{c}\text { Estimativa } \\
\text { padrão }\end{array}$} & \multirow{2}{*}{$S E$} & \multirow{2}{*}{$d$} \\
\hline & & & $L L$ & $U L$ & & & & & \\
\hline \multicolumn{10}{|l|}{ Questões abertas } \\
\hline Condition (IVR) & 0,02 & 0,11 & $-0,24$ & 0,28 & 0,19 & 0,847 & 0,02 & 0,12 & 0,04 \\
\hline Time & 1,51 & 0,10 & 1,30 & 1,71 & 14,64 & $0,000 * * *$ & 1,60 & 0,11 & 4,02 \\
\hline \multicolumn{10}{|l|}{ Preocupação } \\
\hline Condition (IVR) & 0,34 & 0,16 & $-0,02$ & 0,69 & 2,13 & $0,038^{*}$ & 0,49 & 0,23 & 0,19 \\
\hline Time & 0,04 & 0,09 & $-0,15$ & 0,22 & 0,41 & 0,684 & 0,05 & 0,13 & 0,11 \\
\hline \multicolumn{10}{|l|}{ Seriedade } \\
\hline Condition (IVR) & 0,07 & 0,12 & $-0,20$ & 0,34 & 0,61 & 0,547 & 0,12 & 0,19 & 0,12 \\
\hline Time & 0,38 & 0,11 & 0,16 & 0,59 & 3,51 & $0,001^{* *}$ & 0,61 & 0,17 & 0,96 \\
\hline
\end{tabular}

Perguntas abertas para avaliação de aprendizado. Houve uma diferença significativa na pontuação das participantes entre o pré-teste e o pós-teste, com ambas as condições mostrando um aumento significativo na pontuação no pós-teste em relação ao pré-teste $(\beta=1,51, \mathrm{t}(53)=$ 14,64, $p<0,001$, IC 95\% [1,30, 1,71], d = 4,02). Não houve efeito de interação entre condição e tempo nas questões abertas $\left(X^{2}(1)=0,372, p=0,542\right.$, IC95\% $\left.[0,87,1,27], d=0,17\right)$.

Em relação a cada processo cognitivo medido de acordo com a taxonomia de Bloom (Anderson et al., 2001; Mayer et al., 2001), ambas as condições mostraram um aumento significativo, como mostrado a seguir: entendimento $(\beta=1,60, t(53)=12,58, p<0,001, I C 95 \%$ $[1,01,1,55], d=3,45)$; aplicação $(\beta=1,33, t(53)=10,23, p<0,001, I C 95 \%[1,53,2,09], d=2,81)$; criação $(\beta=1,58, t(53)=11,90, p<0,001, I C$ 95\% $[1,32,1,85], d=3,27)$. 
Esses resultados indicam que, com a intervenção, as participantes de ambas as condições demonstraram um aumento significativo do conhecimento em relação a cada um dos processos cognitivos. Não houve efeito significativo de interação da condição e do tempo no entendimento $\left(X^{2}(1)=0,5946 ; p=0,440, I C 95 \%[0,68,1,24], d=0,21\right)$, aplicação de conhecimento $\left(X^{2}(1)=\right.$ $0,0055 ; p=0,938$, IC $95 \%[0,50,1,10], d=0,02)$ ou criação $\left(X^{2}(1)=0,3638 ; p=0,545\right.$, IC 95\% $[1,25,1,83], d=0,17)$.

Preocupação com o oceano. Houve um efeito significativo da condição na preocupação das participantes com a saúde do oceano $(\beta=0,34, \mathrm{t}(53)=2,13, \mathrm{p}=0,038, \mathrm{IC} 95 \%[-0,02,0,69]$, $d=0,19)$. Não houve efeito significativo de interação da condição e do tempo na preocupação das participantes com o oceano $\left(X^{2}(1)=0,6373 ; p=0,424, \operatorname{IC} 95 \%[3,58,4,10], d=0,22\right)$.

Seriedade da acidificação do oceano. Houve diferença significativa entre o pré-teste e pós-teste para as duas condições, indicando que a percepção das participantes sobre a seriedade da acidificação do oceano aumentou após a intervenção, independentemente da condição $(\beta=$ $0,38, t(53)=3,51, p=0,003, I C 95 \%[0,16,0,59], d=0,96)$. Não houve efeito significativo de interação da condição e do tempo percepção da seriedade da acidificação do oceano $\left(X^{2}(1)=\right.$ $0,8205 ; p=0,3365$, IC $95 \%[3,92,4,34], d=0,25)$.

Presença. Os sentimentos de presença foram medidos durante o pós-teste, logo após as participantes assistirem a cada um dos vídeos, independentemente da condição. Encontrou-se diferença significativa nos sentimentos de presença das participantes entre as condições ( $t$ $(43,55)=-9,593 ; p<0,001 ;$ IC95\% $[-2,23,-1,45], d=2,69)$, com as participantes na condição AVI relatando sentimentos de presença significativamente mais intensos do que as participantes da 
condição computador. As estatísticas descritivas para cada variável dependente no pós-teste (tempo 1) são mostradas na Tabela 1.

Crenças sobre causas da acidificação do oceano. Nenhuma das participantes atribuiu as causas da acidificação do oceano a causas principalmente naturais no pré-teste ou no pós-teste. A porcentagem de participantes que respondeu que a acidificação do oceano é causada "principalmente por coisas que as pessoas fizeram" aumentou de 89,3\% no pré-teste para 96,4\% no pós-teste na condição que utilizou AVI, enquanto diminuiu de $92 \%$ para $76 \%$ na condição que utilizou o computador (Figura 1). Não houve diferença significativa entre as condições na proporção de participantes atribuindo a causa da acidificação do oceano a "principalmente por coisas que as pessoas fizeram" antes da intervenção (diferença de 2,7\%, $X^{2}(1)=4,6-31, p=0,5$, IC $95 \%[-0,18,1,0], d=0,19)$. No entanto, uma proporção significativamente maior de participantes na condição AVI atribuiu a causa da acidificação do oceano a "principalmente por coisas que as pessoas fizeram" do que participantes na condição computador após a intervenção (diferença de 20,4\%, $X^{2}(1)=3,19, p=0,037$, IC 95\% $[0,014,1,0], d=0,60$ ), como mostrado na Figura 20. 


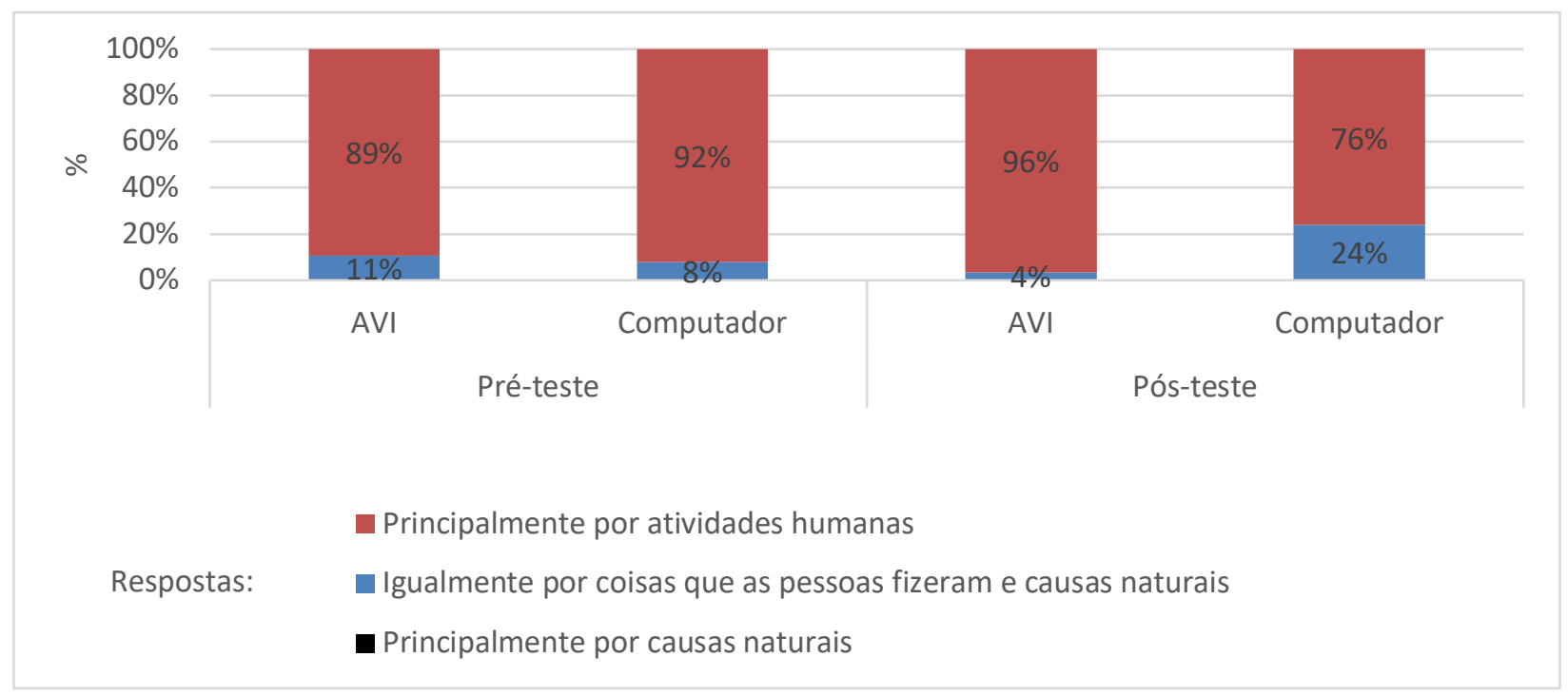

Figura 20. Porcentagem de respostas sobre as causas da acidificação do oceano.

Perguntas de múltipla escolha para avaliação de aprendizado. Foi encontrado um aumento significativo na pontuação para ambas as condições entre o pré-teste e o pós-teste (AVI: $\mathrm{t}(49,98)=-6,90 ; \mathrm{p}<0,001 ; \mathrm{IC} 95 \%[-0,43,-0,24, \mathrm{~d}=1,85]$; Computador: $\mathrm{t}(45,82)=-6,92 ; \mathrm{p}<$ $0,001$; IC $95 \%[-0,48,-0,26], d=1,96)$. Não foi encontrada diferença significativa entre as condições na diferença de pontuação entre pré-teste e pós-teste $(F(1,51)=0,583, p=0,449, \eta 2$ $=0,011$.

Percepção de auto eficácia e motivação para aprender ciências. Foi encontrada uma diferença significativa entre as condições na diferença de pontuação entre pré-teste e pós-teste $(F(1,51)=4,281, p=0,043, \eta 2=0,077)$. A pontuação das participantes na condição AVI aumentou do pré-teste para o pós-teste ( $M=3,52$ no pré-teste e $M=3,65$ no pós-teste), enquanto a pontuação das participantes na condição computador diminuiu após a intervenção ( $M=3,20$ no pré-teste e $M=3,12$ no pós-teste; ver estatística descritiva na Tabela 3.1). 
Análise de Mediação. Para investigar o mecanismo subjacente à relação entre presença e resultados de aprendizagem e aspectos afetivos, foram realizadas análises de mediação causal com aproximação bayesiana e bootstrap não paramétrico de intervalos de confiança (Baron \& Kenny, 1986). Foi realizada uma análise de mediação considerando a condição como preditor, a medida de auto eficácia como mediador e a avaliação de aprendizado (questões abertas) como resultado. Os resultados mostraram que a presença mediou a relação entre a condição e a auto eficácia (ACME =0,568, IC 95\% [0,57, 0,16], p =0,008).

Além disso, uma análise de mediação a posteriori mostrou que a auto eficácia mediou a relação entre a condição e o aprendizado medido pelas questões abertas ( $\mathrm{ACME}=0,210, \mathrm{IC} 95 \%$ $[0,03,0,45], p=0,004)$. 


\subsection{Estudo 2}

Após o estudo 1, foi realizado este segundo estudo visando resolver algumas limitações do estudo 1. Primeiro, a amostra foi ampliada e dessa vez foi utilizada uma amostra de 139 participantes da 6a à 8a série. As participantes eram da mesma escola que fez parte do estudo 1 , todas do sexo feminino. Uma distribuição aleatória pareada das participantes entre as condições (Cozby, 2009) foi utilizada para evitar diferenças significativas entre as condições no pré-teste. Desta forma, as participantes foram distribuídas entre as condições de acordo com os seus resultados no pré-teste. Por exemplo, dentre as duas participantes com o maior escore para auto eficácia, cada uma foi alocada em uma condição, AVI e computador, e assim sucessivamente com as demais participantes.

Ao que se refere às variáveis investigadas, foram desenvolvidas questões para medir o controle sobre a aprendizagem e identificar o quanto as alunas consideram importante ter controle sobre o seu aprendizado. Ainda, foram adicionadas questões referentes à atitude das participantes em relação às disciplinas escolares, com o objetivo de investigar possíveis mecanismos mediadores da percepção de auto eficácia na aprendizagem.

O questionário de percepção de auto eficácia utilizado neste estudo foi a versão completa do questionário sobre percepção de auto eficácia e motivação para aprender ciências de Tuan, Chin e Shieh (2005). Além disso, foram realizadas duas sessões de intervenção, nas quais as participantes assistiram a um vídeo por sessão e as medidas foram tomadas após cada sessão. Finalmente, as participantes completaram mais um pós-teste tardio, seis semanas após as sessões de intervenção, para avaliar os efeitos a longo prazo da intervenção. Consequentemente, 
neste estudo, as medidas foram tomadas em quatro momentos: pré-teste (tempo 0), pós-teste 1 (tempo 1, realizado cinco semanas após o pré-teste), pós-teste 2 (tempo 2, realizado um ou dois dias após o pós-teste 1) e teste de retenção (tempo 3, realizado 6 semanas após o pós-teste 2).

\subsubsection{Método}

\subsubsection{Participantes}

As participantes foram recrutadas na mesma escola do estudo 1 e a participação foi totalmente voluntária. A amostra inicial contou com 164 estudantes do sexo feminino do 60 ao 8o ano do ensino fundamental II $(M=7, D P=0,83)$, com idades entre 11 e 14 anos $(M=12,27$, $\mathrm{DP}=0,91)$. Vinte e cinco estudantes não conseguiram concluir parte do estudo e foram excluídas da análise. A amostra final foi composta por 139 participantes.

\subsubsection{Material}

O material instrucional utilizado foi o mesmo utilizado no estudo 1, os vídeos The Crystal Reef e Coral Compass, nas versões 360 graus e vídeo tradicional. As participantes da condição AVI usaram os mesmos óculos de RV do estudo 1, e as participantes da condição computador usaram o mesmo modelo de computador usado no estudo 1.

\subsection{Instrumentos de avaliação}


Como mencionado anteriormente, os questionários para avaliar presença, aprendizagem (questões de múltipla escola e questões abertas), preocupação ambiental, crenças sobre a acidificação do oceano e seriedade da acidificação do oceano foram os mesmos utilizados no estudo 1. O questionário completo utilizado neste estudo está no Anexo 3 (versão em português) e Anexo 4 (versão em inglês).

Atitude em relação às disciplinas escolares. Dezesseis perguntas sobre o quanto os alunos gostam (por exemplo, "O quanto você gosta de Computação?") e sobre o quanto eles se sentem bem em relação às matérias escolares (por exemplo, "O quanto você se sente bem em relação a matemática?") foram adaptados de Andre e colegas, (1999). As disciplinas escolares utilizadas nestas questões foram adaptadas do Departamento de Educação dos EUA (US, n.d.). Foi realizada uma análise fatorial multinível nas 16 perguntas, com intuito de melhor agrupa-las para análise (Anexo 5). Esta análise resultou em três fatores, nos quais as questões foram agrupadas: Matemática e Ciências; Humanidades; Artes (visuais e performance).

Controle da aprendizagem. Cinco perguntas usando uma escala Likert de 5 pontos foram criadas para investigar a importância do controle sobre $a$ aprendizagem das participantes $(\omega=$ $0,56, \omega=0,67, \omega=0,69$ e $\omega=0,72$ nos tempos $0,1,2$ e 3 respectivamente). Nenhum questionário direcionado a esta investigação foi encontrado, portanto, as questões foram construídas baseadas em teorias sobre os conceitos de agência, controle, percepção de auto eficácia e embodiment (C. W. Baker et al., 2003; David et al., 2008; Gonzalez-Franco \& Peck, 2018; JohnsonGlenberg, 2018; Judge et al., 2002; Schlosser, 2012; Spengler et al., 2009). Por exemplo, uma das 
perguntas foi: "Aprendo mais quando sou eu quem seleciona o que vou aprender" (pontuações variando entre 1 = discordo totalmente e 5 = concordo totalmente).

Percepção de auto eficácia e motivação para aprender ciências. Dezoito perguntas de Tuan, Chin e Shieh (2005) foram adaptadas para avaliar a auto eficácia e a motivação dos participantes para aprender ciências $(\omega=0,85, \omega=0,87, \omega=0,90$ e $\omega=0,89$ nos tempos $0,1,2$ e 3 respectivamente) usando uma escala Likert de 5 pontos $(1=$ discordo totalmente, $5=$ concordo totalmente).

\subsubsection{Procedimento}

Como no estudo 1, todas as participantes receberam um termo de consentimento livre e esclarecido direcionado a seus responsáveis e um termo de assentimento direcionado às alunas. As alunas que foram autorizadas a participar da pesquisa pelos seus responsáveis e que quiseram participar da pesquisa responderam ao pré-teste usando um computador durante a aula de ciências. Este questionário teve as mesmas perguntas utilizadas no estudo 1, avaliando aprendizado (questões abertas e questões de múltipla escolha), preocupação ambiental, crenças sobre acidificação do oceano e seriedade da acidificação do oceano. O pré-teste também incluiu 18 perguntas para avaliar percepção de auto eficácia (Tuan et al., 2005), cinco perguntas para avaliar o controle sobre a aprendizagem (desenvolvida pela pesquisadora com apoio de professores e outros pesquisadores na área), oito perguntas para avaliar o quanto as participantes gostam e o quanto se sentem bem em relação às matérias escolares (Andre et al., 1999). Cinco semanas depois das participantes completarem o pré-teste, a pesquisadora visitou 
a escola para realizar as sessões de intervenção. As participantes foram distribuídas entre a condição AVI ( $N=73)$ e computador $(N=66)$ com base em seus resultados no pré-teste, por meio de distribuição aleatória pareada (Cozby, 2003).

Metade das participantes em cada condição assistiu ao vídeo The Crystal Reef na primeira sessão de intervenção, enquanto a outra metade assistiu ao vídeo Coral Compass. Cada sessão de intervenção ocorreu durante uma aula de ciências de 45 minutos. A pesquisadora ajudou as participantes na condição AVI a colocar os óculos de RV e iniciar os vídeos. As participantes foram instruídas a informar a pesquisadora se houvesse qualquer desconforto, problema na reprodução dos vídeos e quando a reprodução do vídeo tivesse terminado. Nenhuma participante relatou desconforto. Quando as participantes terminaram de assistir ao vídeo, a pesquisadora as ajudou a remover os óculos de RV. Os óculos foram imediatamente higienizados pela pesquisadora, para uso posterior.

Depois de assistir ao vídeo, as participantes usaram um computador para responder às mesmas perguntas usadas no pré-teste, somado a questões avaliando presença. As duas sessões de intervenção tiveram de um a dois dias de intervalo e seguiram o mesmo procedimento, no qual as participantes assistiram a um dos vídeos na primeira sessão e ao outro na segunda sessão.

Seis semanas após as sessões de intervenção, todas as alunas responderam ao teste de retenção, que continha as mesmas questões do pré-teste, durante uma aula de ciências de 45 minutos. Depois que as participantes concluíram o experimento, elas foram informadas sobre o objetivo do estudo e a pesquisadora respondeu às suas perguntas. 


\subsubsection{Análise dos dados}

Um modelo de curva de crescimento linear com efeito fixo da condição (computador versus $\mathrm{AVI}$ ) e tempo (tempo 0 = pré-teste, tempo 1 = pós-teste 1 , tempo 2 = pós-teste 2 e tempo 3 = teste de retenção) foi utilizado para analisar para analisar a maioria das variáveis (exceto crenças sobre a acidificação do oceano). O efeito aleatório dos indivíduos na interceptação e na inclinação da curva também foi incluído nos modelos (Bates et al., 2014). A variável para investigação das crenças sobre as causas da acidificação do oceano é uma variável categórica nominal e foi realizado um teste Qui-quadrado (Campbell, 2007) para comparar as proporções entre as condições ao longo do tempo.

\subsubsection{Resultados}

As estatísticas descritivas nos tempos 0, 1, 2 e 3 são apresentadas na Tabela 6.

Tabela 6. Médias e desvio padrão nos tempos 0, 1, 2, 3 no estudo 2.

\begin{tabular}{|c|c|c|c|c|c|c|c|c|c|c|c|c|c|c|c|c|}
\hline \multirow{3}{*}{ Medidas } & \multicolumn{8}{|c|}{ Computador $(\mathrm{N}=66)$} & \multicolumn{8}{|c|}{ AVI $(N=73)$} \\
\hline & \multicolumn{2}{|c|}{ Tempo 0} & \multicolumn{2}{|c|}{ Tempo 1} & \multicolumn{2}{|c|}{ Tempo 2} & \multicolumn{2}{|c|}{ Tempo 3} & \multicolumn{2}{|c|}{ Tempo 0} & \multicolumn{2}{|c|}{ Tempo 1} & \multicolumn{2}{|c|}{ Tempo 2} & \multicolumn{2}{|c|}{ Tempo 3} \\
\hline & $M$ & $D P$ & $M$ & $D P$ & $M$ & $D P$ & $M$ & $D P$ & $M$ & $D P$ & $M$ & $D P$ & $M$ & $D P$ & $M$ & $D P$ \\
\hline $\begin{array}{l}\text { Aprendizagem - } \\
\text { múltipla escolha }\end{array}$ & 0,40 & 0,20 & 0,59 & 0,27 & 0,64 & 0,26 & 0,64 & 0,24 & 0,41 & 0,20 & 0,59 & 0,25 & 0,60 & 0,22 & 0,63 & 0,22 \\
\hline $\begin{array}{l}\text { Aprendizagem - } \\
\text { questões abertas }\end{array}$ & 1,06 & 0,47 & 2,01 & 0,78 & 2,04 & 0,64 & 1,62 & 0,62 & 1,15 & 0,50 & 2,13 & 0,79 & 2,26 & 0,73 & 1,83 & 0,65 \\
\hline Auto eficácia & 3,83 & 0,42 & 3,75 & 0,49 & 3,73 & 0,53 & 3,73 & 0,50 & 3,92 & 0,46 & 3,92 & 0,44 & 3,90 & 0,47 & 3,81 & 0,52 \\
\hline Preocupação & 3,85 & 0,79 & 4,03 & 0,78 & 4,08 & 0,86 & 3,94 & 0,87 & 4,01 & 0,81 & 4,05 & 0,83 & 4,19 & 0,88 & 3,95 & 0,94 \\
\hline Seriedade & 4,05 & 0,79 & 4,30 & 0,68 & 4,35 & 0,67 & 4,32 & 0,68 & 4,26 & 0,71 & 4,30 & 0,62 & 4,60 & 0,55 & 4,38 & 0,68 \\
\hline $\begin{array}{c}\text { Controle da } \\
\text { aprendizagem }\end{array}$ & 3,56 & 0,50 & 3,33 & 0,41 & 3,32 & 0,44 & 3,45 & 0,56 & 3,55 & 0,49 & 3,46 & 0,43 & 3,42 & 0,38 & 3,58 & 0,54 \\
\hline
\end{tabular}




\begin{tabular}{|c|c|c|c|c|c|c|c|c|c|c|c|c|c|c|c|c|}
\hline $\begin{array}{l}\text { Atitude - } \\
\text { Ciências e } \\
\text { Matemática }\end{array}$ & 3,72 & 0,66 & 3,71 & 0,69 & 3,72 & 0,74 & 3,70 & 0,78 & 3,75 & 0,65 & 3,72 & 0,72 & 3,75 & 0,78 & 3,65 & 0,72 \\
\hline $\begin{array}{c}\text { Atitude - } \\
\text { Humanidades }\end{array}$ & 3,66 & 0,64 & 3,74 & 0,72 & 3,77 & 0,71 & 3,81 & 0,71 & 3,50 & 0,64 & 3,61 & 0,73 & 3,62 & 0,82 & 3,64 & 0,79 \\
\hline Atitude - Artes & 4,20 & 0,96 & 4,19 & 1,06 & 4,16 & 1,13 & 4,13 & 1,04 & 4,19 & 0,81 & 4,32 & 0,81 & 4,29 & 0,92 & 4,30 & 0,89 \\
\hline Presença & - & - & 2,23 & 0,89 & 2,14 & 0,93 & - & - & - & - & 3,82 & 0,78 & 4,01 & 0,66 & - & - \\
\hline
\end{tabular}

Não foram encontradas diferenças significativas entre as duas condições no que se refere às variáveis medidas no pré-teste, conforme mostrado na Tabela 6 . Além disso, não foram encontradas diferenças significativas entre as condições no que se refere à idade $(t(134,83)=$ $0,301 ; p=0,764 ;$ IC95\% $[-0,35,0,26])$ e série $(t(134,66)=-0,203 ; p=0,840 ;$ IC95\% $[-0,31,0,25]$.

Os resultados dos modelos de curva de crescimento linear são mostrados na Tabela 7.

Tabela 7. Resultados dos modelos de curva de crescimento linear.

\begin{tabular}{|c|c|c|c|c|c|c|c|c|c|}
\hline \multirow{2}{*}{ Medidas } & \multirow{2}{*}{ Estimativa } & \multirow{2}{*}{$S E$} & \multicolumn{2}{|c|}{$95 \% \mathrm{Cl}$} & \multirow{2}{*}{$t$} & \multirow{2}{*}{$p$} & \multirow{2}{*}{$\begin{array}{c}\text { Estimativa } \\
\text { padrão }\end{array}$} & \multirow{2}{*}{$S E$} & \multirow{2}{*}{$d$} \\
\hline & & & $L L$ & $U L$ & & & & & \\
\hline \multicolumn{10}{|c|}{ Aprendizagem - múltipla escolha } \\
\hline Condição (AVI) & $-0,01$ & 0,03 & $-0,06$ & 0,04 & $-0,29$ & 0,776 & $-0,03$ & 0,1 & $-0,05$ \\
\hline Tempo & 0,07 & 0,01 & 0,06 & 0,09 & 9,00 & $0,000 * * *$ & 0,32 & 0,04 & 0,88 \\
\hline \multicolumn{10}{|c|}{ Aprendizagem - questões abertas } \\
\hline Condição (AVI) & 0,16 & 0,08 & $-0,38$ & 0,07 & 2,08 & $0,039^{*}$ & 0,21 & 0,10 & 0,36 \\
\hline Tempo & 0,19 & 0,03 & 0,02 & 0,07 & 7,54 & $0,000 * * *$ & 0,28 & 0,04 & 0,74 \\
\hline \multicolumn{10}{|l|}{ Auto eficácia } \\
\hline Condição (AVI) & 0,13 & 0,07 & $-0,01$ & 0,27 & 1,85 & $0,067^{\circ}$ & 0,27 & 0,14 & 0,32 \\
\hline Tempo & $-0,03$ & 0,01 & $-0,05$ & $-0,01$ & $-3,02$ & $0,003^{* *}$ & $-0,08$ & 0,03 & $-0,30$ \\
\hline \multicolumn{10}{|c|}{ Preocupação com oceano } \\
\hline Condição (AVI) & 0,08 & 0,12 & $-0,15$ & 0,31 & 0,67 & 0,507 & 0,09 & 0,14 & 0,11 \\
\hline Tempo & 0,01 & 0,02 & $-0,03$ & 0,05 & 0,53 & 0,600 & 0,02 & 0,03 & 0,05 \\
\hline \multicolumn{10}{|c|}{ Seriedade da acidificação do oceano } \\
\hline Condição (AVI) & 0,13 & 0,09 & $-0,03$ & 0,30 & 1,57 & 0,119 & 0,19 & 0,12 & 0,27 \\
\hline Tempo & 0,08 & 0,02 & 0,04 & 0,12 & 3,81 & $0,000 * * *$ & 0,12 & 0,03 & 0,37 \\
\hline \multicolumn{10}{|c|}{ Controle da aprendizagem } \\
\hline Condição (AVI) & 0,09 & 0,06 & $-0,02$ & 0,20 & 1,53 & 0,128 & 0,18 & 0,12 & 0,26 \\
\hline Tempo & $-0,01$ & 0,01 & $-0,04$ & 0,02 & $-0,95$ & 0,343 & $-0,03$ & 0,03 & $-0,09$ \\
\hline \multicolumn{10}{|c|}{ Atitude - Ciências e Matemática } \\
\hline Condição (AVI) & 0,00 & 0,12 & $-0,22$ & 0,23 & 0,02 & 0,983 & 0,00 & 0,16 & 0,00 \\
\hline
\end{tabular}




\begin{tabular}{|c|c|c|c|c|c|c|c|c|c|}
\hline Tempo & $-0,02$ & 0,01 & $-0,04$ & 0,00 & $-1,83$ & $0,068^{\circ}$ & $-0,03$ & 0,02 & $-0,18$ \\
\hline \multicolumn{10}{|l|}{ Atitude - Humanidades } \\
\hline Condição (AVI) & $-0,15$ & 0,11 & $-0,38$ & 0,07 & $-1,31$ & 0,192 & $-0,21$ & 0,16 & $-0,22$ \\
\hline Tempo & 0,04 & 0,01 & 0,02 & 0,07 & 3,95 & $0,000 * * *$ & 0,07 & 0,02 & 0,39 \\
\hline \multicolumn{10}{|l|}{ Atitude -Artes } \\
\hline Condição (AVI) & 0,10 & 0,15 & 0,00 & 0,12 & 0,69 & 0,492 & 0,11 & 0,16 & 0,12 \\
\hline Tempo & 0,00 & 0,00 & $-0,07$ & 0,02 & 0,23 & 0,815 & 0,00 & 0,00 & 0,02 \\
\hline \multicolumn{10}{|l|}{ Presença } \\
\hline Condição (AVI) & 1,35 & 0,20 & 0,95 & 1,75 & 6,64 & $0,000^{* * *}$ & 1,14 & 0,17 & 0,82 \\
\hline Tempo & $-0,03$ & 0,08 & $-0,18$ & 0,12 & $-0,40$ & 0,692 & $-0,03$ & 0,06 & $-0,07$ \\
\hline $\begin{array}{r}\text { Condição (AVI): } \\
\text { Tempo }\end{array}$ & 0,25 & 0,11 & 0,04 & 0,46 & 2,37 & $0,019 *$ & 0,21 & 0,09 & 0,40 \\
\hline
\end{tabular}

$\cdot p<0.1 ; * p<0.05 ; * * p<0.01 ; * * * p<0.001$.

Presença. As medidas foram tomadas logo após as participantes assistirem a cada um dos vídeos (tempo 1 e tempo 2). Foi encontrada uma diferença significativa entre as condições, sendo que as participantes na condição AVI apresentaram pontuação significativamente maior do que as participantes na condição computador após assistirem aos vídeos $(\beta=1,35, \mathrm{t}(263)=6,64, \mathrm{p}$ $<0,001, \operatorname{IC} 95 \%[0,95,1,75], d=0,82)$. Houve um efeito de interação significativo da condição e tempo no resultado da presença $\left(X^{2}(1)=5,581, p=0,019\right.$, IC 95\% $\left.[0,04,0,46], d=0,40\right)$, com um aumento na pontuação das participantes na condição AVI e uma diminuição na pontuação das participantes na condição computador após a intervenção.

Perguntas abertas para avaliação do aprendizado. Houve um efeito significativo da condição no aprendizado medido por questões abertas, sendo que as participantes na condição AVI apresentaram pontuação mais alta do que as participantes na condição computador após as sessões de intervenção $(\beta=0,16, t(137)=2,08, p=0,039, \operatorname{IC} 95 \%[0,01,0,31], d=0,36)$. Houve um efeito significativo do tempo na aprendizagem, e as participantes em ambas as condições mostraram um aumento significativo na pontuação após o tratamento $(\beta=0,19, \mathrm{t}(416)=7,54$, $p<0,001, I C 95 \%[0,14,0,25], d=0,74)$. Não houve efeito de interação entre condição e tempo 
na aprendizagem avaliada por questões abertas $\left(X^{2}(1)=0,8713, p=0,352, I C 95 \%[-0,05,0,15]\right.$, $d=0,16)$.

Em relação a cada processo cognitivo, medido de acordo com a taxonomia de Bloom (Krathwohl \& Anderson, 2009; Mayer et al., 2001), houve um efeito significativo do tempo para o processo de compreensão do conhecimento $(\beta=0,26$, t $(416)=7,19, p<0,001$, IC95\% [0,19, 0,33], $d=0,70)$, de aplicação de conhecimento $(\beta=0,26, t(416)=7,06, p<0,001,1 C 95 \%[0,20$, $0,33], d=0,69)$ e um efeito marginalmente significativo para o processo de criação do conhecimento $(\beta=0,06, \mathrm{t}(416)=1,95, p=0,052, \mathrm{IC} 95 \%[-0,01,0,11], d=0,19)$, com um aumento na pontuação das participantes em ambas as condições após a intervenção para todos os processos cognitivos. Encontrou-se um efeito significativo da condição na aplicação do conhecimento $(\beta=0,21, \mathrm{t}(137)=2,23, \mathrm{p}=0,028, \mathrm{IC} 95 \%[0,25,0,39], d=0,38)$ e na criação do conhecimento $(\beta=0,20$, t $(137)=2,25, p=0,026$, IC $95 \%[0,26,0,45], d=0,38)$, sendo que as participantes na condição AVI apresentaram pontuação maior do que as participantes na condição computador após a intervenção. Não houve efeito significativo de interação da condição e do tempo na compreensão $\left(X^{2}(1)=0,78 ; p=0,3769, I C 95 \%[-0,08,0,21], d=0,15\right)$, aplicação do conhecimento $\left(X^{2}(1)=0,083 ; p=0,773\right.$, IC 95\% $\left.[-0,13,0,17], d=0,30\right)$ ou criação $\left(X^{2}(1)=2.858 ; p=0,091, I C 95 \%[-0,02,0,21], d=0,29\right)$.

Perguntas de múltipla escolha para avaliação do aprendizado. Houve um efeito significativo do tempo na aprendizagem avaliada utilizando questões de múltipla escolha, com um aumento na pontuação das participantes em ambas as condições após a intervenção $(\beta=$ $0,07, p<0,001, I C 95 \%[0,06,0,09], d=0,88)$. Não houve efeito significativo de interação entre 
condição e tempo no resultado das questões de múltipla escolha $\left(X^{2}(1)=0,368 ; p=0,544\right.$, IC $95 \%[-0,04,0,02], d=0,10)$.

Preocupação com o oceano. Não houve efeito significativo do tempo ou da condição na preocupação dos participantes com a saúde do oceano (consulte a Tabela 4.2). Além disso, não houve efeito significativo de interação da condição e do tempo na preocupação dos participantes com a saúde do oceano $\left(X^{2}(1)=0,779 ; p=0,378, I C 95 \%[-0,12,0,05], d=0,15\right)$.

Crenças sobre as causas da acidificação do oceano. Apenas uma das participantes atribuiu a acidificação do oceano a causas principalmente naturais no tempo 0 , tempo 1 e tempo 3. A porcentagem de respostas para a pergunta "Você acha que o aumento da quantidade de dióxido de carbono na atmosfera foi causado:" a cada momento medido é mostrada na Figura 21. Foi encontrada uma diferença significativa entre as condições logo após as sessões de intervenção, no tempo $1\left(X^{2}(2)=8,36, p=0,015, d=0,42\right)$ e no tempo $2\left(X^{2}(1)=6,87, p=0,008\right.$, $d=0,46)$, com uma proporção significativamente maior de participantes na condição AVI atribuindo causas da acidificação do oceano a "principalmente por coisas que as pessoas fizeram" do que participantes na condição computador no tempo 1 (diferença de $14,4 \%, X^{2}(1)=4,90, p=$ 0,013, IC 95\% [-1,0,-0,03], $d=0,43$ ) e no tempo 2 (diferença de $17,30 \%, X^{2}(1)=6,88, p=0,004$, IC 95\% $[-1,0,-0,06], d=0,50)$. 


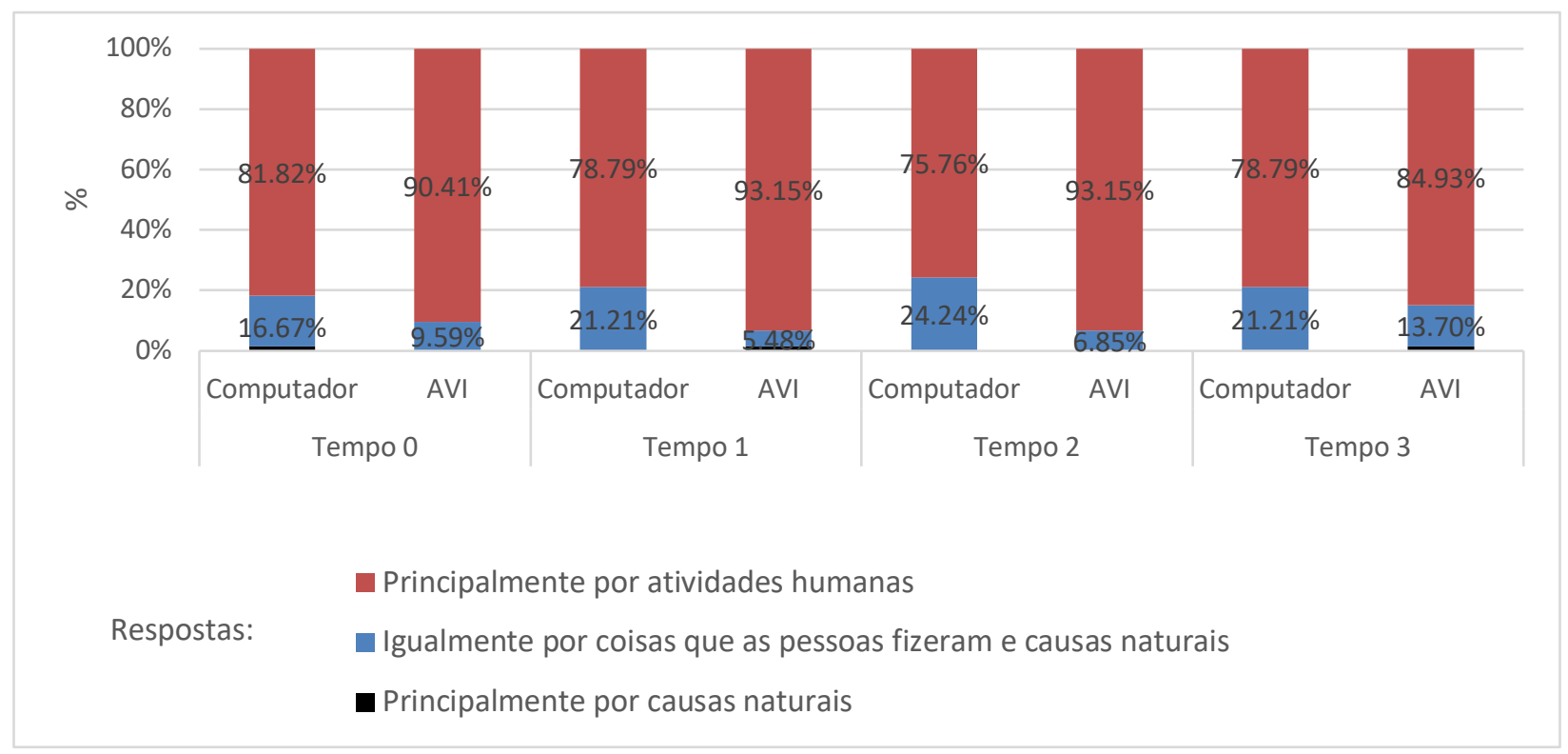

Figura 21. Porcentagem de respostas por condição e tempo para a questão: "Você acha que o aumento de dióxido de carbono na atmosfera foi causado por:"

Gravidade da acidificação do oceano. Foi encontrado um efeito significativo do tempo na avaliação das participantes da gravidade da acidificação do oceano, indicando que a percepção das participantes sobre a gravidade da OA aumentou após o tratamento, independentemente da condição $(\beta=0,08, \mathrm{t}(416)=3,81, p<0,001, \mathrm{IC} 95 \%[0,04,0,12], d=0,37)$. Não houve efeito significativo de interação da condição e do tempo $\left(X^{2}(3)=4,107 ; p=0,250\right.$, IC $95 \%[-0,11,0,07], d=0,20)$.

Controle da aprendizagem. Não foi encontrado efeito significativo do tempo $(\beta=-0,01, t$ $(416)=-0,95, p=0,343$, IC $95 \%[-0,04,0,01], d=-0,09)$ ou da condição $(\beta=0,09, t(137)=1,53$, $p=0,128$, IC $95 \%[-0,02,0,20], d=-0,26)$ na percepção de controle da aprendizagem pelas participantes. Nenhum efeito de interação da condição e do tempo foi encontrado $\left(X^{2}(1)=1,880\right.$; $p=0,170$, IC $95 \%[-0,02,0,10], d=0,23)$. 
Percepção de auto eficácia e motivação para aprender ciências. Houve um efeito marginalmente significativo da condição na percepção de auto eficácia $(\beta=-0,13, t(137)=1,85$, $p=0,067$, IC 95\% $[-0,01,0,27], d=0,32)$ com participantes na condição AVI apresentando pontuação maior do que participantes da condição computador após a intervenção (tempo 1 e tempo 2). Além disso, houve um efeito significativo do tempo na percepção de auto eficácia e motivação para aprender $(\beta=-0,03, \mathrm{t}(416)=-3,02, p=0,003, \mathrm{IC} 95 \%[-0,05,-0,01], d=-0,30)$, com uma ligeira diminuição na pontuação das participantes na condição computador após a intervenção. Nenhum efeito de interação da condição e do tempo na percepção de auto eficácia foi encontrado ao longo do tempo $\left(X^{2}(1)=0,0027 ; p=0,959\right.$, IC 95\% $\left.[-0,04,0,04], d=0,01\right)$.

Atitude em relação às disciplinas escolares. Médias e desvio padrão para cada item estão na Tabela 8.

Tabela 8. Médias e desvio padrão para os itens sobre atitudes em relação às disciplinas escolares

\begin{tabular}{|c|c|c|c|c|c|c|c|c|}
\hline \multirow{2}{*}{$\begin{array}{l}\text { Medidas / } \\
\text { Condições }\end{array}$} & \multicolumn{2}{|c|}{ Tempo 0} & \multicolumn{2}{|c|}{ Tempo 1} & \multicolumn{2}{|c|}{ Tempo 2} & \multicolumn{2}{|c|}{ Tempo 3} \\
\hline & $M$ & $D P$ & $M$ & $D P$ & $M$ & $D P$ & $M$ & $D P$ \\
\hline \multicolumn{9}{|c|}{ Ciências e Matemática } \\
\hline Computador & 3,72 & 0,66 & 3,71 & 0,69 & 3,72 & 0,74 & 3,7 & 0,78 \\
\hline AVI & 3,75 & 0,65 & 3,72 & 0,72 & 3,75 & 0,78 & 3,65 & 0,72 \\
\hline \multicolumn{9}{|l|}{ Humanidades } \\
\hline Computador & 3,66 & 0,64 & 3,74 & 0,72 & 3,77 & 0,71 & 3,81 & 0,71 \\
\hline AVI & 3,5 & 0,64 & 3,61 & 0,73 & 3,62 & 0,82 & 3,64 & 0,79 \\
\hline \multicolumn{9}{|l|}{ Artes } \\
\hline Computador & 4,2 & 0,96 & 4,19 & 1,06 & 4,16 & 1,13 & 4,13 & 1,04 \\
\hline AVI & 4,19 & 0,81 & 4,32 & 0,81 & 4,29 & 0,92 & 4,3 & 0,89 \\
\hline
\end{tabular}

Atitudes em relação a Ciências e Matemática. Houve um efeito significativo marginal do tempo $(\beta=0,04, \mathrm{t}(416)=-1,829, p=0,068, \mathrm{IC} 95 \%[-0,04,0,01], d=-0,18)$, com uma ligeira diminuição na pontuação das participantes nas duas condições após a intervenção. Nenhum 
efeito de interação entre condição e tempo foi encontrado $\left(X^{2}(1)=0,9681 ; p=0,325\right.$, IC95\% [$0,06,0,02], d=0,01)$.

Humanidades. Houve um efeito significativo do tempo nas atitudes das participantes em relação às humanidades $(\beta=0,04, \mathrm{t}(416)=3,95, \mathrm{p}<0,001, \mathrm{IC} 95 \%[0,02,0,07], d=0,39)$, com um aumento na pontuação das participantes em ambas condições após a intervenção. Não foi encontrado efeito de interação da condição e do tempo $\left(\left(X^{2}(1)=0,0752 ; p=0,784\right.\right.$, IC 95\% [$0,05,0,04]), d=0,05)$.

Artes (visuais e performance). Houve um efeito de interação marginalmente significativo da condição e do tempo nas atitudes das participantes em relação às artes $\left(\left(X^{2}(1)=3,3219 ; p=\right.\right.$ 0,068, IC 95\% $[-0,05,0,04], d=0,31)$, com um aumento na pontuação de participantes na condição AVI e uma diminuição na pontuação das participantes na condição computador após a intervenção (veja Tabela 8).

Análise de Mediação. Com intuito de expandir a investigação do estudo 1 sobre o mecanismo subjacente à relação entre as condições e os resultados para aprendizagem cognitiva e afetiva, foram realizadas análises de mediação causal com aproximação bayesiana e bootstrap não-paramétrico dos intervalos de confiança (Baron \& Kenny, 1986) nos tempos 1, 2 e 3. A condição foi usada como parâmetro preditor e em cada análise, presença, controle sobre a aprendizagem ou auto eficácia foram inseridos como mediadores no modelo. Avaliações de aprendizagem (questões de múltipla-escolha e questões abertas), percepção de auto eficácia ou atitudes em relação a ciências e matemática, humanidades e artes foram inseridos como parâmetro de resultados nos modelos de mediação. 
Os resultados mostraram que a presença mediou a relação entre condição e:

a) percepção de auto eficácia no tempo 1 ( $\mathrm{ACME}=0,20$, IC 95\% $[0,06 ; 0,36], \mathrm{p}=0,010)$ e tempo 2 ( $A C M E=0,29$, IC 95\% [0,08 0,50], $p=0,008)$;

b) controle sobre a aprendizagem no tempo $2(\mathrm{ACME}=0,00$, IC 95\% $[0,01 ; 0,35], \mathrm{p}=$ 0,032);

c) atitudes em relação à ciências e matemática no tempo 1 ( $\mathrm{ACME}=0,26$, IC 95\% [0,03; $0,49], p=0,018)$ e no tempo $2(A C M E=0,36$, IC 95\% $[0,06 ; 0,70], p=0,024)$.

A percepção de auto eficácia mostrou mediar a relação entre condição e:

a) aprendizagem (questões abertas) no tempo 1 (ACME $=0,09$, IC 95\% [0,01; 0,19], $p=$ $0,22$ ) e no tempo 2 ( $\mathrm{ACME}=0,05,95 \% \mathrm{Cl}[0 ; 0,13], \mathrm{p}=0,050)$;

b) controle sobre a aprendizagem no tempo 1 ( $\mathrm{ACME}=0,03$, IC 95\% $[0 ; 0,08], \mathrm{p}=0,046)$ e no tempo 2 (ACME =0,04, IC 95\% [0;0,09], $p=0,050)$;

c) atitudes em relação à ciências e matemática no tempo 1 ( $\mathrm{ACME}=0,14, \mathrm{IC} 95 \%[0,01$; $0,29], p=0,036)$ e no tempo 2 (ACME = 0,14, IC 95\% [0;0,3], $p=0,042)$;

d) atitudes em relação às humanidades no tempo 1 (ACME $=0,09$, IC 95\% [0; 0,02], $p=$ 0,048) e no tempo 2 ( $\mathrm{ACME}=0,11, \mathrm{IC} 95 \%[0,01 ; 0,25], \mathrm{p}=0,040)$. 


\section{Discussão}

Dois estudos foram conduzidos para comparar os efeitos da imersão sobre a aprendizagem cognitiva (conhecimento conceitual) e afetiva (percepção de auto eficácia). Participantes de uma escola de ensino fundamental II voltada para alunas (sexo feminino) aprenderam sobre o impacto dos seres humanos no oceano por meio de vídeos imersivos em 360 graus, usando óculos de RV ou através de vídeos tradicionais, usando um monitor de computador.

O estudo 1 encontrou uma diferença significativa na percepção de auto eficácia entre as condições ao longo do tempo (pré-teste e pós-teste), enquanto o estudo 2 encontrou um efeito marginal da condição e um efeito significativo do tempo na percepção de auto eficácia. A pontuação das participantes na condição AVI no questionário que avaliou a percepção de auto eficácia foi significativamente maior após a intervenção do que das participantes na condição computador, em ambos os estudos, o que suporta a hipótese 2.

Além disso, não houve efeito significativo da condição nos resultados da aprendizagem no estudo 1, indicando que a hipótese 1 foi confirmada e replicando o estudo de Makransky, Borre-Gude e Mayer (2019). Makransky e colegas compararam os efeitos de AVI com óculos de RV, simulações computacionais usando um computador e um manual de segurança impresso baseado em texto para aprendizagem e seus resultados também não mostraram diferença significativa entre as condições no pós-teste após a intervenção (questões de múltipla-escolha), mas mostraram uma diferença significativa favorecendo o grupo AVI ao que se refere a motivação intrínseca e percepção de auto eficácia (Makransky et al., 2019). 
Uma possível explicação é dada por Bandura (2018), que observou que atualmente as pessoas passam a maior parte do tempo no ambiente simbólico do mundo cibernético, o que nos permite transcender os limites do ambiente físico e social, que fornecem modelagem social. Segundo Bandura, esses modelos têm muito poder instrutivo, porque podem transmitir via meios de comunicação de massa novas formas de pensar e de se comportar para as pessoas em todo o mundo e proporcionar mais senso de controle, uma condição essencial para percepção de auto eficácia.

Esse impacto positivo da imersão na percepção de auto eficácia também pode ser devido aos efeitos positivos que a imersão demonstrou em estudos anteriores sobre aspectos afetivos da aprendizagem, como envolvimento e motivação (Bailenson et al., 2008; Makransky \& Lilleholt, 2018; Parong \& Mayer, 2018). Sabe-se que esses aspectos influenciam positivamente a percepção de auto eficácia (Bandura, 1995) e, portanto, podem mediar o impacto positivo dos ambientes imersivos sobre ela. Além disso, como apontado anteriormente, sentimentos de maior controle da situação também podem ser responsabilizados pela maior percepção de auto eficácia na condição AVI (Hite et al., 2019; Johnson-Glenberg, 2018).

Como controle e intenção de agir tem demonstrado envolver eficácia causal (David et al., 2008; Schlosser, 2012) esses aspectos podem ter contribuído para aumentar a percepção de auto eficácia na condição de AVI. Essas são ponderações a serem consideradas em pesquisas futuras. Embora os estudos que investigam o impacto do AVI na percepção de auto eficácia ainda sejam escassos, esses achados indicam o potencial dos impactos da imersão nos domínios afetivos da aprendizagem. Como Bandura $(1977,1995)$ afirmou, a percepção de auto eficácia influencia diretamente as atividades e ambientes escolhidos pelas pessoas. Além disso, a 
percepção de auto eficácia afeta diretamente a quantidade de esforço que as pessoas colocam e por quanto tempo elas persistem. Dessa forma, dada a correlação positiva da percepção de da auto eficácia com o desempenho acadêmico e profissional (Zimmerman, 2000), as abordagens educacionais que a desenvolvem nos alunos são de grande valor.

Como previsto, as participantes da condição AVI relataram sentimentos de presença mais intensos do que as participantes da condição computador nos estudos 1 e 2 , o que confirma a hipótese 3. Considerando os resultados variados na literatura sobre o nível de impacto da imersão na aprendizagem (Jensen \& Konradsen, 2017; Parong \& Mayer, 2018; Queiroz, Tori, et al., 2018) e para entender melhor como a presença afeta os domínios afetivos e cognitivos de aprendizagem, foram realizadas análises planejadas e a posteriori de mediação nos dois estudos. No estudo 2, o controle sobre a aprendizagem e as atitudes em relação às disciplinas escolares foram investigadas, a fim de expandir a relação entre condição e os resultados afetivos e cognitivos da aprendizagem.

Os resultados do estudo 1 mostraram que a presença mediou a pontuação das participantes nas perguntas abertas que avaliam o aprendizado e nas questões avaliando a percepção de auto eficácia. No estudo 2, presença mediou: a percepção de auto eficácia nos tempos 1 e 2 (logo após a intervenção); controle sobre a aprendizagem no tempo 2; e atitudes em relação à ciências e matemática nos tempos 1 e 2. Esses resultados confirmam a hipótese 4 de que a presença mediaria os resultados afetivos da aprendizagem.

Embora alguns estudos tenham relatado correlações entre AVI, presença, aprendizado e percepção de auto eficácia, após extensas revisões de literatura, verificou-se que este é o 
primeiro estudo que avalia o papel da presença como mediador do aprendizado no contexto de vídeos imersivos em 360 graus.

Uma análise de mediação a posteriori realizada no estudo 1 mostrou que a percepção de auto eficácia mediou a relação entre condição e aprendizagem (questões abertas), apoiando a hipótese 5. Esse resultado é replicado no estudo 2. Além disso, no estudo 2, as análises de mediação mostraram que a percepção de auto eficácia também mediou a percepção de controle sobre a aprendizagem, atitudes em relação à ciências e matemática e atitudes em relação às humanidades. Os resultados da mediação e o efeito positivo da condição AVI na percepção de auto eficácia lançam luz sobre como o uso de AVIs podem impactar os aspectos afetivos e cognitivos da aprendizagem.

Embora não tenha sido encontrado um efeito principal significativo ou efeito de interação da condição e do tempo na preocupação dos participantes com o oceano, o nível de imersão impactou significativamente as crenças das participantes sobre as causas da acidificação do oceano. Em ambos estudos, após a intervenção, uma parcela significativamente maior de participantes na condição AVI do que participantes na condição computador atribuiu as causas da acidificação do oceano às atividades humanas.

Considerando que dados que pesquisas anteriores mostraram que a população em geral desconhece o processo de acidificação do oceano (Capstick et al., 2016; Mossler et al., 2017), esses resultados oferecem evidências interessantes de que AVIs podem ser mais efetivos do que a mídia tradicional (por exemplo, vídeos televisivos) para aumentar a conscientização das pessoas sobre o impacto das atividades humanas no meio ambiente. 
Embora um aumento significativo tenha sido observado nos resultados para aprendizagem entre o pré-teste e o pós-teste nas condições AVI e computador em ambos os estudos, que indica que o material instrucional utilizado foi efetivo para a aprendizagem, não foi encontrada diferença significativa entre as condições nos resultados medidos pelas questões de múltipla-escolha. Esse resultado corrobora estudos anteriores que compararam os resultados de aprendizagem entre AVI usando óculos de RV e computador. Estes estudos também não encontraram diferença significativa para o aprendizado entre essas mídias (Moreno \& Mayer, 2002; Parong \& Mayer, 2018; Stepan et al., 2017).

No entanto, no estudo 2, um efeito significativo da condição foi encontrado na avaliação de aprendizado medido pelas questões abertas, com as participantes na condição AVI pontuando mais do que as participantes da condição computador após a intervenção.

Ao analisar o resultado da avaliação qualitativa da aprendizagem (questões abertas) de acordo com a taxonomia de Bloom, foi encontrado um efeito significativo da condição para os níveis cognitivos superiores - aplicação e criação de conhecimento - sendo que os participantes na condição AVI pontuaram significativamente mais do que as participantes na condição computador após a intervenção.

Essa constatação corrobora a afirmação de Bell e Fogler (1995) de que a realidade virtual é capaz de abordar níveis cognitivos superiores de aprendizado, como análise e avaliação, e contribui como uma investigação inicial sobre os impactos da imersão nos níveis cognitivos superiores da taxonomia de Bloom. A afirmação dos autores considera aspectos teóricos tanto da taxonomia de Bloom quanto da realidade virtual, e desde a publicação de sua pesquisa, não 
foram realizados estudos investigando o impacto da RV nos níveis cognitivos superiores da taxonomia de Bloom.

Em relação à investigação dos efeitos nível de imersão nos aspectos cognitivos e afetivos da aprendizagem no longo prazo, não foi encontrada diferença significativa entre as condições para qualquer medida avaliada no estudo 2 no pós-teste de retenção (tempo 3). Bernacki, NokesMalach e Aleven (2015) investigaram a estabilidade e a mudança da auto eficácia com alunos do ensino médio durante o aprendizado de matemática. Eles verificaram que a percepção de auto eficácia variava ao longo da tarefa de aprendizagem, o que é coerente com a afirmação teórica de Bandura (1986b) de que os alunos percebem sua eficácia com base em evidências passadas de seu desempenho ao concluir uma tarefa. No estudo 2, as alunas responderam perguntas avaliando o aprendizado logo após as sessões de intervenção e seis semanas após terem sido expostas ao material instrucional (teste de retenção). É possível que, porque elas podem ter esquecido parte do conteúdo em função do tempo decorrido entre a exposição e o teste de retenção, e por terem percebido que tiveram um desempenho melhor nas avaliações logo após a intervenção do que no teste de retenção, elas julgaram sua eficácia com base nessas evidências anteriores (pós-testes), o que pode ter levado à diminuição na sua percepção de auto eficácia no teste de retenção.

Além disso, a ausência de diferença significativa entre as condições nos aspectos afetivos e cognitivos da aprendizagem no teste de retenção corrobora o estudo de Stepan et al (2017) que comparou $\mathrm{AVI}$ e materiais computacionais para aprendizagem de neuro anatomia. Em seu estudo, os participantes aprenderam sobre o sistema ventricular e o cérebro usando AVI ou livros on-line. Medidas de aprendizado e motivação foram investigadas antes, logo após e 8 semanas 
após as sessões de tratamento. Não foi encontrada diferença significativa para a avaliação da aprendizagem entre as condições ao longo do tempo, tampouco no teste de retenção.

Finalmente, os resultados da presente pesquisa sugerem que, embora os impactos da imersão tenham sido imediatos ao tratamento da experiência em RV, eles não persistem ao longo do tempo. Eles também sugerem que, para se beneficiar dos impactos positivos da imersão nos aspectos afetivos e cognitivos da aprendizagem, deve-se considerar mais do que uma única exposição ao AVI. Os resultados são coerentes com estudos anteriores que investigam o nível de impacto de imersão nos domínios afetivos da aprendizagem e o presente estudo inova ao mostrar o efeito da mediação da presença e auto eficácia nas dimensões cognitivas e afetivas da aprendizagem. Isso é importante à luz de uma sociedade em mudança, na qual o uso da tecnologia está aumentando rapidamente e os dispositivos continuam a aumentar o nível de imersão digital constantemente. 


\section{Limitações e estudos futuros}

Esta pesquisa comparou os impactos das experiências em ambientes virtuais imersivos em computador nos resultados de aprendizagem afetiva e cognitiva. Dois estudos foram realizados e avaliaram o nível de impactos de imersão na aprendizagem, percepção de auto eficácia, controle da aprendizagem, presença, atitudes em relação às disciplinas escolares e à saúde dos oceanos. Os resultados deste estudo são encorajadores, entretanto, existem algumas limitações que precisam ser mencionadas.

Primeiro, apesar de as participantes terem sido aleatoriamente designadas para cada condição, houve uma diferença significativa entre as condições no pré-teste no estudo 1 para algumas das variáveis medidas. Um método estatístico que considera as diferenças pré-teste foi selecionado para analisar adequadamente os dados. No entanto, isso não descarta a possibilidade de interferência nos resultados durante o pós-teste.

Para superar essa limitação, um segundo estudo foi realizado utilizando uma distribuição aleatória pareada, bem como uma amostra maior. Esta estratégia se mostrou efetiva e não houve diferenças entre as condições no pré-teste para nenhuma das variáveis investigadas no estudo 2.

Segundo, as participantes dos dois estudos eram estudantes de uma escola situada em um bairro de classe média alta nos Estados Unidos. Portanto, esses achados devem ser considerados com cuidado quanto à sua aplicação em outras populações.

Por fim, avaliar a aprendizagem por meio de perguntas de múltipla escolha e questões abertas apresenta algumas limitações inerentes. Embora as perguntas de múltipla escolha sejam consideradas práticas comuns nas avaliações de aprendizagem, isso pode trazer alguma 
imprecisão devido à extensa prática dos alunos em responder a esse tipo de perguntas. A pontuação de algumas alunas pode ter sido mais afetada por sua capacidade de identificar a resposta correta mais provável do que por ter aprendido sobre o conteúdo apresentado.

Para reduzir esse impacto, foram usadas também perguntas abertas para avaliar o aprendizado. No entanto, mesmo questões abertas têm limitações, principalmente porque, em última análise, dependem de pontuação subjetiva. Um gabarito baseado na teoria do pensamento crítico foi desenvolvido e classificações de pontuação foram usados. Ainda, numa tentativa de reduzir a subjetividade da correção, as questões foram corrigidas por pesquisadores da área e a nota final foi um consenso entre os pesquisadores. Adicionalmente, para reduzir possíveis efeitos de fadiga, no estudo 2 a intervenção foi dividida em duas sessões de 45 minutos, ao invés de uma única sessão de 90 minutos, com foi feito no estudo 1.

Estudos futuros devem levar essas limitações em consideração e é sugerido considerar uma população mais diversificada, múltiplas exposições ao AVI e usar vários métodos de avaliação da aprendizagem, a fim de melhorar a generalização desses achados. Ainda, devido a escassez de pesquisas investigando os efeitos a longo prazo da imersão na aprendizagem, sugere-se que estudos futuros incluam investigações de longo prazo sobre os impactos da imersão na aprendizagem.

Finalmente, apesar dessas limitações, esses achados fornecem evidências encorajadoras dos impactos da imersão nos domínios cognitivos e afetivos da aprendizagem. 


\section{Conclusão}

A presente pesquisa comparou os impactos de experiências em RV utilizando vídeos imersivos em 360 graus com uso de óculos de realidade virtual com experiências usando um computador sobre aspectos afetivos e cognitivos da aprendizagem. Dois estudos foram realizados e avaliaram o impacto do nível de imersão na aprendizagem de conceitos, percepção de auto eficácia, controle sobre a aprendizagem, presença, atitudes em relação às disciplinas escolares e crenças e preocupações em relação ao oceano.

Esses estudos mostraram que o nível de imersão afetou significativamente a percepção de auto eficácia em ambos estudos, com as participantes na condição imersiva relatando maior auto eficácia após a intervenção do que as participantes que usaram um computador.

Com o objetivo de investigar como o nível de imersão afeta os aspectos afetivos e cognitivos da aprendizagem, foram realizadas análises de mediação que demonstraram que a presença e a percepção de auto eficácia foram mediadoras dos aspectos afetivos e cognitivos da aprendizagem. Esses achados corroboram e expandem estudos anteriores e sugerem o papel de ambientes virtuais imersivos na educação, particularmente sobre os impactos dos ambientes imersivos nos aspectos afetivos da aprendizagem. 


\section{Referências Bibliográficas}

Adamo-Villani, N., \& Wilbur, R. B. (2008). Effects of platform (immersive versus non-immersive) on usability and enjoyment of a virtual learning environment for deaf and hearing children. Proc. of EGVE, 8-19.

Alhalabi, W. (2016). Virtual reality systems enhance students' achievements in engineering education. Behaviour \& Information Technology, 35(11), 919-925.

Alperstedt, C. (2001). Universidades corporativas: discussão e proposta de uma definição. Revista de Administração Contemporânea, 5(3), 149-165.

Anderson, J. R. (1982). Acquisition of cognitive skill. Psychological Review, 89(4), 369.

Anderson, L. W., Krathwohl, D. R., Airasian, P. W., Cruikshank, K. A., Mayer, R. E., Pintrich, P. R., Raths, J., \& Wittrock, M. C. (2001). A taxonomy for learning, teaching, and assessing: A revision of Bloom's taxonomy of educational objectives, abridged edition. White Plains, NY: Longman.

Anderson, S. P., Waldfogel, J., \& Stromberg, D. (2016). Handbook of Media Economics, vol $1 A$. Elsevier.

Andre, T., Whigham, M., Hendrickson, A., \& Chambers, S. (1999). Competency beliefs, positive affect, and gender stereotypes of elementary students and their parents about science versus other school subjects. Journal of Research in Science Teaching: The Official Journal of the National Association for Research in Science Teaching, 36(6), 719-747.

Arruda, E. P. (2013). Ensino e aprendizagem na sociedade do entretenimento: desafios para a formação docente. Educação, 36(2).

Ary, D., Jacobs, L. C., Irvine, C. K. S., \& Walker, D. (2013). Introduction to research in education. Cengage Learning.

Associação Brasileira de Educação a Distância. (2015). Censo EAD. BR: Relatório Analítico da 
Aprendizagem a Distância no Brasil 2015. Abed.

Ausubel, D. P. (1982). A aprendizagem significativa. São Paulo: Moraes.

Azuma, R., Baillot, Y., Behringer, R., Feiner, S., Julier, S., \& Maclntyre, B. (2001). Recent advances in augmented reality. IEEE Computer Graphics and Applications, 21(6), 34-47.

Bailenson, J.N., Swinth, K., Hoyt, C., Persky, S., Dimov, A., \& Blascovich, J. (2005). The independent and interactive effects of embodied-agent appearance and behavior on self-report, cognitive, and behavioral markers of copresence in immersive virtual environments. Presence: Teleoperators and Virtual Environments, 14(4), 379-393. https://doi.org/10.1162/105474605774785235

Bailenson, Jeremy N, Yee, N., Blascovich, J., Beall, A. C., Lundblad, N., \& Jin, M. (2008). The use of immersive virtual reality in the learning sciences: Digital transformations of teachers, students, and social context. The Journal of the Learning Sciences, 17(1), 102-141.

Bailey, J. O., \& Bailenson, J. N. (2018). Immersive Virtual Reality and the Developing Child. In Cognitive Development in Digital Contexts (pp. 181-200). Elsevier.

Baker, C. W., Little, T. D., \& Brownell, K. D. (2003). Predicting adolescent eating and activity behaviors: the role of social norms and personal agency. Health Psychology, 22(2), 189.

Baker, R. S., Clarke-Midura, J., \& Ocumpaugh, J. (2016a). Towards general models of effective science inquiry in virtual performance assessments. Journal of Computer Assisted Learning, 32(3), 267-280. https://doi.org/10.1111/jcal.12128

Baker, R. S., Clarke-Midura, J., \& Ocumpaugh, J. (2016b). Towards general models of effective science inquiry in virtual performance assessments. Journal of Computer Assisted Learning, 32(3), 267-280. https://doi.org/10.1111/jcal.12128

Bandura, A. (1977). Self-efficacy: toward a unifying theory of behavioral change. Psychological Review, 84(2), 191.

Bandura, A. (1986a). Social foundations of thought and action. Englewood Cliffs, NJ, 1986, 23-28. 
Bandura, A. (1986b). The explanatory and predictive scope of self-efficacy theory. Journal of Social and Clinical Psychology, 4(3), 359-373.

Bandura, A. (1995). Self-efficacy in changing societies. Cambridge university press.

Bandura, A. (2018). Toward a psychology of human agency: Pathways and reflections. Perspectives on Psychological Science, 13(2), 130-136.

Bandura, A., \& Cervone, D. (1986). Differential engagement of self-reactive influences in cognitive motivation. Organizational Behavior and Human Decision Processes, 38(1), 92-113.

Bandura, A., Freeman, W. H., \& Lightsey, R. (1999). Self-efficacy: The exercise of control. Springer.

Barbosa, D. N. F., Bassani, P. B. S., Martins, R. L., \& Maciel, B. L. (2015). Experiências com o uso de Tablets no contexto da Educação escolar e não escolar. Revista Prâksis, 2, 67-80.

Barfield, W. (2015). Fundamentals of wearable computers and augmented reality (2nd ed.). Kindle Edition.

Baron, R. M., \& Kenny, D. A. (1986). The moderator--mediator variable distinction in social psychological research: Conceptual, strategic, and statistical considerations. Journal of Personality and Social Psychology, 51(6), 1173.

Bates, D., Mächler, M., Bolker, B., \& Walker, S. (2014). Fitting linear mixed-effects models using Ime4. ArXiv Preprint ArXiv:1406.5823.

Bell, J. T., \& Fogler, H. S. (1995). The investigation and application of virtual reality as an educational tool. Proceedings of the American Society for Engineering Education Annual Conference, 1718-1728.

Belloni, M. L. (2001). Educação a distância. 5ª Campinas: Autores Associados.

Bergey, B. W., Ketelhut, D. J., Liang, S., Natarajan, U., \& Karakus, M. (2015). Scientific Inquiry SelfEfficacy and Computer Game Self-Efficacy as Predictors and Outcomes of Middle School Boys' and Girls' Performance in a Science Assessment in a Virtual Environment. Journal of 
Science Education and Technology, 24(5), 696-708. https://doi.org/10.1007/s10956-0159558-4

Bernacki, M. L., Nokes-Malach, T. J., \& Aleven, V. (2015). Examining self-efficacy during learning: variability and relations to behavior, performance, and learning. Metacognition and Learning, 10(1), 99-117.

Bessa, J., Barreira, J., Faria, N., Martins, J., Barbosa, L., \& Bessa, M. (2016). Immersive virtual environments of simulation for exposure therapy: Impact of multi-sensory stimulation in the sense of presence in an acrophobic context | Criação de Ambientes Virtuais de Simulação Imersivos para Terapia de Exposição Impacto da Estimulaçã. Iberian Conference on Information Systems and Technologies, CISTI, 2016-July. https://doi.org/10.1109/CISTI.2016.7521593

Biocca, F., \& Delaney, B. (1995). Immersive virtual reality technology. Communication in the Age of Virtual Reality, 57-124.

Blascovich, J., Loomis, J., Beall, A. C., Swinth, K. R., Hoyt, C. L., \& Bailenson, J. N. (2002a). Immersive virtual environment technology as a methodological tool for social psychology. Psychological Inquiry, 13(2), 103-124.

Blascovich, J., Loomis, J., Beall, A. C., Swinth, K. R., Hoyt, C. L., \& Bailenson, J. N. (2002b). Immersive Virtual Environment Technology as a Methodological Tool for Social Psychology. Psychological Inquiry, 13(2), 103-124. https://doi.org/10.1207/S15327965PLI1302_01

Bloom, B. S., \& others. (1956). Taxonomy of educational objectives. Vol. 1: Cognitive domain. New York: McKay, 20, 24.

Bonamino, A., \& Sousa, S. Z. (2012). Três gerações de avaliação da educação básica no. Educação e Pesquisa, 38(2), 373-388.

Bordenave, J. D., \& Pereira, A. M. (2000). organizadores. O que é ensinar. Estratégias de EnsinoAprendizagem. Petrópolis: Vozes, 39-57. 
Boruchovitch, E. (1994). As variáveis Psicológicas e o processo de aprendizagem: uma contribuição. Psic: Teor e Pesq, 10(1), 129-139.

Boruchovitch, E. (1999). Estratégias de aprendizagem e desempenho escolar: considerações para a prática educacional. Psicologia: Reflexão e $\operatorname{Cr}\left\{\left.\right|^{\prime} \mid i\right\} t i c a, 12(2)$.

Boruchovitch, E. (2006). Avaliação psicoeducacional: desenvolvimento de instrumentos à luz da psicologia cognitiva na teoria do processamento da informação. Avaliaçao Psicologica: Interamerican Journal of Psychological Assessment, 5(2), 145-152.

Bricken, M. (1991). Virtual reality learning environments: potentials and challenges. ACM SIGGRAPH Computer Graphics, 25(3), 178-184.

Brill, J. M., \& Park, Y. (2008). Facilitating engaged learning in the interaction age taking a pedagogically-disciplined approach to innovation with emergent technologies. International Journal of Teaching and Learning in Higher Education, 20(1), 70-78.

Brooks, B. M., \& Rose, F. D. (2003). The use of virtual reality in memory rehabilitation: Current findings and future directions. NeuroRehabilitation, 18(2), 147-157.

Brown, D. J., Kerr, S., \& Wilson, J. R. (1997). Virtual environments in special-needs education. Communications of the ACM, 40(8), 72-75.

Burke, B., Cearley, D. W., \& Blau, B. (2018). Top 10 Strategic Technology Trends for 2018: Immersive Experience. In Top 10 Strategic Technology Trends for 2018: Immersive Experience. https://www.gartner.com/doc/3867163/top--strategic-technology-trends

Campbell, D. T., \& Stanley, J. C. (2015). Experimental and quasi-experimental designs for research. Ravenio Books.

Campbell, I. (2007). Chi-squared and Fisher--Irwin tests of two-by-two tables with small sample recommendations. Statistics in Medicine, 26(19), 3661-3675.

Capstick, S. B., Pidgeon, N. F., Corner, A. J., Spence, E. M., \& Pearson, P. N. (2016). Public understanding in Great Britain of ocean acidification. Nature Climate Change, 6(8), 763-767. 
Casu, A., Spano, L. D., Sorrentino, F., \& Scateni, R. (2015). RiftArt: Bringing Masterpieces in the Classroom through Immersive Virtual Reality. Eurographics Italian Chapter Conference, 7784.

Chaddad, J. M. A., \& Andreassi, T. (2002). O vetor da academia-empresa para o incremento da inovação tecnológica. Revista Univap, São José Dos Campos, 9(17), 78-84.

Cheng, Y., Huang, C.-L., \& Yang, C.-S. (2015). Using a 3D immersive virtual environment system to enhance social understanding and social skills for children with autism spectrum disorders. Focus on Autism and Other Developmental Disabilities, 30(4), 222-236.

Cidrim, L., \& Madeiro, F. (2017). Tecnologias da Informação e da Comunicação (TIC) aplicadas à dislexia: revisão de literatura. Revista CEFAC, 19(1), 99-108.

Cohen-Bendahan, C. C. C., Beijers, R., van Doornen, L. J. P., \& de Weerth, C. (2015). Explicit and implicit caregiving interests in expectant fathers: Do endogenous and exogenous oxytocin and vasopressin matter? Infant Behavior and Development, 41, 26-37. https://doi.org/10.1016/j.infbeh.2015.06.007

Cohen, D., Sevdalis, N., Taylor, D., Kerr, K., Heys, M., Willett, K., Batrick, N., \& Darzi, A. (2013). Emergency preparedness in the 21st century: Training and preparation modules in virtual $\begin{array}{llll}\text { environments. } & \text { Resuscitation, } & \text { 84(1), }\end{array}$ https://doi.org/10.1016/j.resuscitation.2012.05.014

Cohen, Daniel, Sevdalis, N., Taylor, D., Kerr, K., Heys, M., Willett, K., Batrick, N., \& Darzi, A. (2013). Emergency preparedness in the 21st century: Training and preparation modules in virtual environments. $\quad$ Resuscitation, 84(1), 78-84. https://doi.org/https://doi.org/10.1016/j.resuscitation.2012.05.014

Coll, C. (2008). Psicología de la educación virtual: aprender y enseñar con las tecnologías de la información y la comunicación. Ediciones Morata.

Coll, C., \& Monereo, C. (2010). Psicologia da Educação Virtual: Aprender e ensinas com as tecnologias da informação e da comunicação. Artmed Editora. 
Collins, J.-D., Markham, A., Service, K., Reini, S., Wolf, E., \& Sessoms, P. (2015). A systematic literature review of the use and effectiveness of the Computer Assisted Rehabilitation Environment for research and rehabilitation as it relates to the wounded warrior. Work, 50(1), 121-129. https://doi.org/10.3233/WOR-141927

Colombo, S., \& Golzio, L. (2016). The Plant Simulator as viable means to prevent and manage risk through competencies management: Experiment results. Safety Science, 84, 46-56. https://doi.org/10.1016/j.ssci.2015.11.021

Colombo, S., Nazir, S., \& Manca, D. (2014). Immersive virtual reality for training and decision making: Preliminary results of experiments performed with a plant simulator. SPE Economics and Management, 6(4), 165-172. https://doi.org/10.2118/164993-PA

Colombo, S., Nazir, S., \& Manca, D. (2013). Virtual reality as effective tool for training and decision-making: Preliminary results of experiments performed with a plant simulator. Society of Petroleum Engineers - SPE European HSE Conference and Exhibition 2013: Health, Safety, Environment and Social Responsibility in the Oil and Gas Exploration and Production Industry, 405-416.

Colombo, Simone, \& Golzio, L. (2016). The Plant Simulator as viable means to prevent and manage risk through competencies management: Experiment results. Safety Science, 84, 46-56. https://doi.org/https://doi.org/10.1016/j.ssci.2015.11.021

Cook, A. V, Jones, R., Raghavan, A., \& Saif, I. (2017). Digital reality: The focus shifts from technology to opportunity. In Digital reality: The focus shifts from technology to opportunity. https://www2.deloitte.com/insights/us/en/focus/tech-trends/2018/immersivetechnologies-digital-reality.html

Cope, B., \& Kalantzis, M. (2016). Big data comes to school: Implications for learning, assessment, and research. AERA Open, 2(2), 2332858416641907.

Cozby, P. C. (2003). Métodos de pesquisa em ciências do comportamento. Atlas.

Crompton, H., Burke, D., Gregory, K. H., \& Gräbe, C. (2016). The use of mobile learning in science: 
A systematic review. Journal of Science Education and Technology, 25(2), 149-160.

Cummings, J. J., \& Bailenson, J. N. (2016). How immersive is enough? A meta-analysis of the effect of immersive technology on user presence. Media Psychology, 19(2), 272-309.

Dalgarno, B., \& Lee, M. J. W. (2010). What are the learning affordances of 3-D virtual environments? British Journal of Educational Technology, 41(1), 10-32.

Darsie, M. M. P. (1996). Avaliação e aprendizagem. Cadernos de Pesquisa, 99, 47-59.

Das, R. C. (2016). Handbook of Research on Global Indicators of Economic and Political Convergence. IGI Global.

David, N., Newen, A., \& Vogeley, K. (2008). The "sense of agency" and its underlying cognitive and neural mechanisms. Consciousness and Cognition, 17(2), 523-534.

Dawley, L., \& Dede, C. (2014). Situated learning in virtual worlds and immersive simulations. In Handbook of research on educational communications and technology (pp. 723-734). Springer.

Dede, C. (2009). Immersive interfaces for engagement and learning. Science, 323(5910), 66-69.

Dede, C. (2010). Comparing frameworks for 21st century skills. 21st Century Skills: Rethinking How Students Learn, 20, 51-76.

Dede, C., Grotzer, T. A., Kamarainen, A., \& Metcalf, S. (2017). EcoXPT: Designing for Deeper Learning through Experimentation in an Immersive Virtual Ecosystem. Journal of Educational Technology \& Society, 20(4), 166-178. http://www.jstor.org/stable/26229215

Dede, C., Salzman, M., Loftin, R. B., \& Ash, K. (1997). Using virtual reality technology to convey abstract scientific concepts. Learning the Sciences of the 21st Century: Research, Design, and Implementing Advanced Technology Learning Environments. Lawrence Erlbaum: Hillsdale, NJ.

Earnshaw, R. A. (2014). Virtual reality systems. Academic press. 
Eden, S., \& Passig, D. (2007). Three-dimensionality as an effective mode of representation for expressing sequential time perception. Journal of Educational Computing Research, 36(1), 51-63.

Edmans, J., Gladman, J., Hilton, D., Walker, M., Sunderland, A., Cobb, S., Pridmore, T., \& Thomas, S. (2009). Clinical evaluation of a non-immersive virtual environment in stroke rehabilitation. Clinical Rehabilitation, 23(2), 106-116. https://doi.org/10.1177/0269215508095875

Edwards, A. J., Weinstein, C. E., Goetz, E. T., \& Alexander, P. A. (2014). Learning and study strategies: Issues in assessment, instruction, and evaluation. Elsevier.

Fauville, G., Strang, C., Cannady, M. A., \& Chen, Y.-F. (2019). Development of the International Ocean Literacy Survey: measuring knowledge across the world. Environmental Education Research, 25(2), 238-263.

Fino, C. N., \& Sousa, J. M. (2018). As TIC redesenhando as fronteiras do currículo. Revista Educação e Cultura Contemporânea, 2(3), 53-66.

Fischer, R. M. B. (2017). Televisão \& educação-fruir e pensar a tv. Autêntica.

Fowler, C. (2015). Virtual reality and learning: Where is the pedagogy? British Journal of Educational Technology, 46(2), 412-422.

Freina, L., \& Ott, M. (2015). A literature review on immersive virtual reality in education: state of the art and perspectives. The International Scientific Conference ELearning and Software for Education, 1, 133.

Gelsomini, M. (2016). An Affordable Virtual Reality Learning Framework for Children with NeuroDevelopmental Disorder. Proceedings of the 18th International ACM SIGACCESS Conference on Computers and Accessibility, 343-344. https://doi.org/10.1145/2982142.2982143

Gerbase, C. (2006). Desafios na construção de uma estética audiovisual para educação à distância (EAD). Logos, 13(1), 68-76.

Gérin-Lajoie, M., Richards, C. L., Fung, J., \& McFadyen, B. J. (2008). Characteristics of personal 
space during obstacle circumvention in physical and virtual environments. Gait and Posture, 27(2), 239-247. https://doi.org/10.1016/j.gaitpost.2007.03.015

Gipps, C. (1994). Developments in Educational Assessment: what makes a good test? Assessment in Education: Principles, Policy \& Practice, 1(3), 283-292.

Gipps, C. (1998). Student assessment and learning for a changing society. Prospects, 28(1), 31.

Gonzalez-Franco, M., \& Peck, T. C. (2018). Avatar embodiment. towards a standardized questionnaire. Frontiers in Robotics and Al, 5, 74.

Gouvêa, A. R. (2006). Comunicação, educação e mídia. Por um ensino motivador e alegre: estudo de caso da EE Godofredo Furtado. Comunicação \& Educação, 11(1), 101-112.

Guarino, B. (2016). VR Age Limits Are Where Risk Aversion, Bad Science, and Legit Worries Meet. Inverse. https://www.inverse.com/article/12648-vr-age-limits-are-where-risk-aversionbad-science-and-legit-worries-meet

Häfner, P., Häfner, V., \& Ovtcharova, J. (2014). Experiencing Physical and Technical Phenomena in Schools Using Virtual Reality Driving Simulator. In P. Zaphiris \& A. Ioannou (Eds.), Learning and Collaboration Technologies. Technology-Rich Environments for Learning and Collaboration (pp. 50-61). Springer International Publishing.

Harris, K. R., Graham, S., MacArthur, C., Reid, R., \& Mason, L. H. (2011). Self-regulated learning processes and children's writing. Handbook of Self-Regulation of Learning and Performance, 187-202.

Hew, K. F., \& Cheung, W. S. (2010). Use of three-dimensional (3-D) immersive virtual worlds in K12 and higher education settings: A review of the research. British Journal of Educational Technology, 41(1), 33-55.

Hite, R. L., Jones, M. G., Childers, G. M., Ennes, M., Chesnutt, K., Pereyra, M., \& Cayton, E. (2019). Investigating Potential Relationships Between Adolescents' Cognitive Development and Perceptions of Presence in 3-D, Haptic-Enabled, Virtual Reality Science Instruction. Journal 
of Science Education and Technology, 28(3), 265-284.

Hoffman, H. G., Patterson, D. R., Magula, J., Carrougher, G. J., Zeltzer, K., Dagadakis, S., \& Sharar, S. R. (2004). Water-Friendly Virtual Reality Pain Control during Wound Care. Journal of Clinical Psychology, 60(2), 189-195. https://doi.org/10.1002/jclp.10244

Hsin, C.-T., Li, M.-C., \& Tsai, C.-C. (2014). The influence of young children's use of technology on their learning: A review. Educational Technology and Society, 17(4), 85-99.

Huang, Xianwei, Naghdy, F., Naghdy, G., Du, H., \& Todd, C. (2018). The Combined Effects of Adaptive Control and Virtual Reality on Robot-Assisted Fine Hand Motion Rehabilitation in Chronic Stroke Patients: A Case Study. Journal of Stroke and Cerebrovascular Diseases, 27(1), 221-228. https://doi.org/https://doi.org/10.1016/j.jstrokecerebrovasdis.2017.08.027

Huang, Xiaoxia, \& Mayer, R. E. (2019). Adding self-efficacy features to an online statistics lesson. Journal of Educational Computing Research, 57(4), 1003-1037.

Huang, Y., Churches, L., \& Reilly, B. (2015). A case study on virtual reality American football training. Proceedings of the 2015 Virtual Reality International Conference, 6.

IBGE, I. B. de G. (2011). IBGE | Séries Estatísticas \& Séries Históricas | educação | eficiência do sistema de ensino e rendimento escolar | Aprovação, reprovação e abandono - Ensino Fundamental (série nova) | 2007-2010. In IBGE / Séries Estatísticas \& Séries Históricas / sistema de contas nacionais / contas trimestrais - Produto Interno Bruto / Produto Interno Bruto Variação em volumetaxa trimestral l 1996.1-2016.1. http://seriesestatisticas.ibge.gov.br/series.aspx?t=aprovacao-reprovacao-e-abandonoensino-fundamental-serie-nova\&vcodigo=M101

Jensen, L., \& Konradsen, F. (2017). A review of the use of virtual reality head-mounted displays in education and training. Education and Information Technologies, 1-15.

Jensen, L., \& Konradsen, F. (2018). A review of the use of virtual reality head-mounted displays in education and training. Education and Information Technologies, 23(4), 1515-1529. 
Jerald, J. (2015). The VR book: Human-centered design for virtual reality. Morgan \& Claypool.

Jia, D., Bhatti, A., \& Nahavandi, S. (2014). The impact of self-efficacy and perceived system efficacy on effectiveness of virtual training systems. Behaviour \& Information Technology, $33(1), 16-35$.

Jiang, Y., Clarke-Midura, J., Baker, R. S., Paquette, L., \& Keller, B. (2018). How immersive virtual environments foster self-regulated learning. In Digital Technologies and Instructional Design for Personalized Learning. https://doi.org/10.4018/978-1-5225-3940-7.ch002

Johnson-Glenberg, M. C. (2018). Immersive VR and education: Embodied design principles that include gesture and hand controls. Frontiers in Robotics and Al, 5, 81.

Jouriles, E. N., Rosenfield, D., Yule, K., Sargent, K. S., \& McDonald, R. (2016). Predicting HighSchool Students' Bystander Behavior in Simulated Dating Violence Situations. Journal of Adolescent Health, 58(3), 345-351. https://doi.org/10.1016/j.jadohealth.2015.11.009

Judge, T. A., Erez, A., Bono, J. E., \& Thoresen, C. J. (2002). Are measures of self-esteem, neuroticism, locus of control, and generalized self-efficacy indicators of a common core construct? Journal of Personality and Social Psychology, 83(3), 693.

Kalawsky, R. S. (1993). The science of virtual reality and virtual environments: a technical, scientific and engineering reference on virtual environments. Addison-wesley Workingham.

Kamarainen, A. M., Thompson, M., Metcalf, S. J., Grotzer, T. A., Tutwiler, M. S., \& Dede, C. (2018). Prompting connections between content and context: Blending immersive virtual environments and augmented reality for environmental science learning. In Communications in Computer and Information Science (Vol. 840). https://doi.org/10.1007/978-3-319-93596-6_3

Kanfer, R., \& Ackerman, P. L. (1989). Motivation and cognitive abilities: An integrative/aptitudetreatment interaction approach to skill acquisition. Journal of Applied Psychology, 74(4), 657. 
Karabulut-Ilgu, A., Jaramillo Cherrez, N., \& Jahren, C. T. (2018). A systematic review of research on the flipped learning method in engineering education. British Journal of Educational Technology, 49(3), 398-411.

Ketelhut, D. J., Nelson, B., Bergey, B., \& Ryu, M. (2014a). Design and gender in immersive learning environments. Proceedings of the European Conference on Games-Based Learning, 1, 265271.

Ketelhut, D. J., Nelson, B., Bergey, B., \& Ryu, M. (2014b). Design and gender in immersive learning environments. In B. C. (Ed.), Proceedings of the European Conference on Games-based Learning (Vol. 1, pp. 265-271). Dechema e.V. https://www.scopus.com/inward/record.uri?eid=2-s2.084923558075\&partnerID=40\&md5=1d1ac51d20ea42e319c409574ff1d7e7

Ketelhut, D. J., Nelson, B. C., Schifter, C. C., \& Kim, Y. (2010). Using immersive virtual environments to assess science content understanding: The impact of context. Proceedings of the IADIS International Conference on Cognition and Exploratory Learning in the Digital Age, CELDA 2010, 227-230.

Ketelhut, D. J., \& Shelton, A. (2012). Using immersive virtual environments to assess science understanding: The impact of contextualization. Proceedings of the European Conference on Games-Based Learning.

Krathwohl, D. R. (2002). A revision of Bloom's taxonomy: An overview. Theory into Practice, 41(4), 212-218.

Kuo, Y.-C., Walker, A. E., Schroder, K. E. E., \& Belland, B. R. (2014). Interaction, Internet selfefficacy, and self-regulated learning as predictors of student satisfaction in online education courses. The Internet and Higher Education, 20, 35-50.

Ladendorf, K., Schneider, D., \& Xie, Y. (2019). Mobile-based virtual reality: Why and how does it support learning. Handbook of Mobile Teaching and Learning. Springer: New York.

Lányi, C. S., Geiszt, Z., Karolyi, P., Tilinger, Á., \& Magyar, V. (2006). Virtual reality in special needs 
early education. The International Journal of Virtual Reality, 5(4), 55-68.

Lee, J.-S. (2014). The Relationship Between Student Engagement and Academic Performance: Is It a Myth or Reality? The Journal of Educational Research, 107(3), 177-185. https://doi.org/10.1080/00220671.2013.807491

Lemos, A., \& Perl, L. (2015). Comunicação e Tecnologia Uma experiência de "Classe Invertida." Comunicação \& Educação, 20(1), 127-139.

Lévy, P., \& Bononno, R. (1998). Becoming virtual: Reality in the digital age. Da Capo Press, Incorporated.

Li, B. J., Bailenson, J. N., Pines, A., Greenleaf, W. J., \& Williams, L. M. (2017). A Public Database of Immersive VR Videos with Corresponding Ratings of Arousal, Valence, and Correlations between Head Movements and Self Report Measures. Frontiers in Psychology, 8.

Libâneo, J. C. (2001). Pedagogia e pedagogos: inquietações e buscas. Educar Em Revista, 17, 153176.

Libâneo, J. C., \& Alves, N. (2017). Temas de Pedagogia: Diálogios entre didática e currículo. Cortez Editora.

Linnenbrink, E. A., \& Pintrich, P. R. (2003). The role of self-efficacy beliefs instudent engagement and learning intheclassroom. Reading \&Writing Quarterly, 19(2), 119-137.

Luckesi, C. C. (2014). Avaliação da aprendizagem escolar: estudos e proposições. Cortez editora.

Lüdke, M., \& da Cruz, G. B. (2005). Aproximando universidade e escola de educação básica pela pesquisa. Cadernos de Pesquisa, 35(125), 81-109.

Maddux, J. E. (2016). Self-efficacy interpersonal and intrapersonal expectancies. Abingdon: Routledge.

Makransky, G., Borre-Gude, S., \& Mayer, R. E. (2019). Motivational and cognitive benefits of training in immersive virtual reality based on multiple assessments. Journal of Computer 
Assisted Learning, 35(6), 691-707.

Makransky, G., \& Lilleholt, L. (2018). A structural equation modeling investigation of the emotional value of immersive virtual reality in education. Educational Technology Research and Development, 66(5), 1141-1164.

Markowitz, D. M., Laha, R., Perone, B. P., Pea, R. D., \& Bailenson, J. N. (2018). Immersive virtual reality field trips facilitate learning about climate change. Frontiers in Psychology, 9, 2364.

Marton, F., \& Säaljö, R. (1976). On qualitative differences in learning-ii Outcome as a function of the learner's conception of the task. British Journal of Educational Psychology, 46(2), 115127.

Mayer, R. E. (2005). Cognitive theory of multimedia learning. The Cambridge Handbook of Multimedia Learning, 41, 31-48.

Mayer, R. E. (2017). Using multimedia for e-learning. Journal of Computer Assisted Learning, 33(5), 403-423.

Mayer, R. E. (2019). How multimedia can improve learning and instruction.

Mayer, R. E., \& Colvin Clark, R. (2009). Instructional strategies for receptive learning environments. Handbook of Improving Performance in the Workplace: Volumes 1-3, 298328.

Mayer, R. E., Paul, R., Raths, J., \& Wittrock, M. C. (2001). A Taxonomy for Learning Teaching and Assessing A revision of Bloom's Taxonomy of Educational Objectivities. Abridged Edition. New York: Longman Inc.

McMahan, A. (2003). Immersion, engagement and presence. The Video Game Theory Reader, 67, 86.

Merchant, Z., Goetz, E. T., Cifuentes, L., Keeney-Kennicutt, W., \& Davis, T. J. (2014). Effectiveness of virtual reality-based instruction on students' learning outcomes in K-12 and higher education: A meta-analysis. Computers \& Education, 70, 29-40. 
Meyer, O. A., Omdahl, M. K., \& Makransky, G. (2019). Investigating the effect of pre-training when learning through immersive virtual reality and video: A media and methods experiment. Computers \& Education, 140, 103603.

Michie, D., Spiegelhalter, D. J., Taylor, C. C., \& others. (1994). Machine learning. Neural and Statistical Classification, 13(1994), 1-298.

Mikropoulos, T. A., \& Natsis, A. (2011). Educational virtual environments: A ten-year review of empirical research (1999--2009). Computers \& Education, 56(3), 769-780.

Milgram, P., \& Kishino, F. (1994). A taxonomy of mixed reality visual displays. IEICE TRANSACTIONS on Information and Systems, 77(12), 1321-1329.

Monahan, T., McArdle, G., \& Bertolotto, M. (2008). Virtual reality for collaborative e-learning. Computers \& Education, 50(4), 1339-1353.

Moore, M., \& Kearsley, G. (2007). Uma visão integrada. Tradução Por Roberto Galman. São Paulo: Thomson Learning.

Moran, J. M., Masetto, M. T., \& Behrens, M. A. (2005). Integração das tecnologias na educação. Desafios da televisão e do vídeo à escola. Secretaria de Educação a Distância, SEED.

Moreno, R., \& Mayer, R. (2007). Interactive multimodal learning environments. Educational Psychology Review, 19(3), 309-326.

Moreno, R., \& Mayer, R. E. (2002). Learning science in virtual reality multimedia environments: Role of methods and media. Journal of Educational Psychology, 94(3), 598.

Morgan, S. L., \& Winship, C. (2015). Counterfactuals and causal inference. Cambridge University Press.

Mossler, M. V, Bostrom, A., Kelly, R. P., Crosman, K. M., \& Moy, P. (2017). How does framing affect policy support for emissions mitigation? Testing the effects of ocean acidification and other carbon emissions frames. Global Environmental Change, 45, 63-78. 
Multon, K. D., Brown, S. D., \& Lent, R. W. (1991). Relation of self-efficacy beliefs to academic outcomes: A meta-analytic investigation. Journal of Counseling Psychology, 38(1), 30.

National Research Council. (2013). Education for life and work: Developing transferable knowledge and skills in the 21st century. National Academies Press.

Nelson, B.C., Kim, Y., \& Slack, K. (2016). Visual Signaling in a High-Search Virtual World-based Assessment: A SAVE Science Design Study. Technology, Knowledge and Learning, 21(2), 211-224. https://doi.org/10.1007/s10758-016-9281-0

Nelson, B C, Kim, Y., \& Slack, K. (2016). Visual Signaling in a High-Search Virtual World-based Assessment: A SAVE Science Design Study. Technology, Knowledge and Learning, 21(2), 211-224. https://doi.org/10.1007/s10758-016-9281-0

Nelson, Brian C, \& Erlandson, B. E. (2008). Managing cognitive load in educational multi-user virtual environments: Reflection on design practice. Educational Technology Research and Development, 56(5-6), 619-641.

Nelson, Brian C, Kim, Y., Foshee, C., \& Slack, K. (2014). Visual signaling in virtual world-based assessments: The SAVE Science project. Information Sciences, 264, 32-40. https://doi.org/https://doi.org/10.1016/j.ins.2013.09.011

Nosek, M. A., Robinson-Whelen, S., Hughes, R. B., \& Nosek, T. M. (2016). An internet-based virtual reality intervention for enhancing self-esteem in women with disabilities: Results of a feasibility study. Rehabilitation Psychology, 61(4), 358-370. https://doi.org/10.1037/rep0000107

Oliveira, A. (2016). TECNOLOGIA ASSISTIVA-UM TEMA EM ASCENÇÃO: Aplicação de Recursos de Tecnologia Assistiva na Educação. Seminário de Pesquisa, Pós-Graduação e Inovação.

Oshima, F. Y. (2016). A realidade virtual já frequenta escolas públicas brasileiras. O desafio é usála de modo a facilitar o aprendizado dos alunos. Revista Época. http://epoca.globo.com/ideias/noticia/2016/01/realidade-virtual-na-sala-de-aula.html 
Palacios-Navarro, G., Albiol-Pérez, S., \& García-Magariño García, I. (2016). Effects of sensory cueing in virtual motor rehabilitation. A review. Journal of Biomedical Informatics, 60, 4957. https://doi.org/10.1016/j.jbi.2016.01.006

Parmar, D., Isaac, J., Babu, S. V, D’Souza, N., Leonard, A. E., Jörg, S., Gundersen, K., \& Daily, S. B. (2016). Programming moves: Design and evaluation of applying embodied interaction in virtual environments to enhance computational thinking in middle school students. Virtual Reality (VR), 2016 IEEE, 131-140.

Parong, J., \& Mayer, R. E. (2018). Learning science in immersive virtual reality. Journal of Educational Psychology, 110(6), 785.

Parsons, S., \& Cobb, S. (2011). State-of-the-art of virtual reality technologies for children on the autism spectrum. European Journal of Special Needs Education, 26(3), 355-366.

Parsons, T. D., Iyer, A., Cosand, L., Courtney, C., \& Rizzo, A. A. (2009). Neurocognitive and psychophysiological analysis of human performance within virtual reality environments. Studies in Health Technology and Informatics, 142, 247-252. https://doi.org/10.3233/9781-58603-964-6-247

Passig, D. (2009). Improving the sequential time perception of teenagers with mild to moderate mental retardation with 3D Immersive Virtual Reality (IVR). Journal of Educational Computing Research, 40(3), 263-280.

Passig, D. (2015). Revisiting the Flynn effect through 3D immersive virtual reality (IVR). Computers \& Education, 88, 327-342.

Passig, D., \& Eden, S. (2000a). Enhancing the induction skill of deaf and hard-of-hearing children with virtual reality technology. Journal of Deaf Studies and Deaf Education, 5(3), 277-285.

Passig, D., \& Eden, S. (2000b). Improving flexible thinking in deaf and hard of hearing children with virtual reality technology. American Annals of the Deaf, 286-291.

Passig, D., \& Eden, S. (2001). Virtual reality as a tool for improving spatial rotation among deaf 
and hard-of-hearing children. CyberPsychology \& Behavior, 4(6), 681-686.

Passig, D., \& Eden, S. (2003). Cognitive intervention through virtual environments among deaf and hard-of-hearing children. European Journal of Special Needs Education, 18(2), 173-182.

Passig, D., \& Eden, S. (2010). Enhancing time-connectives with 3D immersive virtual reality (IVR). Journal of Educational Computing Research, 42(3), 307-325.

Passig, D., Eden, S., \& Heled, M. (2007). The impact of Virtual Reality on the awareness of teenagers to social and emotional experiences of immigrant classmates. Education and Information Technologies, 12(4), 267-280.

Passig, D., \& Schwartz, T. (2014). Solving Conceptual and Perceptual Analogies with Virtual Reality among Kindergarten Children of Immigrant Families. Teachers College Record, 116(2), n2.

Passig, D., Tzuriel, D., \& Eshel-Kedmi, G. (2016a). Improving children's cognitive modifiability by dynamic assessment in 3D Immersive Virtual Reality environments. Computers \& Education, 95, 296-308.

Passig, D., Tzuriel, D., \& Eshel-Kedmi, G. (2016b). Improving children's cognitive modifiability by dynamic assessment in 3D Immersive Virtual Reality environments. Computers and Education. https://doi.org/10.1016/j.compedu.2016.01.009

Patel, S., Vincent, A. H., Abel, S. R., Jacobs, C. M., Dunlop, S. R., \& Seibert, M. (2011). A virtual clean room to teach USP 797 regulations for intravenous medications. American Journal of Pharmaceutical Education, 75(1). https://doi.org/10.5688/ajpe7517

Paul Armstrong. (2017). Just How Big Is The Virtual Reality Market And Where Is It Going Next? Forbes. https://www.forbes.com/sites/paularmstrongtech /2017/04/06/just-how-big-isthe-virtual-reality-market-and-where-is-it-going-next/\#3a1

Paula, F. V., \& Leme, M. I. da S. (2010). Aprendizagem implícita e explícita: uma visão integradora. Revista Psicologia Em Pesquisa, 4(1), 15-23.

Pekrun, R. (2006). The control-value theory of achievement emotions: Assumptions, corollaries, 
and implications for educational research and practice. Educational Psychology Review, 18(4), 315-341.

Pekrun, R., Goetz, T., Frenzel, A. C., Barchfeld, P., \& Perry, R. P. (2011). Measuring emotions in students' learning and performance: The Achievement Emotions Questionnaire (AEQ). Contemporary Educational Psychology, 36(1), 36-48.

Pekrun, R., Goetz, T., \& Perry, R. P. (2005). Achievement emotions questionnaire (AEQ). User's manual. Unpublished Manuscript, University of Munich, Munich.

Perrenoud, P., Thurler, M. G., Macedo, L. de, Machado, J. N., \& Alessandrini, C. D. (2002). As competências para ensinar no século XXI. XXI--A Formação Dos Professores e o Desafio Da Avaliação. Porto Alegre: Artmed.

Plass, J. L., \& Kaplan, U. (2016). Emotional design in digital media for learning. In Emotions, technology, design, and learning (pp. 131-161). Elsevier.

Pozo, J. I. (2016). Aprendizes e mestres: a nova cultura da aprendizagem. Artmed Editora.

Prezi. (2016). Prezi. https://prezi.com/nnjwfoxkbuc2/m-learning-e-u-learning/

Purvis, C. K., Jones, M., Bailey, J. O., Bailenson, J., \& Taylor, C. B. (2015). Developing a novel measure of body satisfaction using virtual reality. PLOS ONE, 10(10). https://doi.org/10.1371/journal.pone.0140158

Queiroz, A. C. M., Kamarainen, A. M., Preston, N. D., \& Silva Leme, M. I. da. (2018). Immersive Virtual Environments and Climate Change Engagement. Immersive Learning Research Network Proceedings, accepted paper.

Queiroz, A. C. M., Nascimento, A. M., Tori, R., \& da Silva Leme, M. I. (2019). Immersive virtual environments and learning assessments. International Conference on Immersive Learning, $172-181$.

Queiroz, A. C. M., Tori, R., Moreira, N. A., \& Silva Leme, M. I. da. (2018). Using HMD-Based Immersive Virtual Environments in Primary/K-12 Education. Communication in Computer 
and Information Systems, 840(accepted paper), 1-14.

Queiroz, A. C. M., Tori, R., \& Nascimento, A. M. (2017). Realidade Virtual na Educação: Panorama das Pesquisas no Brasil. Anais Do XXVIII Simpósio Brasileiro de Informática Na Educação (SBIE 2017), 203-212.

Rakkolainen, I., Raisamo, R., Turk, M., Höllerer, T., \& Palovuori, K. (2016). Casual immersive viewing with smartphones. Proceedings of the 20th International Academic Mindtrek Conference, 449-452.

Rangel, M. (2005). Métodos de ensino para a aprendizagem e a dinamização das aulas. Papirus Editora.

Rasheed, F., Onkar, P., \& Narula, M. (2015). Immersive virtual reality to enhance the spatial awareness of students. Proceedings of the 7th International Conference on $\mathrm{HCl}$, India HCl 2015, 154-160.

Real, L. M. C., Tavares, M. N. R., \& dos Santos Picetti, J. (2013). Formação de Professores para o Uso Educacional de Tablets no Ensino Médio: possíveis mudanças na prática pedagógica. Anais Dos Workshops Do Congresso Brasileiro de Informática Na Educação, 2(1).

Reiners, T., \& Wood, L. C. (2013). Immersive virtual environments to facilitate authentic education in logistics and supply chain management. In Learning Management Systems and Instructional Design: Best Practices in Online Education. https://doi.org/10.4018/978-14666-3930-0.ch017

Revelle, W., \& Zinbarg, R. E. (2009). Coefficients alpha, beta, omega, and the glb: Comments on Sijtsma. Psychometrika, 74(1), 145.

Ribeiro, S. C. (1991). A pedagogia da repetência. Estudos Avançados, 5(12), 7-21.

Riva, G., Mantovani, F., Capideville, C. S., Preziosa, A., Morganti, F., Villani, D., Gaggioli, A., Botella, C., \& Alcañiz, M. (2007). Affective interactions using virtual reality: the link between presence and emotions. CyberPsychology \& Behavior, 10(1), 45-56. 
Rolfsen-Belda, F., \& de-Souza-Lima, F. (2016). Conteúdos Audiovisuais em Revistas Digitais: um Exame das Revistas Esquire e Katashi em suas Versões para Tablet| Audiovisual Content in Digital Magazines: An Examination of Esquire and Katashi Magazines in their Tablet Versions. Razón y Palabra, 20(1_92), 1560-1577.

Rosa, P. J., Gamito, P., Oliveira, J., Morais, D., Pavlovic, M., \& Smyth, O. (2016). Uso de eye tracking em realidade virtual não imersiva para avaliação cognitiva. Psicologia, Saúde \& Doenças, 17(1), 23-31.

Rosedale, P. (2017). Virtual Reality: The Next Disruptor: A new kind of worldwide communication. IEEE Consumer Electronics Magazine, 6(1), 48-50.

Saccol, A., Schlemmer, E., Barbosa, J., \& Hahn, R. (2011). M-learning e u-learning: novas perspectivas da aprendizagem móvel e ub\{\’i\}qua. São Paulo: Perarson, 30.

Salzman, M. C., Dede, C., \& Loftin, B. R. (2006). Learner-centered design of sensorily immersive microworlds using a virtual reality interface.

Salzman, M. C., Dede, C., \& Loftin, R. B. (1995). Usability and learning in educational virtual realities. Proceedings of the Human Factors and Ergonomics Society Annual Meeting, 39(9), 486-490.

Salzman, M. C., Dede, C., Loftin, R. B., \& Chen, J. (1999). A model for understanding how virtual reality aids complex conceptual learning. Presence: Teleoperators \& Virtual Environments, 8(3), 293-316.

Salzman, M. C., Loftin, R. B., Dede, C., \& McGlynn, D. (1996). ScienceSpace: Lessons for designing immersive virtual realities. Conference Companion on Human Factors in Computing Systems, 89-90.

Sanchez-Vives, M. V, \& Slater, M. (2005). From presence to consciousness through virtual reality. Nature Reviews Neuroscience, 6(4), 332.

Santos, R. V. dos. (2005). Abordagens do processo de ensino e aprendizagem. Integração, Ano XI, 
40, 19-31.

Santos, E. (2014). Pesquisa-formação na cibercultura. Santos Tirso: Whitebooks.

Saxton, E., Belanger, S., \& Becker, W. (2012). The Critical Thinking Analytic Rubric (CTAR): Investigating intra-rater and inter-rater reliability of a scoring mechanism for critical thinking performance assessments. Assessing Writing, 17(4), 251-270.

Schloss, A., Jacobson, J., \& Handron, K. (2012). Active Learning in a Digital Dome with the Living Forest. In PublicVR.

Schlosser, M. E. (2012). Causally efficacious intentions and the sense of agency: In defense of real mental causation. Journal of Theoretical and Philosophical Psychology, 32(3), 135.

Schunk, D. H. (1987). Peer models and children's behavioral change. Review of Educational Research, 57(2), 149-174.

Schunk, D. H. (1991). Self-efficacy and academic motivation. Educational Psychologist, 26(3-4), 207-231.

Schunk, D. H. (1995). Self-efficacy, motivation, and performance. Journal of Applied Sport Psychology, 7(2), 112-137.

Schunk, D. H. (2012). Learning theories an educational perspective sixth edition. Pearson.

Schunk, D. H., \& Dibenedetto, M. K. (2016). Self-efficacy theory in education. Handbook of Motivation at School, 2, 34-54.

Schunk, D. H., \& DiBenedetto, M. K. (2020). Motivation and social cognitive theory. Contemporary Educational Psychology, 60, 101832.

Sears, D. O. (1986). College sophomores in the laboratory: Influences of a narrow data base on social psychology's view of human nature. Journal of Personality and Social Psychology, 51(3), 515.

Shoaib, M., Hussain, I., Mirza, H. T., \& Tayyab, M. (2017). The role of information and innovative 
technology for rehabilitation of children with Autism: A Systematic Literature Review. Computational Science and Its Applications (ICCSA), 2017 17th International Conference On, $1-10$.

Silva, M. (2006). Avaliação da aprendizagem em educação online. Edições Loyola.

Silva, M. W., \& Balzan, N. C. (2007). Universidade Corporativa:(Pré-) tendência do Ensino Superior ou ameaça? Avaliação: Revista Da Avaliação Da Educação Superior, 12(2).

Sinitksi, E. H., Terry, K., Wilken, J. M., \& Dingwell, J. B. (2012). Effects of perturbation magnitude on dynamic stability when walking in destabilizing environments. Journal of Biomechanics, 45(12), 2084-2091. https://doi.org/10.1016/j.jbiomech.2012.05.039

Slater, M., \& Usoh, M. (1993). Representations systems, perceptual position, and presence in immersive virtual environments. Presence: Teleoperators \& Virtual Environments, 2(3), 221233.

Slavin, R., \& Smith, D. (2009). The relationship between sample sizes and effect sizes in systematic reviews in education. Educational Evaluation and Policy Analysis, 31(4), 500-506.

Soares, J. F., \& Candian, J. F. (2007). O efeito da escola básica brasileira: as evidências do PISA e do SAEB. Revista Contemporânea de Educação, 2(4).

Spector, J. M., Ifenthaler, D., Sampson, D., Yang, J. L., Mukama, E., Warusavitarana, A., Dona, K. L., Eichhorn, K., Fluck, A., Huang, R., \& others. (2016). Technology enhanced formative assessment for 21 st century learning.

Spengler, S., von Cramon, D. Y., \& Brass, M. (2009). Was it me or was it you? How the sense of agency originates from ideomotor learning revealed by fMRI. Neuroimage, 46(1), 290-298.

Stavrinos, D., Byington, K. W., \& Schwebel, D. C. (2011). Distracted walking: Cell phones increase injury risk for college pedestrians. Journal of Safety Research, 42(2), 101-107. https://doi.org/https://doi.org/10.1016/j.jsr.2011.01.004

Stepan, K., Zeiger, J., Hanchuk, S., Del Signore, A., Shrivastava, R., Govindaraj, S., \& Iloreta, A. 
(2017). Immersive virtual reality as a teaching tool for neuroanatomy. International Forum of Allergy \& Rhinology, 7(10), 1006-1013.

Steuer, J. (1992). Defining virtual reality: Dimensions determining telepresence. Journal of Communication, 42(4), 73-93.

Strasburger, V. C., Hogan, M. J., Mulligan, D. A., Ameenuddin, N., Christakis, D. A., Cross, C., Fagbuyi, D. B., Hill, D. L., Levine, A. E., McCarthy, C., \& others. (2013). Children, adolescents, and the media. Pediatrics, 132(5), 958-961.

Strickland, D., Marcus, L. M., Mesibov, G. B., \& Hogan, K. (1996). Brief report: Two case studies using virtual reality as a learning tool for autistic children. Journal of Autism and Developmental Disorders, 26(6), 651-659.

Sun, J. C.-Y., \& Rueda, R. (2012). Situational interest, computer self-efficacy and self-regulation: Their impact on student engagement in distance education. British Journal of Educational Technology, 43(2), 191-204.

Suskie, L. (2018). Assessing student learning: A common sense guide. John Wiley \& Sons.

Sutherland, I. E. (1965). The ultimate display. Multimedia: From Wagner to Virtual Reality, 506508.

Sweller, J. (2005). Implications of cognitive load theory for multimedia learning. The Cambridge Handbook of Multimedia Learning, 3(2), 19-30.

Tamaddon, K., \& Stiefs, D. (2017). Embodied experiment of levitation in microgravity in a simulated virtual reality environment for science learning. $K-12$ Embodied Learning through Virtual \& Augmented Reality (KELVAR), 2017 IEEE Virtual Reality Workshop On, 1-5.

Tedesco, J. C. (2004). Educação e novas tecnologias: esperança ou incerteza. São Paulo.

Thompson, P. (2013). The digital natives as learners: Technology use patterns and approaches to learning. Computers \& Education, 65, 12-33. https://doi.org/https://doi.org/10.1016/j.compedu.2012.12.022. 
Tori, R., Kirner, C., \& Siscoutto, R. A. (2006). Fundamentos e tecnologia de realidade virtual e aumentada. Editora SBC.

Tuan, H.-L., Chin, C.-C., \& Shieh, S.-H. (2005). The development of a questionnaire to measure students' motivation towards science learning. International Journal of Science Education, 27(6), 639-654.

US. (n.d.). US Department of Education. 2019.

Usher, E. L., \& Pajares, F. (2008). Sources of self-efficacy in school: Critical review of the literature and future directions. Review of Educational Research, 78(4), 751-796.

van den Brule, R., Dotsch, R., Bijlstra, G., Wigboldus, D. H. J., \& Haselager, P. (2014). Do Robot Performance and Behavioral Style affect Human Trust?: A Multi-Method Approach. International Journal of Social Robotics, 6(4), 519-531. https://doi.org/10.1007/s12369014-0231-5

Van Merriënboer, J. J. G., \& Kirschner, P. A. (2017). Ten steps to complex learning: A systematic approach to four-component instructional design. Routledge.

Voogt, J., Erstad, O., Dede, C., \& Mishra, P. (2013). Challenges to learning and schooling in the digital networked world of the 21st century. Journal of Computer Assisted Learning, 29(5), 403-413.

Vosniakos, G.-C., Deville, J., \& Matsas, E. (2017). On Immersive Virtual Environments for Assessing Human-driven Assembly of Large Mechanical Parts. Procedia Manufacturing, 11, 12631270. https://doi.org/10.1016/j.promfg.2017.07.253

Walsham, G., \& Sahay, S. (2006). Research on information systems in developing countries: Current landscape and future prospects. Information Technology for Development, 12(1), 724.

Watanuki, K., \& Hou, L. (2011). Virtual reality-based lathe operation training based on brain activity assessment using functional near-infrared spectroscopy. Advanced Concurrent 
Engineering, 301-308. https://doi.org/10.1007/978-0-85729-799-0_35

Webster, R. (2016). Declarative knowledge acquisition in immersive virtual learning environments. Interactive Learning Environments, 24(6), 1319-1333.

Werthein, J. (2000). A sociedade da informação e seus desafios. Ciência Da Informação, Bras $\{\backslash \backslash \mid i\} l i a, 29(2), 71-77$.

Wickens, C. D. (1992). Virtual reality and education. Systems, Man and Cybernetics, 1992., IEEE International Conference On, 842-847.

Wiliam, D., \& Thompson, M. (2017). Integrating assessment with learning: What will it take to make it work? In The future of assessment (pp. 53-82). Routledge.

Yahya, S., Ahmad, E. A., \& Jalil, K. A. (2010). The definition and characteristics of ubiquitous learning: A discussion. International Journal of Education and Development Using Information and Communication Technology, 6(1), 1.

Zimmerman, B. J. (1995). Self-efficacy and educational development. Self-Efficacy in Changing Societies, 1, 202-231.

Zimmerman, B. J. (2000). Self-efficacy: An essential motive to learn. Contemporary Educational Psychology, 25(1), 82-91.

Zimmerman, B. J., Bandura, A., \& Martinez-Pons, M. (1992). Self-motivation for academic attainment: The role of self-efficacy beliefs and personal goal setting. American Educational Research Journal, 29(3), 663-676.

Zimmerman, B. J., Schunk, D. H., \& DiBenedetto, M. K. (2017). The role of self-efficacy and related beliefs in self-regulation of learning and performance. Handbook of Competence and Motivation: Theory and Application, 313.

Zorzal, E. R., \& Nunes, F. L. S. (2014). Realidade Aumentada em saúde: uma revisão sobre aplicações e desafios. CSBC/WIM-Brasília. 


\section{Anexos}

7.1. Anexo 1-Questionário Estudo 1 (português)

Nesta pesquisa, faremos algumas perguntas sobre a acidificação do oceano e sobre os recifes de coral. Além disso, solicitaremos sua opinião e sua concordância com algumas sentenças.

As informações serão usadas apenas para fins de pesquisa e não estarão disponíveis por quaisquer outros motivos. Sua identidade e suas respostas serão mantidas estritamente confidenciais.

Selecione em que série você está:

- 6a

- 7a

- 8 a

Até que ponto você se sentiu dentro da experiência virtual?

- De maneira alguma

- Ligeiramente

- Moderadamente

- Muito

- Extremamente

Até que ponto você se sentiu imersa na experiência virtual?

- De maneira alguma

- Ligeiramente

- Moderadamente

- Muito

- Extremamente

Até que ponto você sentiu como se tivesse visitado um outro lugar?

- De maneira alguma

- Ligeiramente

- Moderadamente

- Muito 
- Extremamente

Explique o que você sabe sobre como as atividades humanas alteram a química do oceano.

Como nossa sociedade pode reduzir a acidificação dos oceanos? Sugira o maior número soluções que você puder.

Poucas pessoas sabem sobre a acidificação do oceano. Proponha e detalhe estratégias para aumentar o conhecimento e engajamento do público sobre a acidificação dos oceanos.

Os recifes de coral em Palau, no Oceano Pacífico, são considerados uma das "Sete Maravilhas Subaquáticas do Mundo". Que ações o governo de Palau está tomando para reduzir os danos aos recifes de coral?

Como as ações do governo de Palau para proteger os recifes de coral podem ser aplicadas a outras questões ambientais, como por exemplo, a rápida erosão das praias do sul da Califórnia?

Considerando os esforços do governo de Palau para proteger os recifes de coral, pense em um problema da sua comunidade que precisa de atenção imediata. Proponha um plano de ação detalhado que possa ajudar a resolver esse problema.

Para as próximas perguntas, selecione a opção que melhor responde à pergunta.

Qual é a principal causa da acidificação do oceano?

- Derramamentos químicos no oceano

- Chuva ácida

- Absorção de dióxido de carbono pelo oceano

- Temperaturas mais quentes do oceano

Corais, moluscos e outros organismos marinhos usam o carbono dissolvido no oceano para:

- construir conchas.

- respirar debaixo d'água.

- regular a temperatura do corpo.

- auxiliar na reprodução.

Qual das alternativas a seguir é resultado de emissões de dióxido de carbono causadas pelo homem? 
- A salinidade do oceano e a frequência dos derramamentos de óleo estão aumentando.

- Os recifes de coral estão se degradando e a diversidade da vida oceânica está diminuindo.

- A frequência de derramamentos de óleo está aumentando e os recifes de corais estão se degradando.

- A diversidade da vida do oceano está diminuindo e a salinidade do oceano está aumentando.

Como as emissões de dióxido de carbono estão afetando o oceano?

- Carbono e sal estão aumentando no oceano.

- $\quad$ Fito plâncton e sal estão aumentando no oceano.

- $\quad$ Fito plâncton e as temperaturas estão aumentando no oceano.

- Carbono e temperaturas estão aumentando no oceano.

Qual frase descreve melhor como o turismo em Palau está danificando os recifes de coral?

- O turismo em Palau é responsável por grande parte das emissões de dióxido de carbono no mundo.

- Turistas em Palau jogam mais lixo no oceano do que a maioria dos turistas em outros lugares.

- Os turistas estão danificando os corais com seus equipamentos enquanto mergulham.

- A chuva ácida está aumentando em Palau devido às emissões de dióxido de carbono do turismo.

Selecione a prática de plantio que pode ajudar muito a proteger os recifes de coral em Palau.

- Colocar fazendas de "taro" em áreas estratégicas.

- Eliminar as florestas de mangue que correm ao longo da costa.

- Substituir as florestas de mangue por fazendas.

- Evitar armadilhas de sedimentos ao longo da costa.

Agora estamos interessados em suas opiniões pessoais. Por favor, selecione a opção que melhor descreve sua opinião sobre cada afirmação.

Quão preocupada você está, se é que você está, com a saúde do oceano?

- Nem um pouco preocupada

- Um pouco preocupada 
- Nem muito nem pouco preocupada

- Muito preocupada

- Extremamente preocupada

Você acha que o aumento da quantidade de dióxido de carbono na atmosfera foi causado:

- Principalmente pelas coisas que as pessoas fizeram.

- Principalmente por causas naturais.

- Igualmente por coisas que as pessoas fizeram e por causas naturais.

Para você, qual é a gravidade do aumento da quantidade de dióxido de carbono na atmosfera para a saúde do oceano?

- Extremamente séria

- Muito séria

- Um pouco séria

- Não é muito séria

- Não é nada séria

Agora você será solicitada a expressar seu acordo em cada declaração. Não há respostas certas ou erradas. Sua opinião é o que se deseja. Algumas declarações neste questionário são bastante semelhantes. Não se preocupe com isso. Simplesmente expresse seu acordo/desacordo sobre todas as declarações.

Se o conteúdo de ciências é difícil ou fácil, tenho certeza de que posso entendê-lo.

- Discordo totalmente

- Discordo um pouco

- Não concordo nem discordo

- Concordo um pouco

- Concordo totalmente

Não estou confiante que posso entender conceitos difíceis.

- Discordo totalmente

- Discordo um pouco

- Não concordo nem discordo

- Concordo um pouco

- Concordo totalmente 
Não importa quanto esforço eu coloque, não consigo aprender ciências.

- Discordo totalmente

- Discordo um pouco

- Não concordo nem discordo

- Concordo um pouco

- Concordo totalmente

Quando as atividades de ciências são muito difíceis, eu desisto ou faço apenas as partes fáceis.

- Discordo totalmente

- Discordo um pouco

- Não concordo nem discordo

- Concordo um pouco

- Concordo totalmente

Eu acho que aprender ciências é importante porque eu posso usar esse conhecimento na minha vida diária.

- Discordo totalmente

- Discordo um pouco

- Não concordo nem discordo

- Concordo um pouco

- Concordo totalmente

É importante ter a oportunidade de satisfazer minha própria curiosidade ao aprender ciências.

- Discordo totalmente

- Discordo um pouco

- Não concordo nem discordo

- Concordo um pouco

- Concordo totalmente

Estou disposta a participar deste curso de ciências porque o conteúdo é empolgante.

- Discordo totalmente

- Discordo um pouco

- Não concordo nem discordo

- Concordo um pouco 
- Concordo totalmente

Acho que posso me orgulhar do que sei sobre esse assunto.

- Discordo totalmente

- Discordo um pouco

- Não concordo nem discordo

- Concordo um pouco

- Concordo totalmente

Eu estudo mais do que o necessário, porque gosto muito.

- Discordo totalmente

- Discordo um pouco

- Não concordo nem discordo

- Concordo um pouco

- Concordo totalmente

O assunto me assusta, porque eu não o entendo completamente.

- Discordo totalmente

- Discordo um pouco

- Não concordo nem discordo

- Concordo um pouco

- Concordo totalmente

Estou tão feliz com o progresso que fiz que estou motivada a continuar estudando.

- Discordo totalmente

- Discordo um pouco

- Não concordo nem discordo

- Concordo um pouco

- Concordo totalmente

Esse assunto é tão agradável que estou motivada a fazer leituras extras sobre ele.

- Discordo totalmente 
- Discordo um pouco

- Não concordo nem discordo

- Concordo um pouco

- Concordo totalmente 
7.2. Anexo 2 - Questionário Estudo 1 (inglês)

Today you will watch two videos about ocean acidification and coral reefs. After watching each video, we will ask you some questions and your opinion about some statements. The information will be used for research purposes only and will not be available for any other reasons. Your identity and your answers will be kept strictly confidential.

Select your grade:

- 6 th

- 7 th

- 8th

To what extent did you feel like you were inside the virtual experience?

- Not at all

- Slightly

- Moderately

- Very

- Extremely

To what extent did you feel immersed in the virtual experience?

- Not at all

- Slightly

- Moderately

- Very

- Extremely

How much did if feel as if you visited another place?

- Not at all

- Slightly

- Moderately

- Very

- Extremely

Explain what you know about how human activities change the ocean chemistry.

Describe ways that could help reduce ocean acidification.

Propose strategies to increase engagement of general public with ocean acidification.

Palau's coral reefs are considered to be one of the "Seven Underwater Wonders of the World".

What actions is the Palau government taking to reduce damages to the coral reefs? 
How could the Palauan government actions to protect the coral reefs be applied to other environmental issues, for example, the fast erosion of South California beaches?

Considering the Palauan government efforts to protect the coral reefs, think about one issue from your community that needs immediate attention. Propose an action plan that could help address this issue.

\section{For the next questions, please select the option that best answers the question.}

What is the main cause of ocean acidification?

- Chemical spills in the ocean

- Acid rain

- Absorption of carbon dioxide by the ocean

- Warmer ocean temperatures

Corals, shellfish and other marine organisms use the carbon dissolved in the ocean to:

- build shells.

- breathe underwater.

- regulate body temperature.

- assist in reproduction.

Which of the following is a result of human-caused carbon dioxide emissions?

- Ocean salinity and the frequency of oil spills are increasing.

- Coral reefs are degrading, and the diversity of ocean life is decreasing.

- The frequency of oil spills is increasing, and coral reefs are degrading.

- The diversity of ocean life is decreasing, and ocean salinity is increasing.

How carbon dioxide emissions are affecting the ocean?

- Carbon and salt are increasing in the ocean.

- Phytoplankton and salt are increasing in the ocean.

- Phytoplankton and temperatures are increasing in the ocean.

- Carbon and temperatures are increasing in the ocean.

Which sentence best describe how tourism in Palau is damaging the coral reefs?

- Tourism in Palau are responsible for great part of carbon dioxide emissions in the world.

- Tourists in Palau throw more trash into the ocean than most tourists in other places.

- Tourists are damaging the corals with their fins while diving.

- Acid rain is increasing in Palau due to tourism's carbon dioxide emissions.

Select the land practice that can greatly help to protect the coral reefs in Palau.

- Place taro farms in strategic areas. 
- Eliminate the mangrove forests that run along the coastline.

- Replace the mangrove forests with farms.

- Avoid sediment traps along coastline.

Now we are interested in your personal opinions. Please select the option that best describes your opinion about each statement.

How concerned, if at all, are you about the health of the ocean?

- Not at all concerned

- A little concerned

- Somewhat concerned

- Very concerned

- Extremely concerned

Do you think that the increased amount of carbon dioxide in the atmosphere was caused:

- Mostly by things people did.

- Mostly by natural causes.

- About equally by things people did and natural causes.

How serious of a problem do you think the increased amount of carbon dioxide in the atmosphere is for the health of the ocean?

- Extremely serious

- Very serious

- Somewhat serious

- Not too serious

- Not serious at all

Now you will be asked to express your agreement on each statement. There are no "right" or "wrong" answers. Your opinion is what is wanted. Some statements in this questionnaire are fairly similar to other statements. Don't worry about this. Simply express your agreement about all statements.

Whether the science content is difficult or easy, I am sure that I can understand it.

- Strongly disagree

- Somewhat disagree

- Neither agree nor disagree

- Somewhat agree

- Strongly agree

I am not confident about understanding difficult concepts.

- Strongly disagree

- Somewhat disagree

- Neither agree nor disagree 
- Somewhat agree

- Strongly agree

No matter how much effort I put in, I cannot learn science.

- Strongly disagree

- Somewhat disagree

- Neither agree nor disagree

- Somewhat agree

- Strongly agree

When science activities are too difficult, I give up or only do the easy parts.

- Strongly disagree

- Somewhat disagree

- Neither agree nor disagree

- Somewhat agree

- Strongly agree

I think that learning science is important because I can use it in my daily life.

- Strongly disagree

- Somewhat disagree

- Neither agree nor disagree

- Somewhat agree

- Strongly agree

It is important to have the opportunity to satisfy my own curiosity when learning science.

- Strongly disagree

- Somewhat disagree

- Neither agree nor disagree

- Somewhat agree

- Strongly agree

I am willing to participate in this science course because the content is exciting.

- Strongly disagree

- Somewhat disagree

- Neither agree nor disagree

- Somewhat agree

- Strongly agree

I think that I can be proud of what I know about this subject.

- Strongly disagree

- Somewhat disagree

- Neither agree nor disagree

- Somewhat agree 
- Strongly agree

I study more than required because I enjoy it so much.

- Strongly disagree

- Somewhat disagree

- Neither agree nor disagree

- Somewhat agree

- Strongly agree

The subject scares me since I don't fully understand it.

- Strongly disagree

- Somewhat disagree

- Neither agree nor disagree

- Somewhat agree

- Strongly agree

I am so happy about the progress I made that I am motivated to continue studying.

- Strongly disagree

- Somewhat disagree

- Neither agree nor disagree

- Somewhat agree

- Strongly agree

This subject is so enjoyable that I am motivated to do extra readings about it.

- Strongly disagree

- Somewhat disagree

- Neither agree nor disagree

- Somewhat agree

- Strongly agree 


\subsection{Anexo 3 - Questionário Estudo 2 (português)}

Questionário Estudo 2 - português

Obrigada por participar deste estudo!

Nesta pesquisa, faremos algumas perguntas sobre a acidificação do oceano e sobre os recifes de coral. Além disso, solicitaremos sua opinião e sua concordância com algumas sentenças.

As informações serão usadas apenas para fins de pesquisa e não estarão disponíveis por quaisquer outros motivos. Sua identidade e suas respostas serão mantidas estritamente confidenciais.

Selecione em que série você está:

- 6a

- 7aㅡ

- 8 a

Até que ponto você se sentiu dentro da experiência virtual?

- De maneira alguma

- Ligeiramente

- Moderadamente

- Muito

- Extremamente

Até que ponto você se sentiu imersa na experiência virtual?

- De maneira alguma

- Ligeiramente

- Moderadamente

- Muito

- Extremamente

Até que ponto você sentiu como se tivesse visitado um outro lugar? 
- De maneira alguma

- Ligeiramente

- Moderadamente

- Muito

- Extremamente

Explique o que você sabe sobre como as atividades humanas alteram a química do oceano.

Como nossa sociedade pode reduzir a acidificação dos oceanos? Sugira o maior número soluções que você puder.

Poucas pessoas sabem sobre a acidificação do oceano. Proponha e detalhe estratégias para aumentar o conhecimento e engajamento do público sobre a acidificação dos oceanos.

Os recifes de coral em Palau, no Oceano Pacífico, são considerados uma das "Sete Maravilhas Subaquáticas do Mundo". Que ações o governo de Palau está tomando para reduzir os danos aos recifes de coral?

Como as ações do governo de Palau para proteger os recifes de coral podem ser aplicadas a outras questões ambientais, como por exemplo, a rápida erosão das praias do sul da Califórnia?

Considerando os esforços do governo de Palau para proteger os recifes de coral, pense em um problema da sua comunidade que precisa de atenção imediata. Proponha um plano de ação detalhado que possa ajudar a resolver esse problema.

\section{Para as próximas perguntas, selecione a opção que melhor responde à pergunta.}

Qual é a principal causa da acidificação do oceano?

- Derramamentos químicos no oceano

- Chuva ácida

- Absorção de dióxido de carbono pelo oceano

- Temperaturas mais quentes do oceano

Corais, moluscos e outros organismos marinhos usam o carbono dissolvido no oceano para:

- construir conchas.

- respirar debaixo d'água.

- regular a temperatura do corpo.

- auxiliar na reprodução. 
Qual das alternativas a seguir é resultado de emissões de dióxido de carbono causadas pelo homem?

- A salinidade do oceano e a frequência dos derramamentos de óleo estão aumentando.

- Os recifes de coral estão se degradando e a diversidade da vida oceânica está diminuindo.

- A frequência de derramamentos de óleo está aumentando e os recifes de corais estão se degradando.

- A diversidade da vida do oceano está diminuindo e a salinidade do oceano está aumentando.

Como as emissões de dióxido de carbono estão afetando o oceano?

- Carbono e sal estão aumentando no oceano.

- $\quad$ Fito plâncton e sal estão aumentando no oceano.

- $\quad$ Fito plâncton e as temperaturas estão aumentando no oceano.

- Carbono e temperaturas estão aumentando no oceano.

Qual frase descreve melhor como o turismo em Palau está danificando os recifes de coral?

- O turismo em Palau é responsável por grande parte das emissões de dióxido de carbono no mundo.

- Turistas em Palau jogam mais lixo no oceano do que a maioria dos turistas em outros lugares.

- Os turistas estão danificando os corais com seus equipamentos enquanto mergulham.

- A chuva ácida está aumentando em Palau devido às emissões de dióxido de carbono do turismo.

Selecione a prática de plantio que pode ajudar muito a proteger os recifes de coral em Palau.

- Colocar fazendas de "taro" em áreas estratégicas.

- Eliminar as florestas de mangue que correm ao longo da costa.

- Substituir as florestas de mangue por fazendas.

- Evitar armadilhas de sedimentos ao longo da costa.

Agora estamos interessados em suas opiniões pessoais. Por favor, selecione a opção que melhor descreve sua opinião sobre cada afirmação.

Quão preocupada você está, se é que você está, com a saúde do oceano? 
- Nem um pouco preocupada

- Um pouco preocupada

- Nem muito nem pouco preocupada

- Muito preocupada

- Extremamente preocupada

Você acha que o aumento da quantidade de dióxido de carbono na atmosfera foi causado:

- Principalmente pelas coisas que as pessoas fizeram.

- Principalmente por causas naturais.

- Igualmente por coisas que as pessoas fizeram e por causas naturais.

Para você, qual é a gravidade do aumento da quantidade de dióxido de carbono na atmosfera para a saúde do oceano?

- Extremamente séria

- Muito séria

- Um pouco séria

- Não é muito séria

- Não é nada séria

Agora você será solicitada a expressar seu acordo em cada declaração. Não há respostas certas ou erradas. Sua opinião é o que se deseja. Algumas declarações neste questionário são bastante semelhantes. Não se preocupe com isso. Simplesmente expresse seu acordo/desacordo sobre todas as declarações.

Se o conteúdo de ciências é difícil ou fácil, tenho certeza de que posso entendê-lo.

- Discordo totalmente

- Discordo um pouco

- Não concordo nem discordo

- Concordo um pouco

- Concordo totalmente

Não estou confiante que posso entender conceitos difíceis.

- Discordo totalmente

- Discordo um pouco

- Não concordo nem discordo

- Concordo um pouco

- Concordo totalmente 
Eu tenho certeza que posso ir bem em provas de ciências

- Discordo totalmente

- Discordo um pouco

- Não concordo nem discordo

- Concordo um pouco

- Concordo totalmente

Não importa quanto esforço eu coloque, não consigo aprender ciências.

- Discordo totalmente

- Discordo um pouco

- Não concordo nem discordo

- Concordo um pouco

- Concordo totalmente

Quando as atividades de ciências são muito difíceis, eu desisto ou faço apenas as partes fáceis.

- Discordo totalmente

- Discordo um pouco

- Não concordo nem discordo

- Concordo um pouco

- Concordo totalmente

Durante as atividades de ciências, eu prefiro perguntar as respostas para outras pessoas do que

eu mesma pensar sozinha.

- Discordo totalmente

- Discordo um pouco

- Não concordo nem discordo

- Concordo um pouco

- Concordo totalmente

Quando eu acho o conteúdo difícil, eu tento não o aprender.

- Discordo totalmente

- Discordo um pouco

- Não concordo nem discordo

- Concordo um pouco

- Concordo totalmente 
Eu acho que aprender ciências é importante porque eu posso usar esse conhecimento na minha vida diária.

- Discordo totalmente

- Discordo um pouco

- Não concordo nem discordo

- Concordo um pouco

- Concordo totalmente

Eu acho que aprender ciências é importante porque estimula meu pensamento.

- Discordo totalmente

- Discordo um pouco

- Não concordo nem discordo

- Concordo um pouco

- Concordo totalmente

Em ciências, eu acho que é importante aprender a resolver problemas.

- Discordo totalmente

- Discordo um pouco

- Não concordo nem discordo

- Concordo um pouco

- Concordo totalmente

Em ciências, eu acho que é importante participar de atividades de investigação.

- Discordo totalmente

- Discordo um pouco

- Não concordo nem discordo

- Concordo um pouco

- Concordo totalmente

É importante ter a oportunidade de satisfazer minha própria curiosidade ao aprender ciências.

- Discordo totalmente

- Discordo um pouco

- Não concordo nem discordo

- Concordo um pouco

- Concordo totalmente 
Estou disposta a participar deste curso de ciências porque o conteúdo é empolgante.

- Discordo totalmente

- Discordo um pouco

- Não concordo nem discordo

- Concordo um pouco

- Concordo totalmente

Estou disposta a participar deste curso de ciências porque o conteúdo é dinâmico.

- Discordo totalmente

- Discordo um pouco

- Não concordo nem discordo

- Concordo um pouco

- Concordo totalmente

Estou disposta a participar deste curso de ciências porque o professor usa vários métodos de ensino.

- Discordo totalmente

- Discordo um pouco

- Não concordo nem discordo

- Concordo um pouco

- Concordo totalmente

Estou disposta a participar deste curso de ciências porque o professor não coloca tanta pressão em mim.

- Discordo totalmente

- Discordo um pouco

- Não concordo nem discordo

- Concordo um pouco

- Concordo totalmente

Estou disposta a participar deste curso de ciências porque o professor presta atenção em mim.

- Discordo totalmente

- Discordo um pouco

- Não concordo nem discordo 
- Concordo um pouco

- Concordo totalmente

Estou disposta a participar deste curso de ciências porque é desafiador.

- Discordo totalmente

- Discordo um pouco

- Não concordo nem discordo

- Concordo um pouco

- Concordo totalmente

Estou disposta a participar deste curso de ciências porque os alunos estão envolvidos nas discussões.

- Discordo totalmente

- Discordo um pouco

- Não concordo nem discordo

- Concordo um pouco

- Concordo totalmente

Eu consigo controlar minha performance acadêmica.

- Discordo totalmente

- Discordo um pouco

- Não concordo nem discordo

- Concordo um pouco

- Concordo totalmente

Eu aprendo mais quando eu mesma seleciono o que vou aprender.

- Discordo totalmente

- Discordo um pouco

- Não concordo nem discordo

- Concordo um pouco

- Concordo totalmente

Minhas escolhas sobre o que estudar influenciam meus resultados de aprendizagem.

- Discordo totalmente

- Discordo um pouco 
- Não concordo nem discordo

- Concordo um pouco

- Concordo totalmente

Eu prefiro que outras pessoas me digam o que eu tenho que estudar do que ter que decidir por mim mesma.

- Discordo totalmente

- Discordo um pouco

- Não concordo nem discordo

- Concordo um pouco

- Concordo totalmente

É importante para mim escolher para onde olhar quando estou num laboratório de ciências.

- Discordo totalmente

- Discordo um pouco

- Não concordo nem discordo

- Concordo um pouco

- Concordo totalmente

É importante para mim escolher onde focar minha atenção quando assisto a um vídeo.

- Discordo totalmente

- Discordo um pouco

- Não concordo nem discordo

- Concordo um pouco

- Concordo totalmente

O quanto você gosta de cada uma dessas disciplinas?

\begin{tabular}{l|ccccc} 
& $\begin{array}{c}\text { Nem um } \\
\text { pouco }\end{array}$ & Não muito & Neutro & Um pouco & Muito \\
\hline Computação & 0 & 0 & 0 & 0 & 0
\end{tabular}




\begin{tabular}{|c|c|c|c|c|c|}
\hline Inglês, Literatura e Artes & 0 & 0 & 0 & 0 & 0 \\
\hline $\begin{array}{l}\text { História } \quad-\quad \text { Ciências } \\
\text { Sociais }\end{array}$ & 0 & 0 & 0 & 0 & 0 \\
\hline Matemática & 0 & 0 & 0 & 0 & o \\
\hline Educação Física & 0 & 0 & 0 & 0 & 0 \\
\hline Ciências & 0 & 0 & 0 & 0 & 0 \\
\hline $\begin{array}{l}\text { Artes Visuais } \\
\text { Performance }\end{array}$ & 0 & 0 & 0 & 0 & 0 \\
\hline Idiomas mundiais & 0 & 0 & 0 & 0 & $\mathrm{O}$ \\
\hline
\end{tabular}

O quanto você se sente bem em relação a cada uma dessas disciplinas?

\begin{tabular}{l|ccccc} 
& $\begin{array}{c}\text { Nem um } \\
\text { pouco bem }\end{array}$ & $\begin{array}{c}\text { Não muito } \\
\text { bem }\end{array}$ & Apenas ok & Bem & Muito bem \\
\hline \begin{tabular}{l|c} 
Computação \\
Inglês, Literatura e Artes
\end{tabular} & 0 & 0 & 0 & 0 & 0 \\
$\begin{array}{l}\text { História }-\quad \text { Ciências } \\
\text { Sociais }\end{array}$ & 0 & 0 & 0 & 0 & 0 \\
$\begin{array}{l}\text { Matemática } \\
\text { Educação Física }\end{array}$ & 0 & 0 & 0 & 0 & 0 \\
Ciências & 0 & 0 & 0 & 0 & 0 \\
Artes Visuais & 0 & 0 & 0 & 0 & 0 \\
Performance & 0 & 0 & 0 & 0 & 0 \\
Idiomas mundiais & 0 & 0 & 0 & 0 & 0
\end{tabular}




\subsection{Anexo 4 - Questionário Estudo 2 (inglês)}

\section{Thank you for participating in this study!}

In this survey we will ask you some questions about ocean acidification and coral reefs. Also, we will ask your opinion and your agreement to some statements. The information will be used for research purposes only and will not be available for any other reasons. Your identity and your answers will be kept strictly confidential.

Select your grade:

- 6th

- 7th

- 8th

To what extent did you feel like you were inside the virtual experience?

- Not at all

- Slightly

- Moderately

- Very

- Extremely

To what extent did you feel immersed in the virtual experience?

- Not at all

- Slightly

- Moderately

- Very

- Extremely

How much did if feel as if you visited another place?

- Not at all

- Slightly

- Moderately

- Very

- Extremely

Explain what you know about how human activities change the ocean chemistry.

Describe ways that could help reduce ocean acidification.

Propose strategies to increase engagement of general public with ocean acidification.

Palau's coral reefs are considered to be one of the "Seven Underwater Wonders of the World".

What actions is the Palau government taking to reduce damages to the coral reefs? 
How could the Palauan government actions to protect the coral reefs be applied to other environmental issues, for example, the fast erosion of South California beaches?

Considering the Palauan government efforts to protect the coral reefs, think about one issue from your community that needs immediate attention. Propose an action plan that could help address this issue.

\section{For the next questions, please select the option that best answers the question.}

What is the main cause of ocean acidification?

- Chemical spills in the ocean

- Acid rain

- Absorption of carbon dioxide by the ocean

- Warmer ocean temperatures

Corals, shellfish and other marine organisms use the carbon dissolved in the ocean to:

- build shells.

- breathe underwater.

- regulate body temperature.

- assist in reproduction.

Which of the following is a result of human-caused carbon dioxide emissions?

- Ocean salinity and the frequency of oil spills are increasing.

- Coral reefs are degrading, and the diversity of ocean life is decreasing.

- The frequency of oil spills is increasing, and coral reefs are degrading.

- The diversity of ocean life is decreasing, and ocean salinity is increasing.

How carbon dioxide emissions are affecting the ocean?

- Carbon and salt are increasing in the ocean.

- Phytoplankton and salt are increasing in the ocean.

- Phytoplankton and temperatures are increasing in the ocean.

- Carbon and temperatures are increasing in the ocean.

Which sentence best describe how tourism in Palau is damaging the coral reefs?

- Tourism in Palau are responsible for great part of carbon dioxide emissions in the world.

- Tourists in Palau throw more trash into the ocean than most tourists in other places.

- Tourists are damaging the corals with their fins while diving.

- Acid rain is increasing in Palau due to tourism's carbon dioxide emissions.

Select the land practice that can greatly help to protect the coral reefs in Palau.

- Place taro farms in strategic areas. 
- Eliminate the mangrove forests that run along the coastline.

- Replace the mangrove forests with farms.

- Avoid sediment traps along coastline.

Now we are interested in your personal opinions. Please select the option that best describes your opinion about each statement.

How concerned, if at all, are you about the health of the ocean?

- Not at all concerned

- A little concerned

- Somewhat concerned

- Very concerned

- Extremely concerned

Do you think that the increased amount of carbon dioxide in the atmosphere was caused:

- Mostly by things people did.

- Mostly by natural causes.

- About equally by things people did and natural causes.

How serious of a problem do you think the increased amount of carbon dioxide in the atmosphere is for the health of the ocean?

- Extremely serious

- Very serious

- Somewhat serious

- Not too serious

- Not serious at all

Now you will be asked to express your agreement on each statement. There are no "right" or "wrong" answers. Your opinion is what is wanted. Some statements in this questionnaire are fairly similar to other statements. Don't worry about this. Simply express your agreement about all statements.

Whether the science content is difficult or easy, I am sure that I can understand it.

- Strongly disagree

- Somewhat disagree

- Neither agree nor disagree

- Somewhat agree

- Strongly agree

I am not confident about understanding difficult science concepts.

- Strongly disagree

- Somewhat disagree 
- Neither agree nor disagree

- Somewhat agree

- Strongly agree

I am sure that I can do well on science tests.

- Strongly disagree

- Somewhat disagree

- Neither agree nor disagree

- Somewhat agree

- Strongly agree

No matter how much effort I put in, I cannot learn science.

- Strongly disagree

- Somewhat disagree

- Neither agree nor disagree

- Somewhat agree

- Strongly agree

When science activities are too difficult, I give up or only do the easy parts.

- Strongly disagree

- Somewhat disagree

- Neither agree nor disagree

- Somewhat agree

- Strongly agree

During science activities, I prefer to ask other people for the answer rather than think for myself.

- Strongly disagree

- Somewhat disagree

- Neither agree nor disagree

- Somewhat agree

- Strongly agree

When I find the science content difficult, I do not try to learn it.

- Strongly disagree

- Somewhat disagree

- Neither agree nor disagree

- Somewhat agree

- Strongly agree

I think that learning science is important because I can use it in my daily life. 
- Strongly disagree

- Somewhat disagree

- Neither agree nor disagree

- Somewhat agree

- Strongly agree

I think that learning science is important because it stimulates my thinking.

- Strongly disagree

- Somewhat disagree

- Neither agree nor disagree

- Somewhat agree

- Strongly agree

In science, I think that it is important to learn to solve problems.

- Strongly disagree

- Somewhat disagree

- Neither agree nor disagree

- Somewhat agree

- Strongly agree

In science, I think it is important to participate in inquiry activities.

- Strongly disagree

- Somewhat disagree

- Neither agree nor disagree

- Somewhat agree

- Strongly agree

It is important to have the opportunity to satisfy my own curiosity when learning science.

- Strongly disagree

- Somewhat disagree

- Neither agree nor disagree

- Somewhat agree

- Strongly agree

I am willing to participate in this science course because the content is exciting.

- Strongly disagree

- Somewhat disagree

- Neither agree nor disagree

- Somewhat agree

- Strongly agree

I am willing to participate in this science course because the content is changeable. 
- Strongly disagree

- Somewhat disagree

- Neither agree nor disagree

- Somewhat agree

- Strongly agree

I am willing to participate in this science course because the teacher uses a variety of teaching methods.

- Strongly disagree

- Somewhat disagree

- Neither agree nor disagree

- Somewhat agree

- Strongly agree

I am willing to participate in this science course because the teacher does not put a lot of pressure on me.

- Strongly disagree

- Somewhat disagree

- Neither agree nor disagree

- Somewhat agree

- Strongly agree

I am willing to participate in this science course because the teacher pays attention to me.

- Strongly disagree

- Somewhat disagree

- Neither agree nor disagree

- Somewhat agree

- Strongly agree

I am willing to participate in this science course because it is challenging.

- Strongly disagree

- Somewhat disagree

- Neither agree nor disagree

- Somewhat agree

- Strongly agree

I am willing to participate in this science course because the students are involved in discussions.

- Strongly disagree

- Somewhat disagree

- Neither agree nor disagree 
- Somewhat agree

- Strongly agree

I can control my academic performance.

- Strongly disagree

- Somewhat disagree

- Neither agree nor disagree

- Somewhat agree

- Strongly agree

I learn more when I am the one selecting what I am going to learn.

- Strongly disagree

- Somewhat disagree

- Neither agree nor disagree

- Somewhat agree

- Strongly agree

My choices about what to study influence my learning outcomes.

- Strongly disagree

- Somewhat disagree

- Neither agree nor disagree

- Somewhat agree

- Strongly agree

I prefer other people to tell me what I have to study than deciding by my own.

- Strongly disagree

- Somewhat disagree

- Neither agree nor disagree

- Somewhat agree

- Strongly agree

Being able to choose where to focus my attention when watching a video is important to me.

- Strongly disagree

- Somewhat disagree

- Neither agree nor disagree

- Somewhat agree

- Strongly agree

How much do you like the following areas?

Not at all Not much Neutral Some Very much




\begin{tabular}{|c|c|c|c|c|}
\hline Computer Science & 0 & 0 & 0 & 0 \\
\hline English Language Arts & 0 & 0 & 0 & 0 \\
\hline History - Social Science & 0 & 0 & 0 & 0 \\
\hline Mathematics & 0 & 0 & 0 & 0 \\
\hline Physical Education & 0 & 0 & 0 & 0 \\
\hline Science & 0 & 0 & 0 & $\mathrm{O}$ \\
\hline Visual \& Performing Arts & 0 & 0 & 0 & 0 \\
\hline World Language & 0 & 0 & 0 & 0 \\
\hline
\end{tabular}

How good do you feel you are in the following areas?

\begin{tabular}{l|ccccc} 
& $\begin{array}{c}\text { Not good } \\
\text { at all }\end{array}$ & $\begin{array}{c}\text { Not so } \\
\text { good }\end{array}$ & Just ok & Good & $\begin{array}{r}\text { Really } \\
\text { good }\end{array}$ \\
\hline Computer Science & 0 & 0 & 0 & 0 & 0 \\
English Language Arts & 0 & 0 & 0 & 0 & 0 \\
History - Social Science & 0 & 0 & 0 & 0 & 0 \\
Mathematics & 0 & 0 & 0 & 0 & 0 \\
Physical Education & 0 & 0 & 0 & 0 & 0 \\
Science & 0 & 0 & 0 & 0 & 0 \\
Visual \& Performing Arts & 0 & 0 & 0 & 0 & 0 \\
World Language & 0 & 0 & 0 & 0 & 0
\end{tabular}


7.5. Anexo 5-Questões e análise multinível das atitudes em relação às disciplinas escolares.

Questões

\begin{tabular}{cl}
\hline Número & Questão \\
\hline 1 & O quanto você gosta de Computação? \\
2 & O quanto você gosta de Inglês, Literatura e Artes? \\
3 & O quanto você gosta de História e Ciências Sociais? \\
4 & O quanto você gosta de Matemática? \\
5 & O quanto você gosta de Educação Física? \\
6 & O quanto você gosta de Ciências? \\
7 & O quanto você gosta de Artes Visuais e Performances? \\
8 & O quanto você gosta de idiomas mundiais? \\
9 & O quanto você se sente bem em relação a Computação? \\
10 & O quanto você se sente bem em relação a Inglês, Literatura e Artes? \\
11 & O quanto você se sente bem em relação a História e Ciências Sociais? \\
12 & O quanto você se sente bem em relação a Matemática? \\
13 & O quanto você se sente bem em relação a Educação Física? \\
14 & O quanto você se sente bem em relação a Ciências? \\
15 & O quanto você se sente bem em relação a Artes Visuais e Performances? \\
16 & O quanto você se sente bem em relação aos idiomas mundiais? \\
\hline
\end{tabular}

Eigenvalues e variância explicados para os componentes principais (PCA) do questionário sobre as atitudes em relação às disciplinas escolares

\begin{tabular}{lccc}
\hline & & & Variância acumulada \\
& Eingenvalue & Variância (\%) & $(\%)$ \\
\hline Dimensão 1 & 2,22 & 31,77 & 31,77 \\
Dimensão 2 & 1,36 & 19,48 & 51,25 \\
Dimensão 3 & 1,06 & 15,13 & 66,38 \\
Dimensão 4 & 0,77 & 10,93 & 77,31 \\
Dimensão 5 & 0,64 & 9,16 & 86,47 \\
Dimensão 6 & 0,58 & 8,26 & 94,73 \\
Dimensão 7 & 0,37 & 5,27 & 100,00 \\
\hline
\end{tabular}

Carga Fatorial para cada item do questionário de atitudes em relação às disciplinas escolares 


\begin{tabular}{ccccccc}
\hline Questão & $\begin{array}{c}\text { Fator } 1 \\
\text { (Humanidades) }\end{array}$ & $\begin{array}{c}\text { Fator } 2 \\
\text { (Ciências e } \\
\text { Matemática) }\end{array}$ & $\begin{array}{c}\text { Fator } 3 \\
\text { (Artes) }\end{array}$ & h2 & u2 & com \\
\hline 1 & -0.08 & 0,74 & $-0,18$ & 0,494 & 0,506 & 1,140 \\
2 & 0,73 & 0,03 & $-0,16$ & 0,514 & 0,486 & 1,096 \\
3 & 0,82 & $-0,15$ & $-0,07$ & 0,601 & 0,399 & 1,078 \\
4 & $-0,03$ & 0,52 & 0,18 & 0,342 & 0,658 & 1,251 \\
5 & $-0,07$ & $-0,05$ & 0,76 & 0,545 & 0,455 & 1,024 \\
6 & 0,13 & 0,45 & 0,04 & 0,267 & 0,733 & 1,169 \\
8 & 0,47 & 0,02 & 0,15 & 0,289 & 0,712 & 1,213 \\
9 & 0,04 & 0,74 & $-0,05$ & 0,556 & 0,444 & 1,015 \\
10 & 0,7 & 0,17 & 0,04 & 0,616 & 0,384 & 1,129 \\
11 & 0,72 & 0,05 & 0,14 & 0,605 & 0,395 & 1,084 \\
12 & 0,01 & 0,57 & 0,24 & 0,458 & 0,542 & 1,342 \\
13 & 0,04 & 0,02 & 0,85 & 0,746 & 0,254 & 1,007 \\
14 & 0,23 & 0,51 & 0,15 & 0,459 & 0,541 & 1,578 \\
15 & 0,15 & 0,09 & 0,21 & 0,106 & 0,894 & 2,226 \\
16 & 0,43 & 0,1 & 0,23 & 0,327 & 0,673 & 1,627 \\
\hline
\end{tabular}


7.6. Anexo 6. Lista de produção acadêmica durante o programa de doutorado

Fauville, G., Queiroz, A. C. M., \& Bailenson, J. N. (2020). Virtual reality as a promising tool to promote climate change awareness. Technology and Health, 91-108.

Nascimento, A. M., Queiroz, A. C. M., Vismari, L. F., Bailenson, J. N., Cugnasca, P. S., Junior, J. B. C., \& de Almeida, J. R. (2019). The Role of Virtual Reality in Autonomous Vehicles' Safety. 2019 IEEE International Conference on Artificial Intelligence and Virtual Reality (AIVR), 50507.

Nascimento, A. M., \& Queiroz, A. C. M. (2017). EnANPAD 2017. Panorama Das Pesquisas Sobre Inteligência Artificial Em Administração No Brasil.

Nascimento, A M, Vismari, L. F., Queiroz, A. C. M., Cugnasca, P. S., Camargo, J. B., \& de Almeida, J. R. (2019). The Moral Machine: Is It Moral? International Conference on Computer Safety, Reliability, and Security, 405-410.

Nunes, F. L. S., Oliveira, J. C., Machado, L. S., Nunes, E. P. dos S., Costa, R. M., \& Queiroz, A. C. M. (2019). Realidade Virtual e Aumentada aplicadas à Saúde. In R. Tori \& M. da S. Hounsell (Eds.), Introdução a Realidade Virtual e Aumentada (1st ed.). Sociedade Brasileira de Computação.

Queiroz, A. C. M., Nascimento, A. M., Tori, R., Brashear, T. A., Melo, V. de M., de Souza Meirelles, F., \& Leme, M. I. da S. (2018). Immersive virtual environments in corporate education and training. Americas Conference on Information Systems 2018: Digital Disruption, AMCIS 2018.

Queiroz, A. C. M., Tori, R., Nascimento, A. M., \& Leme, M. I. da S. (2018). Augmented and Virtual Reality in Education: The Role of Brazilian Research Groups. 2018 20th Symposium on Virtual and Augmented Reality (SVR), 170-175.

Queiroz, A. C. M., Kamarainen, A. M., Preston, N. D., \& Leme, M. I. S. (2018). Immersive Virtual Environments and Climate Change Engagement. Immersive Learning Research Network Proceedings, accepted paper.

Queiroz, A. C. M., Nascimento, A. M., Brashear, T. A., Tori, R., Melo, V., Souza Meirelles, F., \& Leme, M. I. da S. (2018). Virtual Reality in Marketing: Technological and Psychological Immersion. Americas Conference on Information Systems 2018: Digital Disruption, AMCIS 
2018.

Queiroz, A. C. M., Nascimento, A. M., Tori, R., \& da Leme, M. I. S. (2019). Immersive virtual environments and learning assessments. International Conference on Immersive Learning, $172-181$.

Queiroz, A. C. M., Tori, R., Moreira, N. A., \& Leme, M. I. S. (2018). Using HMD-Based Immersive Virtual Environments in Primary/K-12 Education. Communication in Computer and Information Systems, 840(accepted paper), 1-14.

Queiroz, A. C. M., Tori, R., \& Nascimento, A. M. (2017). Realidade Virtual na Educação: Panorama das Pesquisas no Brasil. Anais Do XXVIII Simpósio Brasileiro de Informática Na Educação (SBIE 2017), 203-212.

Tori, R., \& Queiroz, A. C. M. (2017). As pesquisas de EaD na área de Engenharia pelo recorte dos grupos de pesquisa cadastrados no Diretório CNPq/Lattes. In V. M. Kenski (Ed.), Grupos que pesquisam EaD no Brasil.

Tori, R., Queiroz, A. C. M., Corrêa, A. G. D., \& Netto, A. V. (2019). Realidade Virtual e Aumentada aplicadas à Educação. In R. Tori \& M. da S. Hounsell (Eds.), Introdução a Realidade Virtual e Aumentada (1st ed.). Sociedade Brasileira de Computação. 